University of New Hampshire

University of New Hampshire Scholars' Repository

2018

\title{
Cruise Report for cruise Kilo Moana KM1811 in the U.S. Gulf of
}

\section{Alaska continental margin}

Joyce Miller

University of Hawaii

Andrew A. Armstrong

University of New Hampshire

James V. Gardner

University of New Hampshire, Durham, jim.gardner@unh.edu

Paul Johnson

University of New Hampshire, Paul.Johnson@unh.edu

Follow this and additional works at: https://scholars.unh.edu/ccom

\section{Recommended Citation}

Miller, J., Armstrong, A.A., and Gardner, J.V., 2018, Cruise report of UNCLOS ECS cruise KM1811 on the northern Line Islands Ridge, central Pacific Ocean, https://dx.doi.org/10.34051/p/2019.2. Accessed on ddmmyyyy

This Report is brought to you for free and open access by the Center for Coastal and Ocean Mapping at University of New Hampshire Scholars' Repository. It has been accepted for inclusion in Center for Coastal and Ocean Mapping by an authorized administrator of University of New Hampshire Scholars' Repository. For more information, please contact Scholarly.Communication@unh.edu. 


\title{
CRUISE REPORT
}

\author{
R/V Kilo Moana
}

\section{U.S. Extended Continental Shelf Cruise to Map Gulf of Alaska, Eastern Pacific}

\author{
Cruise KM1811 \\ July 1 - August 3, 2018 \\ Honolulu, HI to Seattle, WA
}

Joyce E. Miller ${ }^{1}$, Tiziana Munene ${ }^{2}$, James V. Gardner ${ }^{2}$ and Andrew A. Armstrong ${ }^{2}$

\author{
${ }^{1}$ University of Hawai'i, Honolulu, HI \\ ${ }^{2}$ Center for Coastal and Ocean Mapping and \\ NOAA-UNH Joint Hydrographic Center \\ University of New Hampshire \\ Durham NH 03824
}

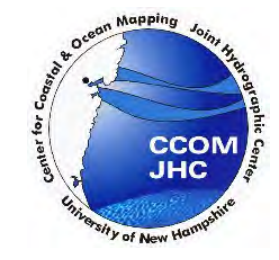

August 7, 2018

UNH-CCOM/JHC Technical Report 18-001

Doi:10.25999/pyw6-kk95 


\section{Table of Contents}

Section page

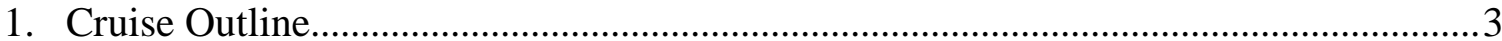

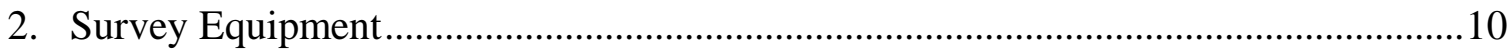

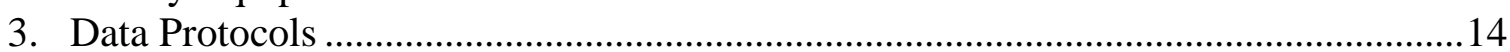

4. Patch-Test Results ................................................................................................ 18

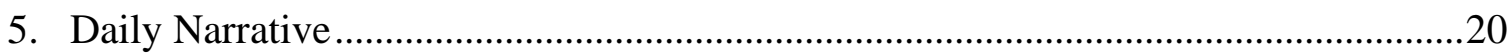

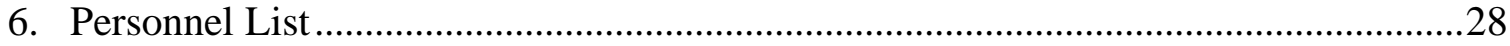

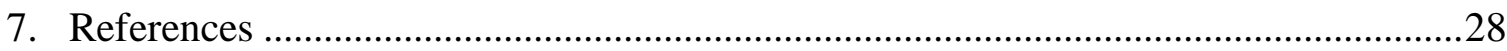

8. Appendix A: File Name Translations .......................................................................29

Table A.1. Conversion of SIS MBES file names to UNH file names ................29

Table A.2. Conversion of Knudsen file names to UNH file names .......................33

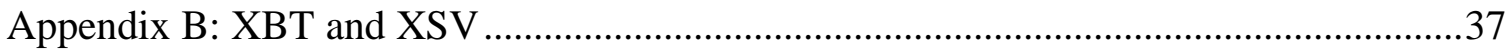

Appendix C: Shipboard Preliminary Products ................................................................43

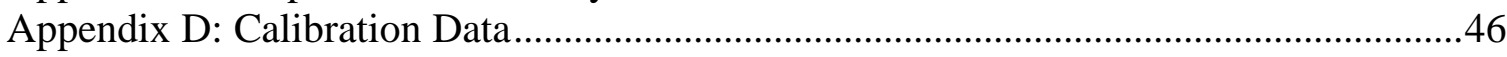

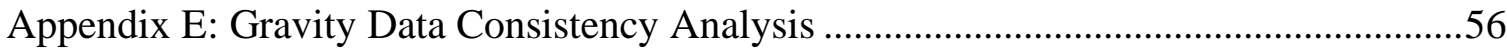

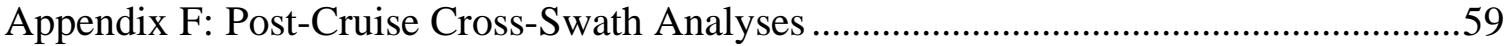

Appendix G: Built-In Self Tests (BIST) of EM122 ........................................................ 71 


\section{Cruise Outline}

KM1811 is the third cruise of bathymetric mapping of the continental shelf in the Gulf of Alaska (GOA) in the NE Pacific. The objective of the cruise was to collect all of the bathymetric, acoustic backscatter, and high resolution sub-bottom data that might be useful to support a potential submission by the U.S. under the U.N. Convention on the Law of the Sea, Article 76 (Mayer et al, 2002). The responsibility for conducting the mapping was given to the National Oceanic and Atmospheric Administration (NOAA) by the U.S. Congress, and has been implemented since 2003 through a cooperative agreement with the Center for Coastal and Ocean Mapping and NOAA-UNH Joint Hydrographic Center at the University of New Hampshire. The cruise DOI is

This cruise supplements data from two legs of a prior cruise (Gardner and Mayer, 2005) on the RV Kilo Moana (Fig. 1.1) in the Gulf of Alaska to identify the morphology of the base of the slope (BoS) zone (Fig. 1.2). The 2018 cruise consisted of primary bathymetric mapping in water depths of approximately $500 \mathrm{~m}$ to $4000 \mathrm{~m}$ using the R/V Kilo Moana operated by the University of Hawai'i. The primary mapping sonar was a Kongsberg EM122 multibeam echosounder (MBES), supplemented with a Knudsen Engineering 3260 chirp sub-bottom profiler, and a Bell Aerospace BGM-3 marine gravimeter. Motion measurement and positioning was provided by an Applanix POS/MV 320 (V5) GNSS-aided inertial motion unit (IMU), and sound-speed profile measurements used Lockheed Martin Co. Sippican expendable bathythermograph (XBT) calibrated to Lockheed Martin Co. expendable sound speed (XSV) casts. Details of the systems used can be found in Section 2. Scientific personnel for the cruise were provided by CCOMJHC, NOAA, University of Hawai'i, The College of Charleston, the University of Southern Mississippi, Memorial University (Newfoundland) and the University of Hawai'i marine technician group. The personnel list can be found in Section 6 .

Cruise mobilization started on June 29, 2018, with the RV Kilo Moana alongside the University of Hawai'i Marine Facility in Honolulu, HI. Mobilization and dock-side testing were conducted on June 29 and June 30. An opening gravity tie was conducted on June 30 at $\sim 1500$ $\mathrm{hr}$ and the ship departed Honolulu, HI on July 1 at $1800 \mathrm{Z}$ (0800 HST). The ship proceeded past the Aloha Tower and out to sea, making 10.5 kts. on the transit to the Gulf of Alaska. A Built-InSelf Test (BIST) was conducted for the EM122 as the ship moved into deeper water, which the system passed with no faults (see Appendix G). As the ship transited to deeper water, an XBT was launched for training purposes and to confirm the validity of the XBT system against an XSV measurement.

The Kilo Moana then proceeded toward the first waypoint to deploy the first of seven ARGO floats that were deployed for an independent NOAA project. Routine mapping with both the MBES and the Knudsen profiler commenced on July 2 at 0930L/1930Z. Sufficient XBTs were taken during the transit to assess any changes in sound speed in the local water mass, with routine XBT casts at 6-hr. or more frequent intervals as required. The XBT launcher failed on July 5 (JD 186) and the UNH Sound Velocity Manager was used to generate profiles on the transit. A new XBT launcher was received in Sitka, AK on July 11 (JD 192) and was immediately installed and tested. XSVs were cast twice to confirm the validity of XBT-generated sound-speed profiles. Sound speed at the transducer head was compared with the sound speed at the transducer depth on the XBT profile from the most recent sound-speed profile using the Kongsberg Seafloor Information System (SIS) software, and a new XBT launch was conducted when the difference between the two estimates was between $0.5 \mathrm{~m} / \mathrm{s}-1.0 \mathrm{~m} / \mathrm{s}$ for more than a few 
minutes. Details of the XBT launch frequency, location, and other metadata are provided in Appendix B.

A total of 7,640 km (4,141 nmi) of lines (excluding transits) were planned in the survey area (Fig. 1.2). The mapping effort was monitored by the science party and supervised by the Chief Scientist, with the assistance of the ship's crew and the University of Hawai'i marine technicians. Data quality was monitored in real time using the watch standers in the ship's survey lab, and data processing and quality control were conducted during ship-board operations as detailed in Section 2.6 and Section 3. Shipboard preliminary data products were created to ensure data quality (see Appendix C), but final data products were constructed at UNH after the cruise.

Seven ARGO floats were launched at pre-determined positions along the transit lines to the Gulf of Alaska as shown in Table 1.1. Pitch, roll, and heading patch tests were conducted in the Gulf of Alaska area as shown in Fig. 1.3.

Mapping continued until 1029Z (0229L) on July 31, 2018 (JD212) when the ship entered the Canadian Exclusive Economic Zone (EEZ) on the way to Seattle, WA. All sonars were secured and no data were collected during transit through the Canadian EEZ. A final successful BIST was conducted on the EM122 as the ship was leaving the survey area. The ship arrived at Pier 91 in Seattle, WA. on August 3, 2018 (JD 215) at 0800L/1600Z. A closing gravity tie was conducted at on August 7, 2018 (JD 220).

A total area of $98,777 \mathrm{~km}^{2}\left(28,799 \mathrm{nmi}^{2}\right)$ was mapped (excluding transits) during the cruise in 22 survey days (Fig. 1.4, 1.5, and 1.6). There were 14 days of transit. A survey calendar is shown in Table 1.2.

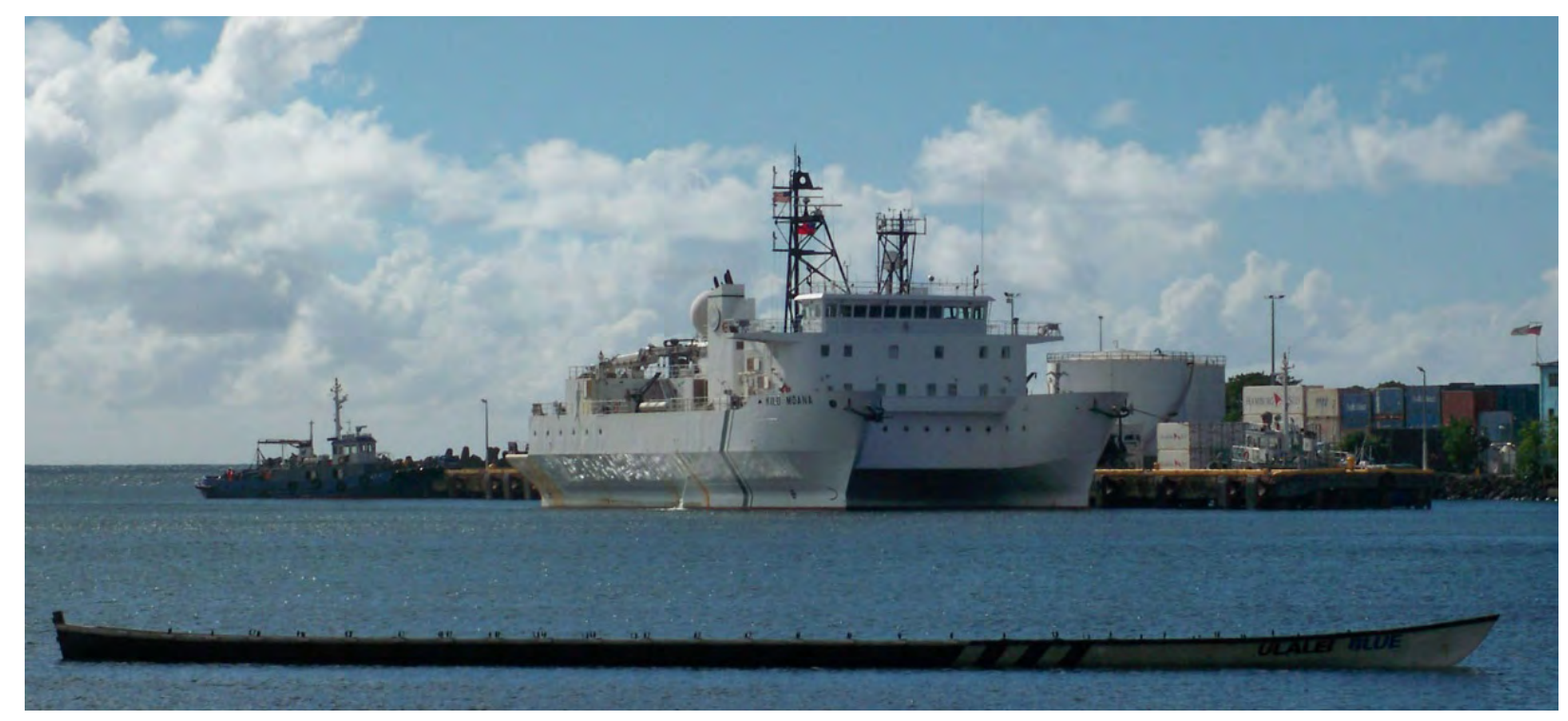

Figure 1.1: The R/V Kilo Moana in Apia, Western Samoa, in 2010. The Kilo Moana is a SWATH (Small Waterplane Area Twin Hull) vessel owned by the U.S. Navy and operated by the University of Hawai'i. 


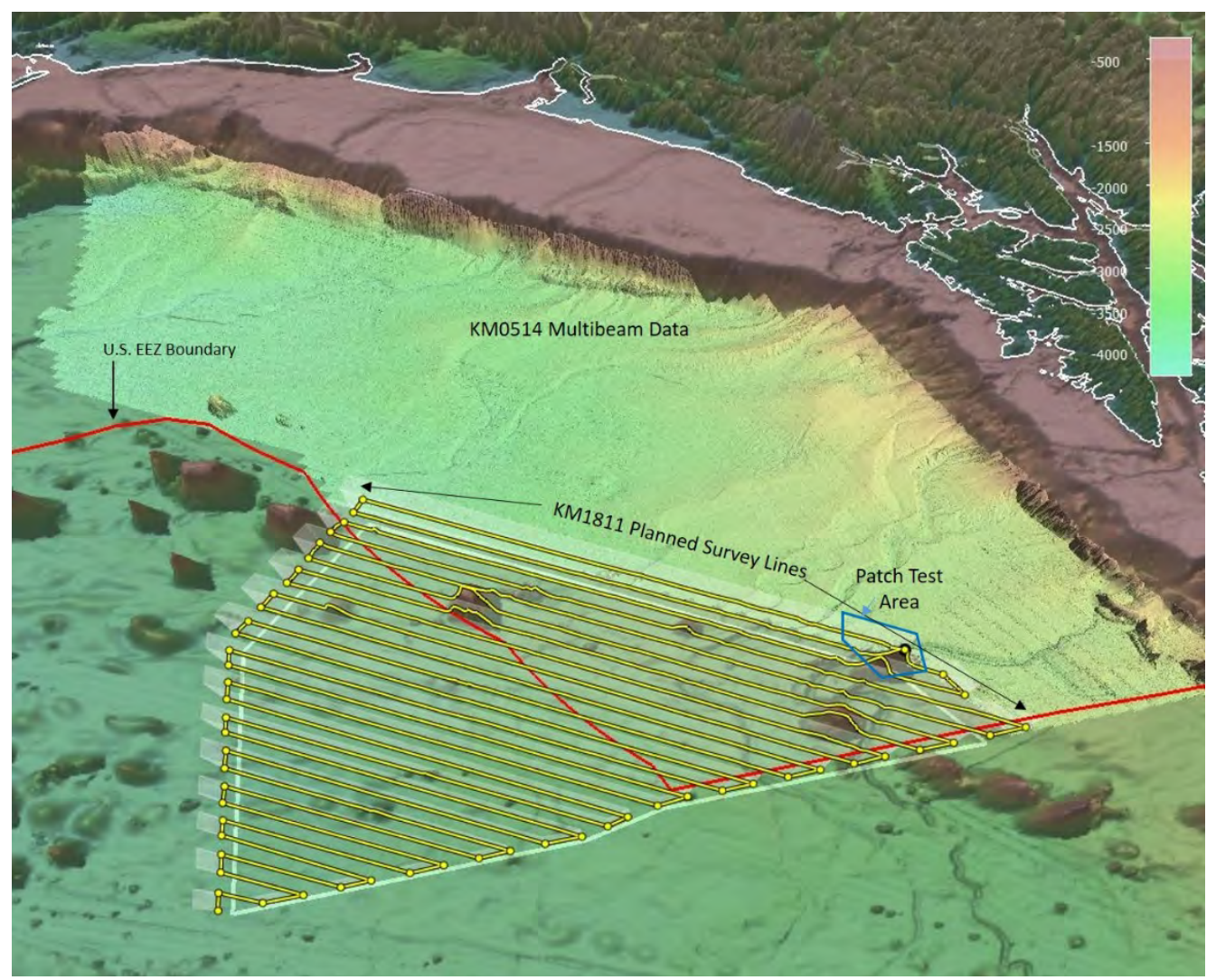

Figure 1.2: Overview of previously mapped area in the Gulf of Alaska from cruise KM0514-1 and KM0514-2 in 2005 with overlay of the pre-cruise planned waypoints and patch test area for KM1811.

Table 1.1: ARGO Float Deployments During Cruise 1811.

\begin{tabular}{|c|c|c|c|c|}
\hline $\begin{array}{c}\text { Serial } \\
\text { Number }\end{array}$ & Julian Date & $\begin{array}{c}\text { Time } \\
(\mathrm{GMT})\end{array}$ & Latitude & Longitude \\
\hline 0942 & 184 & 2113 & $28^{\circ} 59.9^{\prime} \mathrm{N}$ & $155^{\circ} 00.1^{\prime} \mathrm{W}$ \\
\hline 0939 & 185 & 1201 & $31^{\circ} 15.1^{\prime} \mathrm{N}$ & $1^{\circ} 4^{\circ} 05.9^{\prime} \mathrm{W}$ \\
\hline 0938 & 186 & 0226 & $33^{\circ} 29.2^{\prime} \mathrm{N}$ & $153^{\circ} 09.1^{\prime} \mathrm{W}$ \\
\hline 0941 & 186 & 1636 & $35^{\circ} 42.8^{\prime} \mathrm{N}$ & $152^{\circ} 09.2^{\prime} \mathrm{W}$ \\
\hline 0940 & 187 & 0645 & $37^{\circ} 56.3^{\prime} \mathrm{N}$ & $151^{\circ} 06.0^{\prime} \mathrm{W}$ \\
\hline 0937 & 188 & 1108 & $42^{\circ} 21.2^{\prime} \mathrm{N}$ & $148^{\circ} 46.7^{\prime} \mathrm{W}$ \\
\hline 0943 & 189 & 0100 & $44^{\circ} 32.4^{\prime} \mathrm{N}$ & $147^{\circ} 30.0^{\prime} \mathrm{W}$ \\
\hline
\end{tabular}




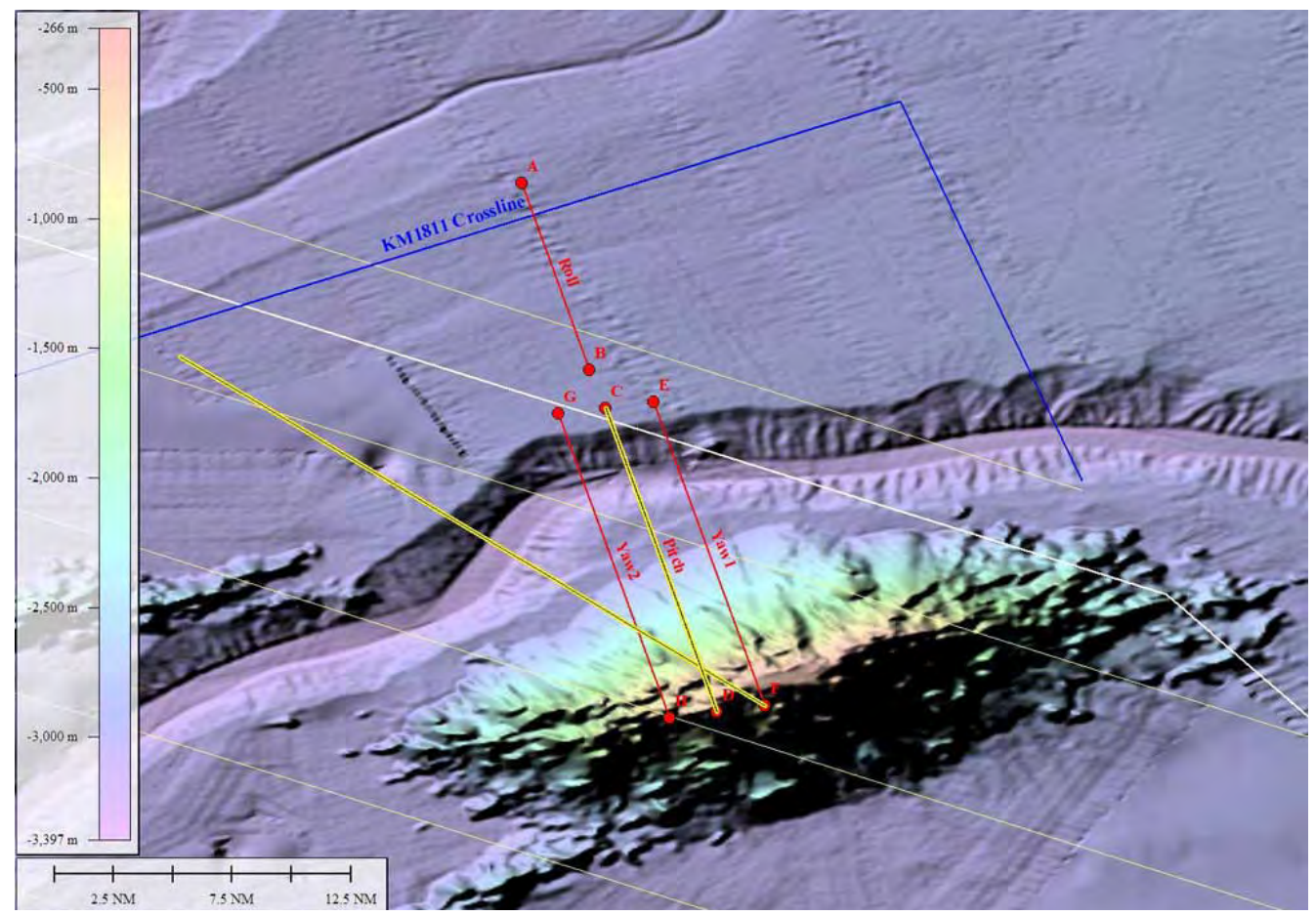

Figure 1.3: Patch Test Survey Pattern at NE Corner of KM1811 Gulf of Alaska survey, centered at $55^{\circ} 44.32^{\prime} \mathrm{N}, 137^{\circ} 7.63 \mathrm{~W}$.

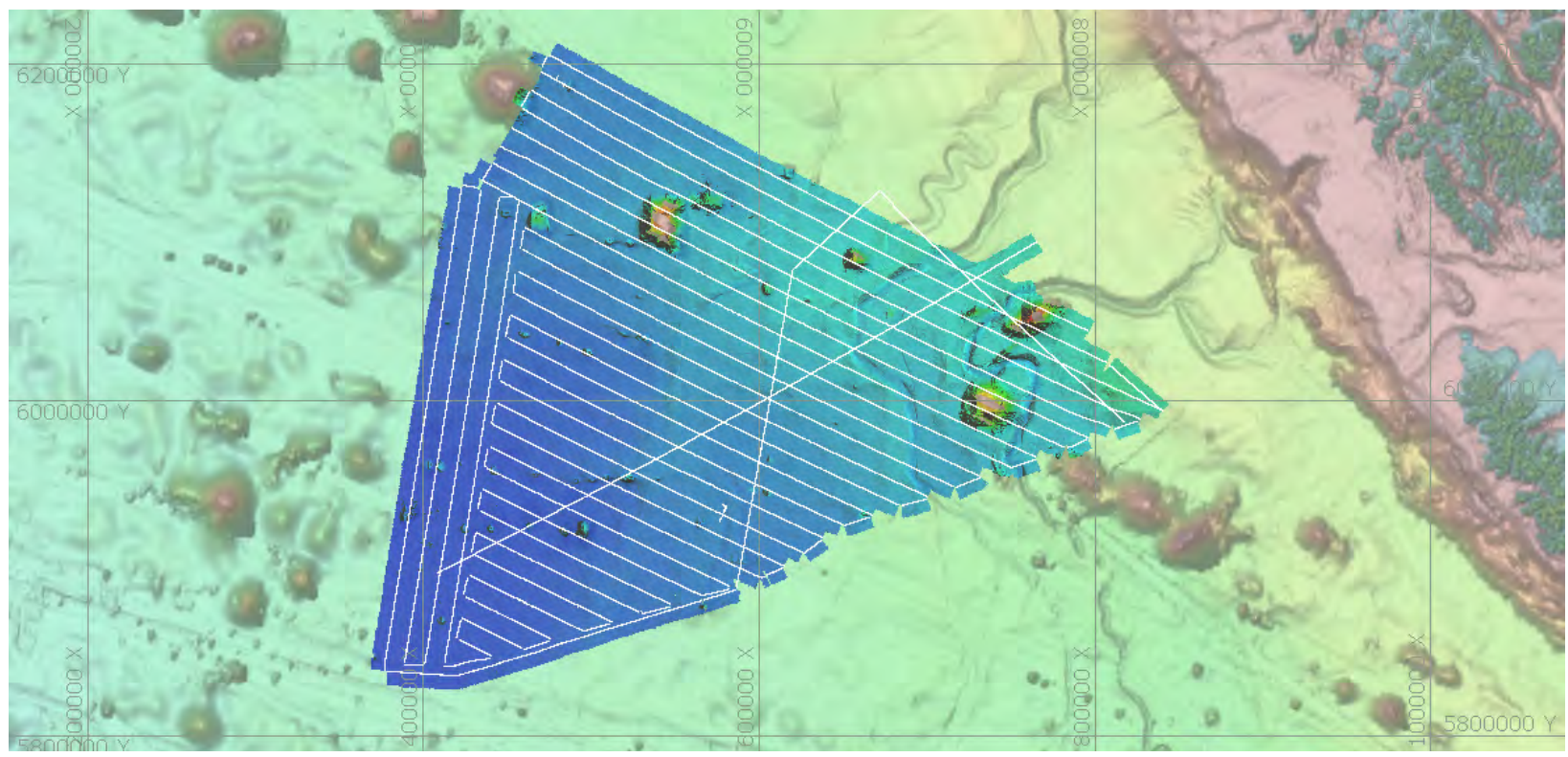

Figure 1.4: Overview of the lines as run during KM1811. A total of $8,680 \mathrm{~km}(4,687 \mathrm{nmi})$ of lines were completed in 22 survey days, for a total area mapped of $98,777 \mathrm{~km}^{2}\left(28,799 \mathrm{nmi}^{2}\right)$. 


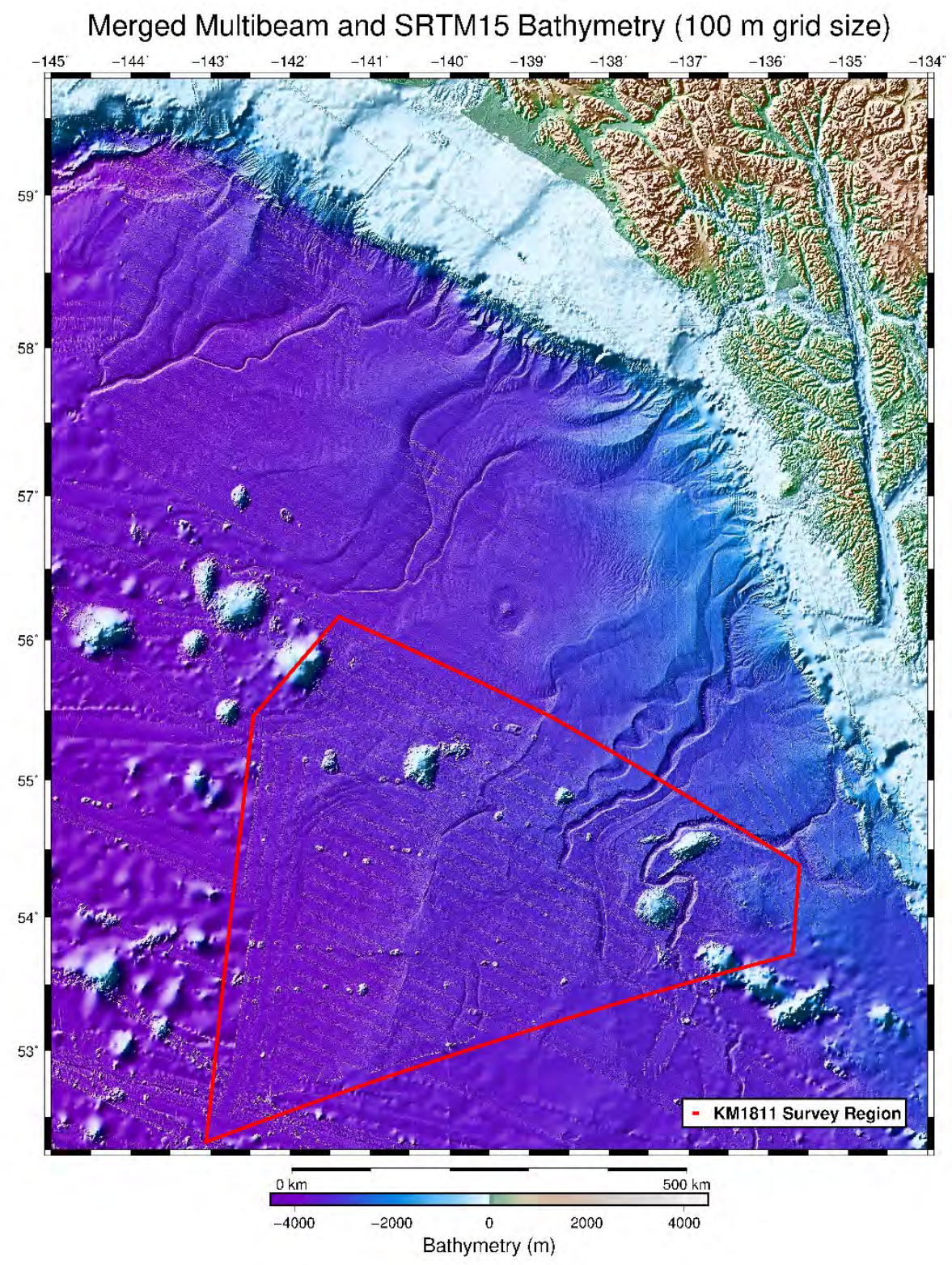

Figure 1.5: KM1811 survey data area shown on map of multibeam coverage in the area. Existing multibeam data has been merged with KM1811 coverage and SRTM15 (Shuttle Radar Topography Mission 15) satellite altimetry and plotted using Generic Mapping Tools 5.4.4. 


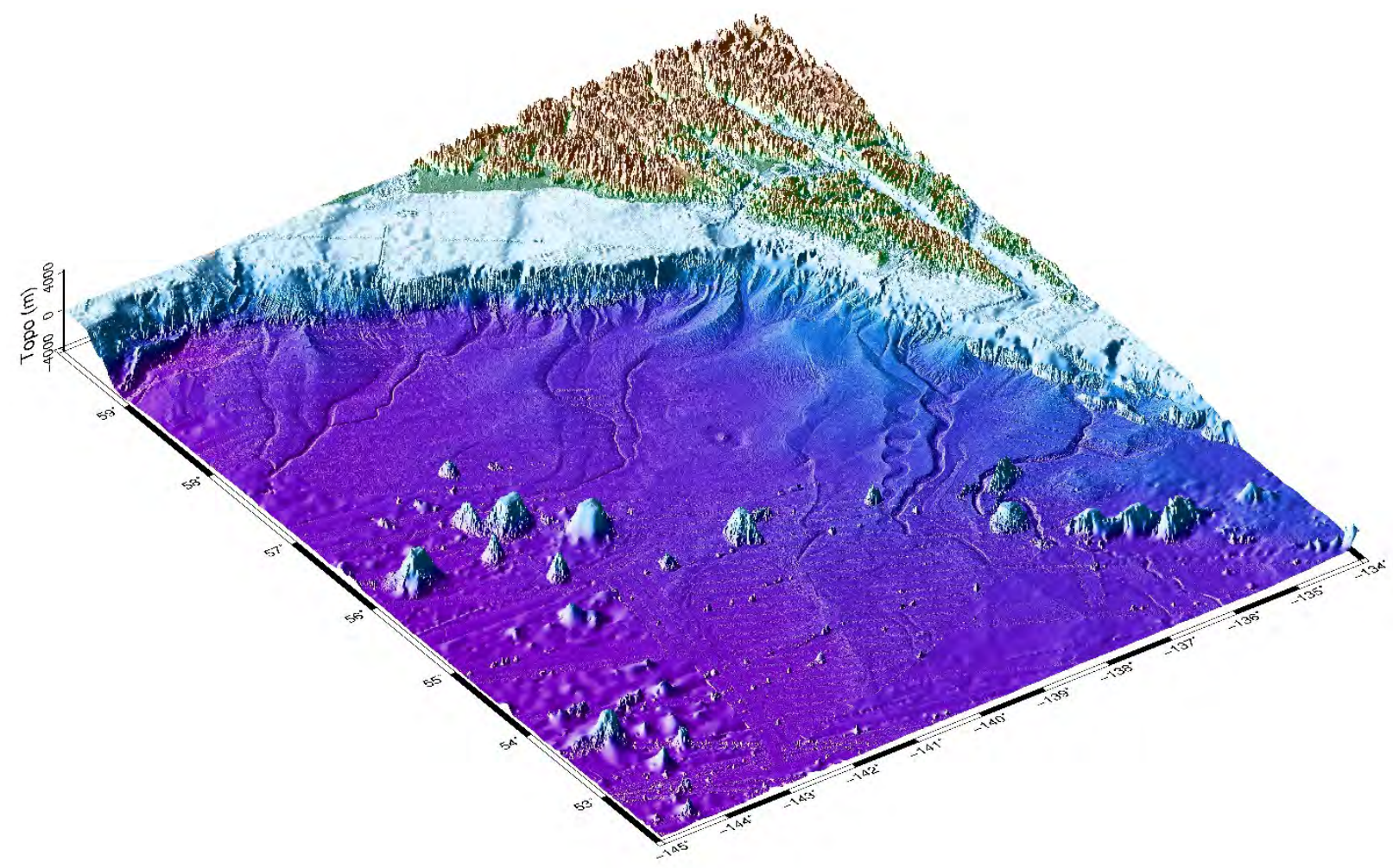

Figure 1.6: 3-D Image of Gulf of Alaska Multibeam Bathymetry Data combined SRTM15 satellite altimetry data. Produced using Generic Mapping Tools 5.4.4. 
Table 1.2: KM1811 Survey Calendar

\begin{tabular}{|c|c|c|c|c|c|c|}
\hline \multicolumn{7}{|c|}{ July/August 2018 (all times in UTC) } \\
\hline Sunday & Monday & Tuesday & Wednesday & Thursday & Friday & Saturday \\
\hline $\begin{array}{l}1 \text { JD } 182 \\
\text { 1800 Depart } \\
\text { Honolulu } \\
\text { 2000 Safety } \\
\text { Training }\end{array}$ & $\begin{array}{l}2 \text { JD } 183 \\
\text { 1800 Training } \\
\text { 1930 Start } \\
\text { MB/SB Logging } \\
\text { on KM1811- } \\
\text { Transit1 }\end{array}$ & $\begin{array}{l}3 \text { JD } 184 \\
1500 \text { Restart } \\
\text { Knudsen } \\
2145 \text { ARGO \#F942 } \\
\text { deployed }\end{array}$ & $\begin{array}{l}4 \text { JD } 185 \\
1200 \text { ARGO \#F938 } \\
\text { deployed } \\
1958 \text { SIS restart } \\
\text { I }\end{array}$ & $\begin{array}{l}5 \text { JD 186 } \\
\text { 0226 ARGO F939 } \\
\text { deployed } \\
1500 \text { Knudsen restart } \\
1636 \text { ARGO F941 } \\
\text { deployed } \\
1645 \text { XBT launcher } \\
\text { failed }\end{array}$ & $\begin{array}{l}6 \text { JD } 187 \\
\text { 0645 ARGO F940 } \\
\text { deployed }\end{array}$ & $\begin{array}{l}7 \text { JD188 } \\
\text { 0330 Knudsen } \\
\text { restart } \\
\text { 0530 SIS } \\
\text { restart } \\
1108 \text { ARGO } \\
\text { F937 deployed }\end{array}$ \\
\hline $\begin{array}{l}8 \text { JD } 189 \\
\text { 0100 ARGO } \\
\text { F943 deployed }\end{array}$ & $\begin{array}{l}9 \text { JD } 190 \\
\text { Transit continues }\end{array}$ & $\begin{array}{l}10 \text { JD } 191 \\
\text { 0433 SOL GOA } \\
\text { crossline }\end{array}$ & $\begin{array}{l}\text { 11 JD } 192 \\
\text { 0010 EOL crossline } \\
0035 \text { SIS restart } \\
\text { 1400-1500 Arrive } \\
\text { Sitka, XBT launcher } \\
\text { install } \\
1500 \text { - Transit }\end{array}$ & $\begin{array}{l}\text { 12 JD } 193 \\
\text { 0600-1745 Patch test } \\
\text { 1932 SOL HYPACK } \\
\text { (HP) Line } 2\end{array}$ & $\begin{array}{l}13 \text { JD } 194 \\
\text { XBT launches at } \\
1-2 \mathrm{hr} \text { intervals } \\
1359 \text { SOL HP } 3\end{array}$ & $\begin{array}{l}14 \text { JD } 195 \\
1105 \text { SOL HP } \\
4 \\
\text { Note: Line } \\
\text { spacing issues } \\
\text { between Lines } \\
3 \text { and } 4 .\end{array}$ \\
\hline $\begin{array}{l}5 \text { JD } 196 \\
0848 \text { SOL HP } 5 . \\
\text { Line Spacing } \\
\text { Issues cont. }\end{array}$ & $\begin{array}{l}16 \text { JD } 197 \\
0604 \text { SOL HP } 6 \\
\text { 1030: SIS } \\
\text { gridding issues, } \\
\text { stop/start survey }\end{array}$ & $\begin{array}{l}\text { 17 JD } 198 \\
\text { 0250: Turn, restart } \\
\text { SIS \& new project } \\
\text { KM1811 } \\
\text { 0320: SOL HP } 7 \\
\text { 2303 SOL HP } 8\end{array}$ & $\begin{array}{l}18 \text { JD } 199 \\
1907 \text { SOL HP } 9\end{array}$ & $\begin{array}{l}19 \text { JD } 200 \\
1400 \text { SOL HP } 10 \\
\text { 2000: Changed line } \\
\text { plan to exclude } \\
\text { western triangle }\end{array}$ & $\begin{array}{l}20 \text { JD } 201 \\
0646 \text { SOL HP 11a } \\
2227 \text { SOL HP 12a }\end{array}$ & $\begin{array}{l}21 \text { JD } 202 \\
1358 \text { SOL HP } \\
13 a\end{array}$ \\
\hline $\begin{array}{l}22 \text { JD } 203 \\
0406 \text { SOL HP } \\
14 a \\
1740 \text { SOL HP } \\
15 a\end{array}$ & $\begin{array}{l}23 \text { JD204 } \\
0625 \text { SOL HP } \\
16 a \\
1805 \text { SOL HP } \\
17 a\end{array}$ & $\begin{array}{l}24 \text { JD } 205 \\
\text { 0551 SOL HP 18a } \\
\text { 0838-0851 Auto- } \\
\text { pilot problems } \\
1657 \text { SOL HP 19a }\end{array}$ & $\begin{array}{l}25 \text { JD } 206 \\
0326 \text { SOL HP 20a } \\
\text { Skip HP 21a } \\
\text { 1300 SOL HP 22a } \\
2135 \text { SOL HP 23a }\end{array}$ & $\begin{array}{l}26 \text { JD } 207 \\
0546 \text { SOL HP 24a } \\
1315 \text { SOL HP 25a } \\
1917 \text { SOL HP 26a }\end{array}$ & $\begin{array}{l}27 \text { JD 208 } \\
0049 \text { SOL HP 27a } \\
0518 \text { SOL HP 28a } \\
0905 \text { SOL HP 29a } \\
1145 \text { SOL HP 30a } \\
1305 \text { SOL HP 31a } \\
1410 \text { SOL 32a } \\
1430 \text { SOL W1 }\end{array}$ & $\begin{array}{l}28 \text { JD } 209 \\
0437 \text { SOL W2 } \\
1909 \text { SOL W3 }\end{array}$ \\
\hline $\begin{array}{l}29 \text { JD } 210 \\
0938 \text { SOL HP } \\
\text { W4 }\end{array}$ & $\begin{array}{l}30 \text { JD } 211 \\
0014 \text { SOL } \\
\text { South5 } \\
1112 \text { SOL SBP6 } \\
2102 \text { SOL SBP7 }\end{array}$ & $\begin{array}{l}31 \text { JD } 212 \\
0040 \text { Start Transit } \\
1040 \text { Stop all } \\
\text { logging }\end{array}$ & $\begin{array}{l}\text { Aug 1 JD } 213 \\
\text { Transit }\end{array}$ & $\begin{array}{l}2 \text { JD } 214 \\
\text { Transit }\end{array}$ & $\begin{array}{l}3 \text { JD } 215 \\
1600 Z(0800 \mathrm{~L}) \\
\text { Arrive Seattle }\end{array}$ & \\
\hline
\end{tabular}




\section{Survey Equipment}

\subsection{Multibeam Echosounder}

RV Kilo Moana is equipped with a Kongsberg Maritime 12-kHz EM122 multibeam echosounder, model 309653, serial number $109^{1}$. The system generates a narrow sound pulse in the region of $12 \mathrm{kHz}$ in a $150^{\circ}$ swath $\sim 1^{\circ}$-wide along-track and the acoustic reflections from the seafloor are received on $2^{\circ}$-wide across-track receivers. A sequence of up to nine acoustic sectors at frequencies varying from $11.550-12.596 \mathrm{kHz}$ can be generated on transmit to compensate for ship's yaw, at a source level of approximately $220 \mathrm{~dB}$ re. $1 \mu \mathrm{Pa}$ at $1 \mathrm{~m}$. Optionally, the outer sectors of the transmit beam can be frequency modulated to improve overall signal-tonoise ratio. The system was operated in Deep FM high-density equidistant mode throughout the cruise, with a pulse length of approximately $15 \mathrm{~ms}$. Pulse repetition rate varied with water depth, but has a period of approximately $15 \mathrm{~s}$ to $20 \mathrm{~s}$ for the majority of the cruise.

The departure draft at the beginning of the cruise of RV Kilo Moana was $7.57 \mathrm{~m}$ port forward; $7.65 \mathrm{~m}$ starboard forward; $7.72 \mathrm{~m}$ port aft; and $7.92 \mathrm{~m}$ starboard aft. The arrival draft at the conclusion of the cruise was $7.01 \mathrm{~m}$ fore, and $7.32 \mathrm{~m}$ aft . Although the draft varied slightly up and down during the cruise as a result of fuel consumption and ballast changes, the changes in draft were insignificant for this survey.

An AML Oceanographic Smart SV\&T, serial number 20020, was used to measure sound speed at the transducer. Calibration was conducted by the manufacturer on 2016-02-25/27; the certificates of calibration are in Appendix D.2.

Kongsberg Seafloor Information System (SIS) version 4.3 .2 build 31 (2016-02-24), marked as "For EM122 rev. 2.2.2_OCT_2016" was used to monitor and control the EM122 MBES.

\subsection{Applanix POS/MV Motion Sensor}

The EM122 was provided with position and motion information using an Applanix POS/MV inertial motion unit (IMU) version 5, PCS serial number 7995, IMU 64 serial number 3494 (antennae were AeroAntenna AT1675-540TS, port serial 10312, starboard serial 10299), which was provided with wide-area satellite-based differential positioning using the built-in Fugro Marinestar service on the BD982 receiver card (GNSS G2 service was used throughout). The POS/MV system provided motion estimates with uncertainty on the order of $0.02^{\circ}$ (r.m.s.) for roll, pitch, and heading, heave accuracy of the maximum of $0.05 \mathrm{~m}$ (r.m.s.) or $5 \%$ of measured heave, and positioning accuracy of approximately $0.5 \mathrm{~m}$ (CEP). Applanix MVPOS-View software, version 9.82 (firmware 9.82), was used to monitor and control the performance of the POS/MV.

1 There exists at least one other EM122 that also claims to be serial number 109 (specifically, on the RV Marcus G. Langseth). It is therefore unknown if this is an older serial number left over from the EM120 previously installed on RV Kilo Moana, or if all EM122 systems claim that this is their serial number, or if this is not actually a serial number in the conventional sense. 


\subsection{Knudsen 3260 Sub-bottom Profiler}

The sub-bottom profiler (SBP) usedon KM1811 was a Knudsen Engineering 3.5-kHz 3260 rack-mounted echosounder, serial number K2K-07-0911, connected to two permanently hullmounted transducer arrays (transmitter K2K-07-0884, firmware 2.64, 15 TR-75 Massa transducers) and $12-\mathrm{kHz}$ (transmitted $\mathrm{K} 2 \mathrm{~K}-07-0890$ ). The system was used at a nominal frequency of $3.5 \mathrm{kHz}$ so as not to interfere with the EM122, and was synchronized to the firing rate of the EM122 so as to minimize interference between the two systems. The source level of the Knudsen 3260 is expected to be approximately $220 \mathrm{~dB}$ re. $1 \mu \mathrm{Pa}$ at $1 \mathrm{~m}$, but may vary in practice. The system was configured for $64 \mathrm{~ms}$ linear frequency modulated (LFM) pulses, with 3.0-kHz bandwidth.

Knudsen EchoControlClient software version, 2.64, operating on a portable laptop computer, was used to monitor and control the system. The Knudsen EchoControlServer software used to interface to the echosounder was version 2.64. Although a replacement computer and an updated version of software and firmware were available, it was decided to conduct the survey with the existing configuration of hardware and software, which worked well throughout the cruise.

\subsection{Gravity Meter}

The Kilo Moana carries a Bell Aerospace BGM-3 marine gravimeter, with component part serial numbers 219 (sensor), 315 (CPS), and 322 (platform). The system is mounted in a secure space on the deck in the science office. The portable gravity meter used to provide tie-points was a Lacoste and Romberg Inc. model with no discernable model number, serial number 1 . The gravimeter was operated throughout the cruise.

\subsection{XBT Launch System}

The XBT launch system was a Sippican (Lockheed-Martin) Mk21 LM3A launcher (serial number illegible). The control computer, located in the Wet Lab on the main deck aft, ran version 2.1.1 of Lockheed Martin Sippican's WinMk21 software (MkCoeff 2.3.1, Mk21AL 2.3.1). The replacement XBT launcher was also a Lockheed Martin Sippican Mk21 LM3A, serial number 111601.

\subsection{System Configuration}

Fig. 2.1 shows the placement of the instrument displays in the main lab. A summary of serial numbers and software versions is provided in Table 2.1. 


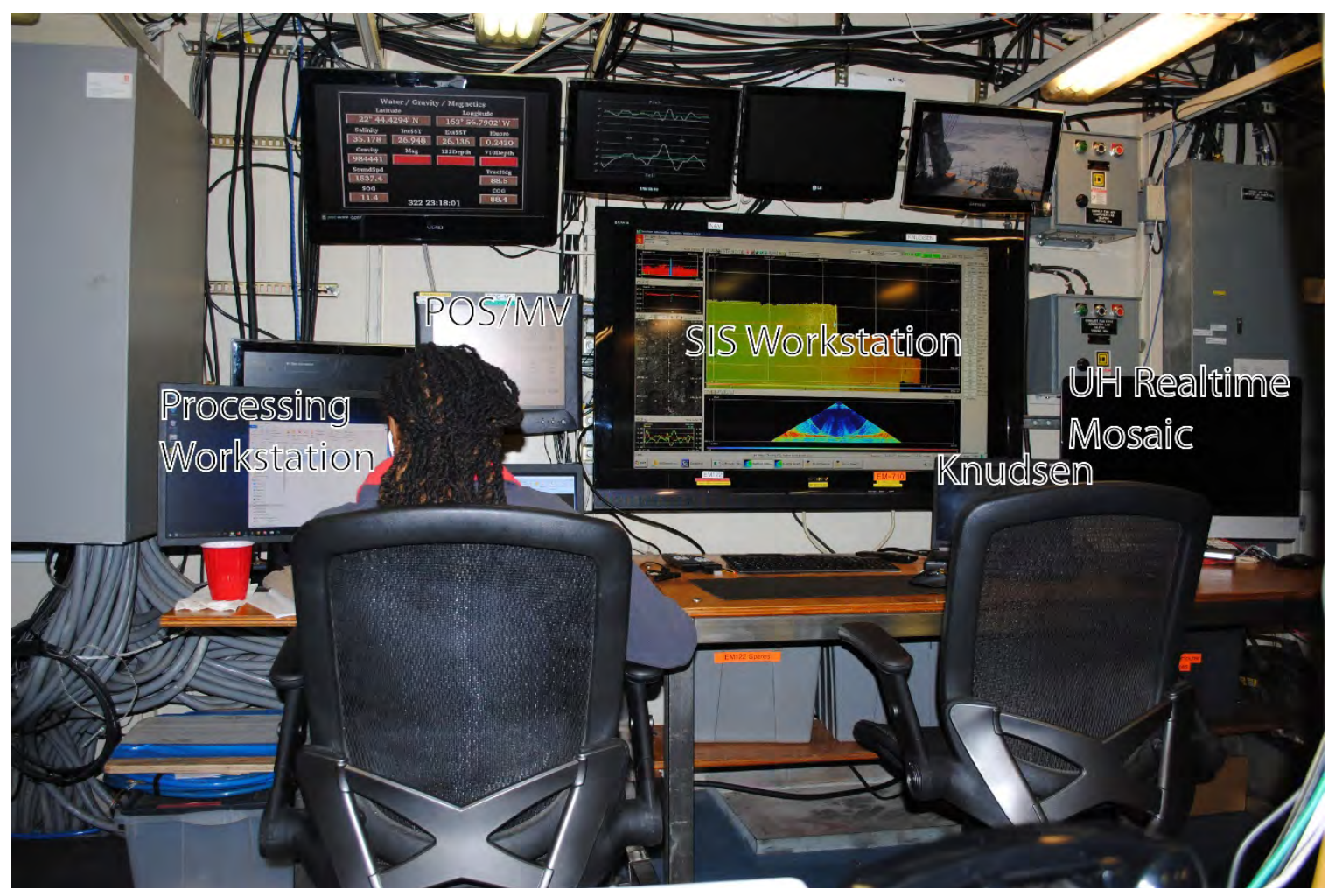

Figure 2.1: Instrument displays in the main lab of the RV Kilo Moana during KM1811. The large center screen is used for SIS, and the screen to the left displays the POS/MV real-time performance metrics, while the laptop to the right was used for Knudsen display. The laptop to the left was used for data processing and quality control. A separate real-time data mosaic service (far right) that was tested but not used for survey purposes was provided by University of Hawai' i. 
Table 2.1: Summary of serial numbers and software versions for the various components of the mapping system, including data processing software, used during the mapping mission.

\begin{tabular}{|c|c|c|c|c|}
\hline Instrument & Part & Make & Model/Release & Serial \#/Date \\
\hline \multicolumn{5}{|c|}{ Multibeam Kongsber: EM 122} \\
\hline & Transceiver Unit & Kongsberg Maritime AS & 309653 & 109 \\
\hline & SIS Workstation & Kongsberg Maritime AS & HWS-C3 & 47467В09 \\
\hline & SIS (software) & Kongsberg Maritime AS & 4.3 .2 & $2016-02-24$ \\
\hline & TX36 (firmware) & Kongsberg Maritime AS & 1.11 & 2013-05-07 \\
\hline & RX32 (firmware) & Kongsberg Maritime AS & 1.11 & 2010-02-18 \\
\hline & BSP67B (firmware) & Kongsberg Maritime AS & 2.2 .3 & 2009-07-02 \\
\hline & CPU (firmware) & Kongsberg Maritime AS & 1.3 .8 & $2016-10-01$ \\
\hline & DSV (firmware) & Kongsberg Maritime AS & 3.1 .8 & $2014-11-25$ \\
\hline & DDS (firmware) & Kongsberg Maritime AS & 3.5 .10 & 2014-01-06 \\
\hline \multicolumn{5}{|c|}{ Applanix POS/MV 320} \\
\hline & MV-320 (hardware) & Applanix Corporation & MV-320 V5 & $1.4-12$ \\
\hline & MV-320 PCS (hardware) & Applanix Corporation & MV-320 V5 & 7995 \\
\hline & MV-320 IMU (hardware) & Applanix Corporation & IMU-64 & 3494/July 2016 \\
\hline & MV-320 (software) & Applanix Corporation & 9.82 & 10005101 \\
\hline & Primary GPS Receiver & Furuno & GP 150 & $6416-8482$ \\
\hline & Primary Antenna & AeroAntenna Technology & RG-45-NM-R & 10312 \\
\hline & Secondary GPS Receiver & As Primary & As Primary & As Primary \\
\hline & Secondary Antenna & AeroAntenna Technology & RG-45-NM-R & 10299 \\
\hline & MS-POSView (software) & Applanix Corporation & 9.82 & \\
\hline \multicolumn{5}{|c|}{ Marihestar GNSS } \\
\hline & Build in (POS/MV) & Fugro MarineStar & $/ /$ & 1010117134 \\
\hline \multicolumn{5}{|c|}{ Transducer Sound Speed Sensor } \\
\hline & Probe & AML Oceanographic & SV\&T & $20020 / 2-27-2016$ \\
\hline \multicolumn{5}{|c|}{ XBT System Sippican MIK21/USB } \\
\hline & MK21 OI Board & Sippican & MK21/USB & 0320 \\
\hline & & Sippican & MK21-LM3A & 111601 \\
\hline & WinMK21 & Sea-Air Systems & 2.1 .1 & 2003 \\
\hline \multicolumn{5}{|c|}{ SBP Knudsen Chirp 3260} \\
\hline & Topside Processor & Knudsen Eng. Ltd & D229-04331 & K2K-07-0911 \\
\hline & Ch\#1 3.5 kHz (hardware) & Knudsen Eng. Ltd & // & K2K-07-0884 \\
\hline & Ch\#1 3.5 kHz (software) & Knudsen Eng. Ltd & D409-04195 & 2.64 \\
\hline & Ch\#2 12 kHz (hardware) & Knudsen Eng. Ltd & // & K2K-07-0890 \\
\hline & Ch\#2 12 kHz (software) & Knudsen Eng. Ltd & D409-04195 & 2.64 \\
\hline & Software EchoControlClient & Knudsen Eng. Ltd & D409-04184 & 2.64 \\
\hline \multicolumn{5}{|c|}{ Marine Gravity Meter System Bell BGM-3 } \\
\hline & Sensor & Bell Aerospace Textron & $/ /$ & 219 \\
\hline & CPS & Bell Aerospace Textron & // & 315 \\
\hline & Platform & Bell Aerospace Textron & $6109-307001-3$ & 322 \\
\hline \multicolumn{5}{|c|}{ Land Gravity Meter System Bell BGM-3 } \\
\hline & Geodetic Gravity Meter & Lacoste \& Romberg Inc & $/ /$ & 1 \\
\hline \multicolumn{5}{|c|}{ Processing Software } \\
\hline & HIPS/SIPS & CARIS & 10.3 .3 & 2017-09-08 \\
\hline & Fledermaus & QPS & 7.8 .4 & 2018-05-23 \\
\hline & FMGT & QPS & 7.8 .4 & 2018-05-23 \\
\hline & SonarWeb & Chesapeake Technologies & 3.16 .0096 & $2009-10-13$ \\
\hline & SonarWiz & Chesapeake Technologies & 7.00.0011 & 2017-09-28 \\
\hline & HyPack MAX & Xylem & 18.0.15.0 & // \\
\hline & Sound Speed Manager & HydrOffice & 2018.1.40 & 2018 \\
\hline & Qimera & QPS & 1.6 .3 & 2018-05-24 \\
\hline
\end{tabular}




\section{Data Protocols}

\subsection{Collections}

Data collection was conducted using standard hydrographic protocols for deep-water mapping. Static offsets for the positions of the components of the survey system were provided to RV Kilo Moana based on the latest survey report for the ship (dated 2015-03, Appendix D.1). Static angular offsets were assessed through the patch-test procedure described in Section 4 and were applied in the SIS software and thence to the real-time processing module in the EM122. The offsets determined on 2017-07-26 during a system test cruise (KM1711) were found to be correct, and no changes to the existing values were applied.

The SIS software was configured to automatically start new lines every eight hours, but lines were incremented manually every six hours. Line changes on the Knudsen 3260 were synchronized with the EM122 so that corresponding lines were always captured on each system. Turns were recorded separately for both systems, and each turn file was labeled as such to distinguish those files from the main data.

Speed of sound at the transducer was determined by an AML Oceanographic SV\&T sensor that feds directly into the EM122 processing station in order to correct for refraction in the beamsteering computations. Sound-speed profiles (SSP) in the upper part of the water column were derived from XBT launches and occasional XSV launches (as required) and extended to deep water depths using almanac data from the World Ocean Atlas 2009 (WOA09) using the HydrOffice Sound Speed Manager software, version 2018.1.14, installed on the SIS workstation. (Note: There were a few problems with communications in the version 2018.1.14 HydrOffice Sound Speed Manager software, which required manual query to obtain draft and surface sound velocity. However, even with these issues, the program provided the functionality needed for transmission of the sound speed data to SIS. Therefore, it was decided that installation of a new version of the HydrOffice Sound Speed Manager software that was downloaded during the cruise was not necessary. After manual inspection and editing, these extended and simplified profiles were then sent to the EM122 over the network in order to avoid any dropped pings or stop/start update cycles. The profiles (raw, extended, and simplified) were also stored in a local database for further analysis. Routine XBT launches were conducted as needed or at 6-hr intervals. In many cases temporal variability in the water column necessitated XBT casts much more frequently (1-1.5 hours) than at $6 \mathrm{hr}$ intervals. During the transit to the survey area, the XBT launcher failed and the SSP was derived from the HydrOffice Sound Speed Manager database until the replacement launcher was installed. The replacement launcher was used successfully for the entire survey map area. The sound speed at transducer depth from the SSP was compared in the SIS console with the current real-time sound speed at the transducer and if a difference of more than $0.5 \mathrm{~m} / \mathrm{s}-1.0 \mathrm{~m} / \mathrm{s}$ was observed for more than a few minutes, a new XBT cast was made. The XBT launch system is described in Section 2.5, and the metadata for the launches and probes is given in Appendix B.

The Knudsen Engineering 3260 SBP was operated throughout the cruise, except during the patch-test, typically with a nominal depth gate (range setting) of $500 \mathrm{~m}$ about the expected depth. A priority sub-bottom line with a range setting of $200 \mathrm{~m}$ and internal triggering was run at the end of the survey in an area requested by ECS experts. All sub-bottom data were recorded with an assumed sound speed of $1500 \mathrm{~m} / \mathrm{s}$. Full digital records were recorded in SEG-Y format and the Knudsen proprietary KEB format. 
The gravity meter calibration ties and gravity data analysis were conducted by Jonathan Tree, one of the science crew who has extensive experience with gravimetry surveys, and/or the UH marine science technicians. The gravity tie data is provided in Appendix D and the gravity results are presented in Appendix E.

Although not formally part of the cruise, Acoustic Doppler Current Profiler (ADCP) data at $300 \mathrm{kHz}$ and $38 \mathrm{kHz}$ were collected continuously while underway. Data reduction and archive submission for this data were handled separately by University of Hawai'i.

\subsection{Processing}

Data from both the EM122 and the Knudsen 3260 were made available on the Kilo Moana's internal network using a network share from the ship's primary Network Attached Storage (NAS) device. Files from the EM122 were synchronized automatically to the NAS shortly after being completed; files from the Knudsen 3260 were copied to the NAS manually. Files were copied from the NAS to local storage for archive and processing at the completion of each line. For purposes of efficiency in data processing, the data were separated into sub-projects. The transits from Honolulu and to Seattle and the patch test data were kept as two separate projects in post-processing.

Data processing for the MBES bathymetry was conducted using QPS Qimera 1.6.3 (05-2418) with visualization products created with QPS Fledermaus 7.8.4 (05-23-18). A separate flowpath between Qimera and HYPACK was established for intermediate gridded products created in Qimera, so that current data could be placed in the same geographic context with prior data. Generic Sensor Format (GSF) files, which contain both edited bathymetric data and backscatter imagery, were exported from Qimera. GSF files and GeoTIFF images were used for transfer. Preliminary onboard data processing for the Knudsen 3260 data was conducted in Chesapeake SonarWiz 7.00.0011 and HYPACK 18.0.15.0.

The MBES bathymetry data were processed using the $C U B E$ algorithm, implemented in Qimera. A grid resolution of $100 \mathrm{~m}$ was used for all depths of water encountered. The CUBE calibration parameters used are given in Appendix D.4. Quality control of the MBES data during the cruise was carried out by the watch standers, to ensure that any anomalous depth measurements were either appropriately handled by the $C U B E$ algorithms within QPS Qimera, or were edited by hand if necessary. Post-cruise cross-swath analyses were conducted by Dr. James V. Gardner, UNH/CCOM-JHC to determine the bathymetry uncertainty of the EM122 aboard the RV Kilo Moana. Results of the cross-swath analyses are given in Appendix F.

After the bathymetry grid was finalized in QPS Qimera, surface filtering was applied to the raw data so that legacy point-cloud files of surface-consistent sounding observations could be generated for archival purposes. Processed QPD files were exported in the Generic Sensor Format (GSF) in order to archive processed multibeam data files and for import into QPS Fledermaus and QPS FMGT. The files were also exported in ASCII longitude-latitude-depth format for use in future products. Grids were exported in BAG and GeoTIFF formats from QPS Qimera, and separate grids in geographic coordinates were constructed in QPS Fledermaus from the exported ASCII data. Preliminary data products were constructed onboard, and are illustrated in Appendix $\mathrm{C}$, but final adjustment, cross comparisons, and product creation were conducted ashore by Dr. Gardner, UNH/CCOM-JHC. 
The MBES backscatter data were processed using the QPS FMGT 7.8.4 (2018-05-23). A grid resolution of $100 \mathrm{~m}$ was used for the backscatter mosaics. The calibration parameters used are given in Appendix D.5. Mosaics of backscatter were exported in GeoTIFF and QPS Fledermaus SD format for review and for combination with bathymetric data in the visualization environment. Mosaics of bathymetry, backscatter and gravity were also created using the open source MBSystem software and plotted using the open source Generic Mapping Tools (GMT) 5.4.4 software.

Sub-bottom profiler data was processed using SonarWiz and HYPACK to convert the data into imagery and for export it in forms suitable for review and correlation with the MBES data. No further quality control was conducted.

For compatibility with previous legs of the cruise, the filenames used by the SIS software were translated into sequential filenames, starting with line number 200. Translation tables for MBES and Knudsen data are provided in Appendix A. FGDC-compliant metadata were constructed post-cruise by Dr. Gardner for each line of MBES and Knudsen data, as well as constructed overview grids of bathymetry and backscatter.

Data from the cruise in native Kongsberg Maritime .all format were archived for ingestion through the R2R program, and were made available after the cruise on a portable hard drive. Separately, CCOM-JHC provided processed data with metadata to the National Centers for Environmental Information (NCEI). The shipboard archive also contains raw data from all instruments, including meteorological observation, ship bridge logs, navigation information, and other underway sensor information.

\section{Raw Gravity data collection and file format:}

Marine gravity was continuously collected during the KM1811 cruise using the Bell BGM3 marine gravimeter on board the RV Kilo Moana. Raw gravity data files are produced daily, and are labeled km1811_raw_grav_[JDAY].rg. The data structure of these files is summarized below.

\begin{tabular}{|c|c|c|c|c|c|c|c|c|c|c|c|c|c|c|c|c|}
\hline Year & Jday & $\mathrm{Hr}$ & Mir & $\mathrm{Sec}$ & $\begin{array}{l}\text { Unix } \\
\text { Time }\end{array}$ & Lat. & Lo & $\mathrm{Hd}$ & $\mathrm{SO}$ & $\mathrm{CC}$ & Sens & & $\begin{array}{l}\text { Raw } \\
\text { coun }\end{array}$ & & & Raw \\
\hline
\end{tabular}

\section{Raw Gravity Processing:}

Raw gravity data were processed daily using GMT program filter1d, and awk scripts to calculate east component of velocity vectors to calculate the Eötvös correction, and determine the value of gravity for positions using the 1984 International Gravity Formula (IGRF). Free-air gravity anomaly (FAA) was calculated by subtracting the IGRF value and adding the Eötvös correction. The results of these calculations are present in the final processed data files; named km1811_raw_grav_[JDAY].rg.faa. Processed gravity files are decimated to 15-s intervals. The format of these files are summarized below.

\begin{tabular}{|l|l|l|l|l|l|l|l|l|}
\hline Year & JDay & $\begin{array}{l}\text { Unix } \\
\text { Time }\end{array}$ & Longitude & Latitude & $\begin{array}{l}\text { Raw } \\
\text { Gravity } \\
\text { (mgal) }\end{array}$ & $\begin{array}{l}\text { Eötvös } \\
\text { Correction } \\
\text { (mgal) }\end{array}$ & $\begin{array}{l}\text { IGRF } \\
\text { Value } \\
\text { (mgal) }\end{array}$ & $\begin{array}{l}\text { Free-air } \\
\text { Anomoly } \\
\text { (mgal) }\end{array}$ \\
\hline
\end{tabular}

Daily free-air gravity anomaly files were combined and gridded using the GMT programs blockmedian and nearneighbor. A discussion of the gravity results is in Appendix E. The final 
map of the free-air gravity anomaly within the survey area is shown in Figures 3.1 and E.1 and intermediate products are shown in Fig. E.2.

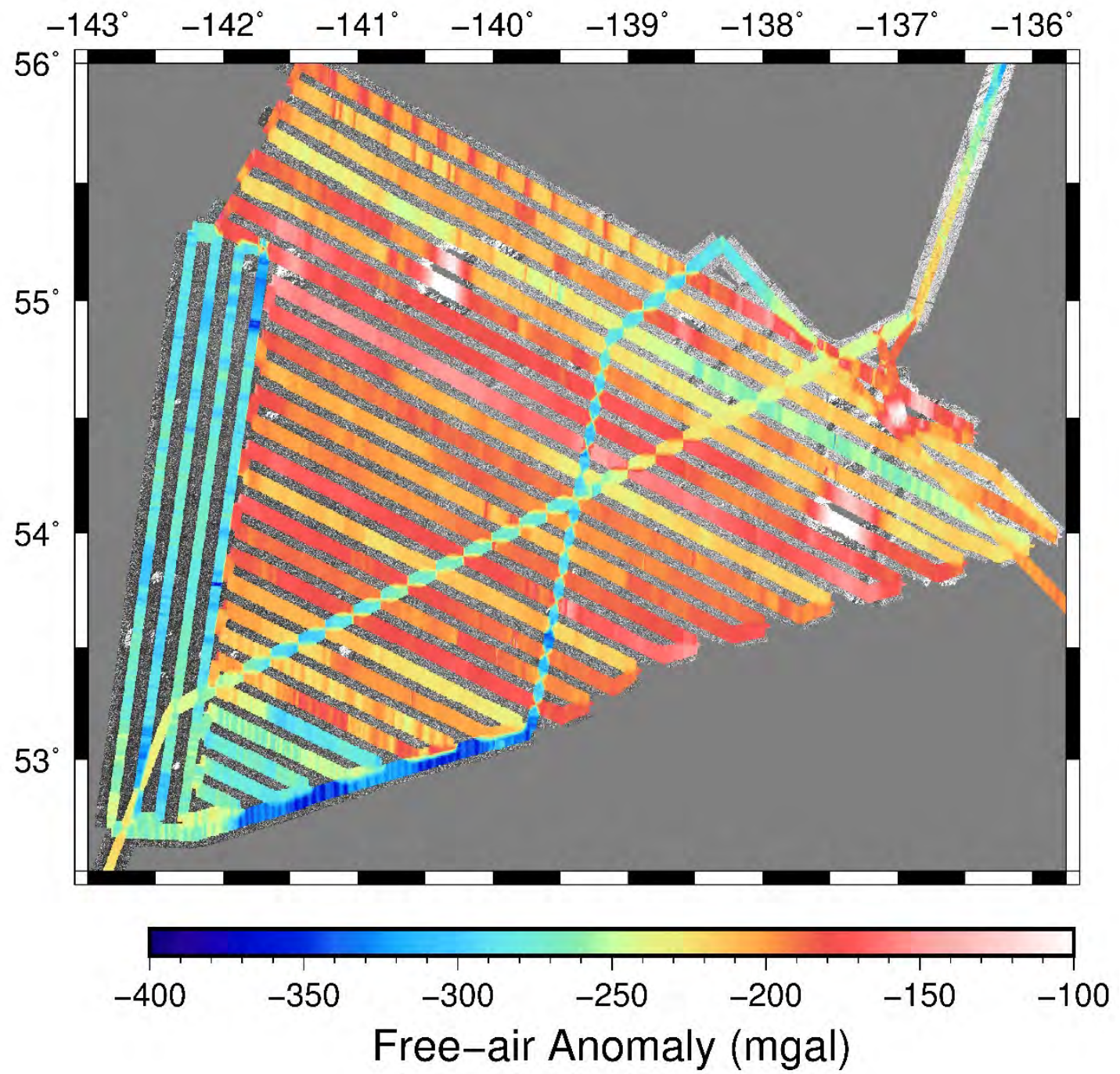

Figure 3.1: Map of the free-air gravity anomaly plotted on top of the multibeam backscatter.

Note the inconsistency between cross-lines through the survey and western margin northsouth survey lines. Strong variations within the NW-SE survey lines, which are suspected to be inaccurate, were observed. The largest variation was observed at the western margin. 


\section{Patch-Test Results}

The most recent patch test of the EM122 on the RV Kilo Moana was performed during cruise KM1718 in November 2017. The patch test confirmed a patch test performed on July 24-26, 2017 conducted by Paul Johnson of UNH/CCOM-JHC on behalf of the NSF Multibeam Advisory Committee. However, regardless, a separate patch test was conducted prior to commencement of mapping in the survey area of KM1811 in order to re-confirm the values present in the system. Data from this patch test were named separately from the main survey and transit lines and held in a separate data directory. The patch tests were run with the initial offsets entered into the SIS software. A total of 6 patch-test lines were run prior to commencing the KM1811 survey (Fig. 4.1).

1. Pitch Test: Two sets of reciprocal lines on slope and top of ridge $10 \mathrm{kts}(\mathrm{C}-\mathrm{D}-\mathrm{C}$ and E-F-E)

2. Roll Test: Reciprocal lines on flat region at $10 \mathrm{kts}$ (B-A-B)

3. Heading Test: Parallel lines in same direction on slope and top of ridge (E-F \& G-H)

No timing (latency) test lines were run, because detection of latency offsets is not feasible in deep water.

The data were ingested into Qimera in a project separate from that where the main-scheme lines were processed ("KM1811_PatchTest"), and conventional processing was applied to allow the data to be used in the calibration tool within Qimera and the raw data was processed in the Kongsberg SIS software for comparison. Examination of the data showed, over the various pairs of lines that can be used to solve for roll, pitch, latency, and yaw, that there was no distinctive pattern of offset-derived artifacts from the data.

It was therefore concluded that the initial offsets (Fig. 4.2) of

Pitch: $-0.35^{\circ}$

Roll: $-0.07^{\circ}$

Yaw: $+0.05^{\circ}$

Timing: $0 \mathrm{~ms}$

would remain operational for the duration of the survey.

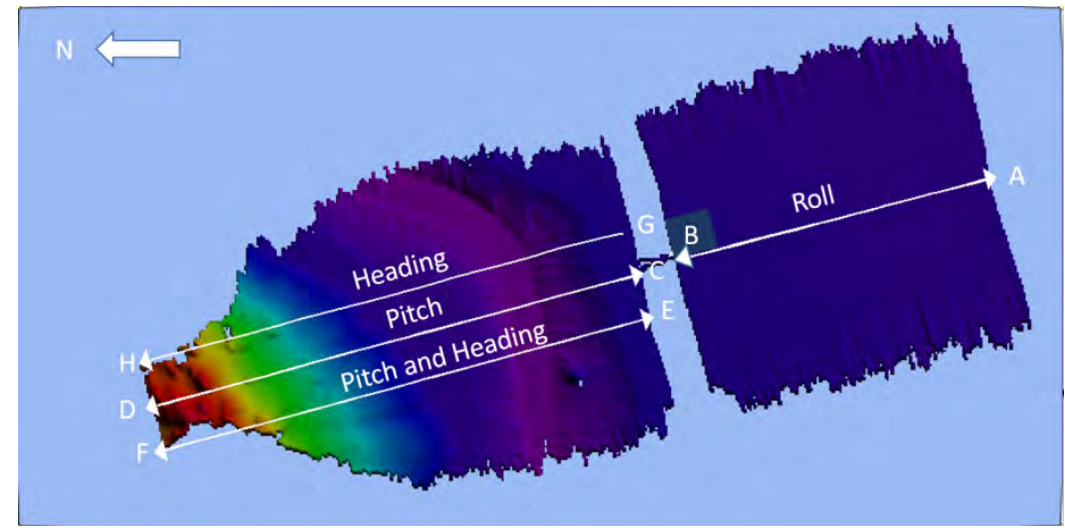

Figure 4.1: Patch-test lines run immediately prior to the KM1811 survey; the center of the area is at approximately $55^{\circ} 44.12^{\prime} \mathrm{N}, 137^{\circ} 04.91^{\prime} \mathrm{W}$. All lines were run at $10-11 \mathrm{kts}$. The lines were run from C-D-C (pitch), then B-A-B (roll); E-F-E (repeat pitch) and E-F and G-H (heading). 


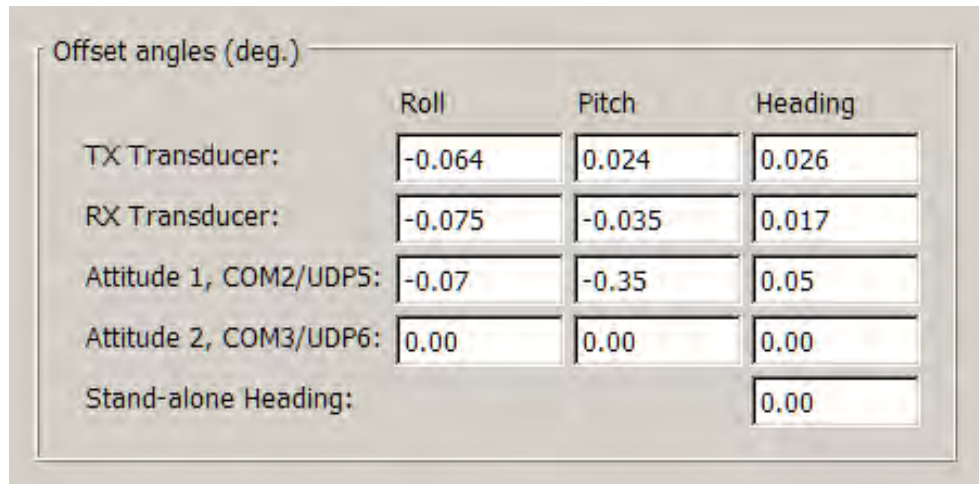

Figure 4.2: Angular offsets in effect during KM1811. 


\section{Daily Narrative}

All times in UTC unless noted otherwise.

Friday, June 29, 2018 \& Saturday, June 30, 2018 JD 180-182.

- Andy Armstrong and Paul Johnston arrive aboard RV Kilo Moana to set up and configure data processing equipment for cruise. Confirmed that the XBT and XSV supplies were loaded and stowed.

- Chief scientist and watch standers arrive on RV Kilo Moana for familiarization and training

- Seven ARGO floats loaded on board

- Gravity tie performed at University of Hawaii marine center

JD 182 -- July 1, 2018

- Depart Honolulu, 1800, safety meeting, drills

JD 183 -- July 2, 2018

- 1800: Training

- 1930: Start logging multibeam and sub-bottom data at 25 deg. N.

JD 184 - July 3, 2018

- 1550-1555 Knudsen lost GPS feed, regained signal after restart

○ Ended raw line 11 (.sgy) before restart

- Started raw line 12 (.sgy) after restart

- 2145: ARGO float \#942 deployed

JD 185 -- July 4, 2018

- 1200: ARGO float \#F0938 deployed

- 1200: Time zone changed to -9 UTC

- 1958: Kongsberg EM122 froze and restarted SIS - maintained logging in line 208.

JD 186 -- July 5, 2018

- 0226: ARGO float \#F0939 launched

- 0530: Pyrotechnics training on aft deck

- 1500: Knudsen software updated; machine restarted, GPS feed problem.

- 1636: ARGO float \#F0941 deployed

- 1645: XBT launcher failed to collect data, repairs pending

JD 187 -- July 6, 2018

- 0600: Ascending steep rise, Knudsen SBP is having difficulty tracking bottom

- 0645: ARGO float \#F0940 deployed

- 0730: Descending rise, Knudsen SBP seemingly settling down and tracking better

- 0945: Still chasing bathymetry with Knudsen 
JD 188 -- July 7, 2018

- 0230: Knudsen's SEG-Y Carrier Type was switched to filtered

- 0334: Knudsen machine was shut down in an attempt to reconnect it to the server

- 0340: Knudsen back up and running

- 0530: Reboot SIS, computer, TRU. Loss of sectors on port side persisted beyond initial SIS only restart.

- 20550: SIS back online and logging. Two files for this recording period, $217 \& 218$. Lost some Knudsen SBP data during SIS reboot before switching to internal sync (same file, not advanced).

- 1108: ARGO float \#F0937 deployed

JD 189 - July 8, 2018

- 0100: ARGO float \#F0943 deployed

- 0540: Changed Penetration Filter setting from Weak to Medium to reduce nadir artifacts.

- 0750: Entering area of more bathymetric relief, switched Penetration Filter back to Weak.

- 1002: Changed Penetration Filter setting from Weak to Medium, intermittent artifacts again.

- 1010: Now seeing a continuous 'feature', changed Penetration Filter setting from Medium to Strong.

- 1014: Changed Penetration Filter setting back to Medium after determining that continuous low relief features were real with orientations oblique to track. Fear the waterfall display

JD 190 - July 9, 2018

- 0700 - Time change to Zone -8 UTC.

- XBT launcher repair tested, not successful.

JD 191 - July 10, 2018

- 0433: Begin official survey, SOL 'Crossline' toward inshore start of main survey lines: GOA_Line_230

- 1033: First file change of the official survey

- 1100: Odd "C C"-shaped seamount

- 1230: SV red majority of the time; sometimes up to $3 \mathrm{~m} / \mathrm{s}$ difference than sensor

$\circ$ Frequent changes in magnitudes $>1 \mathrm{~m} / \mathrm{s}$ common in short durations of time

- Consistent side lobes on inner and outer beams (GOA Lines 232 \& 233) easily removed by Qimera

- Sub-bottom data revealed weak to nonexistent stratification/massive bedding structure

- Auto-tilt runtime setting changed from $3^{\circ}$ to $4^{\circ}$ in attempt to fix side lobe issues (1730; GOA Line 233)

- Adjustment seemed to have little effect

JD 192 - July 11, 2018

- 0010: EOL 'Crossline', turn toward Sitka for resupply of XBT launchers 
- 0035: SIS crashed and restarted. Switched to line 236 after restart

- 0515: Water-column data was not being logged (after SIS crash?). Began logging WCL.

- 0815: SV has gone red, Sound Speed Manager not working

- 0915: Switched to AUTO ping mode, now inshore of previous survey data at $1145 \mathrm{~m}$ water depth, but SIS is still choosing to operate in DEEP mode.

- 0921: Reboot SIS to bring it back up with Data Distribution tool (it was inadvertently shut down) and hopefully fix other woes. Knudsen stopped pinging since it was on external sync.

- 0928: Stopped logging on Knudsen after changing to internal sync. Still pinging. Data Distribution settings were set to pre-KM1811 departure values.

- 0932: Started logging again on both SIS (file \#238) and Knudsen (file \#067). Knudsen .kea and .keb files are missing for files \#065, 066 - was changing Range setting.

- 0945: Knudsen switched back to external sync. Sound Speed Manager active again and new SVP applied, clear.

- 1015: EM 122 in MEDIUM ping mode, 600+ m w.d.

- 1037: EM 122 in SHALLOW ping mode, $250 \mathrm{~m}$ w.d.

- 1044: Stopped logging and pinging Knudsen. Stopped logging EM 122, <250 m w.d.

- 1400-1500: Arrive Sitka and pick up new XBT launcher

- 1500-2400: Transit from Sitka to patch test; XBT launcher installed and tested. Testing Sound Speed Manager because of intermittent problems with SIS/SVP Manager communication. This issue is bothersome but not critical to use of SVP manager, because information can be loaded into SVP manager manually.

JD 193 - July 12, 2018

- 0000-0600: Continue transit to Patch Test.

- 0600: Take XSV and XBT. Apply XSV to data

- Preexisting bias values in the MRU: Roll $=-0.07^{\circ}, \mathrm{Pitch}=-0.35^{\circ}, \mathrm{Hdg}=+0.05^{\circ}$, Time $=0.00 \mathrm{~s}$

- 0624-0738: First pitch test line (C to D), \#239

- 0749-0908: Reciprocal pitch test line (D to C), \#240

- 1010: Compared results using SIS, Qimera, and HYPACK patch test tools with varied results. Moving on to roll test lines without changing pitch values (yet).

- 1025-1113: First roll test line (B to A), \#241

- 1122-1208: Reciprocal roll test line (A to B), \#242. Did not resume HYPACK logging until 1200.

Determined that no change in roll value is necessary.

- 1307- 1423: First yaw test line (E to F), \#243

- 1434: Reciprocal line (F to E) (for pitch comparison), \#243

- 1615: 2 $2^{\text {nd }}$ yaw test line ( $\mathrm{G}$ to $\left.\mathrm{H}\right)$

- 1745: Patch test complete. No changes made to system biases. 
- 1745: Transit to plan line 2 (Line 1 deleted): Data logging SIS Line

- 1923: Start main scheme survey - HYPACK Line 2 (GOA_Line_246)

JD 194 - July 13, 2018

- 0512 short gap in Knudsen SBP record on raw line \#073, shifted to wrong scale range

- Having to launch XBTs every $1-2 \mathrm{hr}$. because of distinct surface layer.

- 1359: Start HYPACK Line 03 (GOA_Line_251)

JD 195 - July 14, 2018

- 0843: EOL HYPACK Line 03

- 0851: SOL turn line 03 to 04 , hdg $135^{\circ}$

- 1059: EOL turn line 03 to 04

- 1105: SOL HYPACK Line 04, hdg $299^{\circ}$ (GOA_Line_255)

JD 196 - July 15, 2018

- 0546: Diverted $2^{\circ}$ stbd to avoid data gap $w / \sim 20 \mathrm{~nm}$ to go, new hdg $301^{\circ}$, projected to be $1.1 \mathrm{~nm}$ to stbd at EOL. Overlap was $<10 \%$.

- 0645: Came back over $1^{\circ}$ to port, new hdg $300^{\circ}$. Overlap now $\sim 20 \%$.

- 0802: EOL HYPACK Line 04. Finished $\sim 0.5 \mathrm{~nm}$ to north of line with good overlap.

- 0810: SOL turn line 04 to 05 , hdg $210^{\circ}$.

- 0841: EOL turn line 04 to 05 . Coming in $~ 0.5 \mathrm{~nm}$ north of HYPACK Line 05

- 0848: SOL HYPACK Line 05 , hdg $120^{\circ}, \sim 20 \%$ overlap near SOL (GOA_Line_260)

- HydrOffice Sound Speed Manager software.

- At $~ 1230$, overlap was only $5 \%$, asked bridge to adjust course $1 \mathrm{~km}$ to port on SIS_line_262, HYPACK Line 5

- 01:30: Loud electrical pop from EM 122 TRU area, will run BIST test on next turn

JD 197- July 16, 2018

- 04:10: Gap has been forming, moving $100 \mathrm{~m}$ to port near EOL HYPACK Line $05 \mathrm{w} / \sim 7$ $\mathrm{km}$ to go

- 04:14: Moving another $300 \mathrm{~m}$ to port. And then some...

- 05:02: EOL HYPACK Line 05. $\sim 2.2 \mathrm{~nm}(\sim 4 \mathrm{~km})$ offset north of line 05 at EOL.

- 05:12: EM 122 passed BIST test. SOL turn line 05 to 06, hdg $255^{\circ}$

- 05:55: EOL turn line 05 to 06 . Coming in $1.5 \mathrm{~nm}$ short on oblique turn line to compensate for EOL offset of line 05.

- 06:04: SOL HYPACK Line 06, course 299 (GOA_Line_265)

- 06:16: Maintaining 20\% overlap at SOL. Slowly heading back to line, targeting $6 \mathrm{~nm}$ downline, approximately where diversion on line 05 occurred. Requires gradual course change of $6^{\circ}$.

- 07:12: Have been back online with 10\% overlap

- 09:10: Gap forming on stbd side, but on edge of seamount so continuing online over channels to either side of edifice 
- 10:33: SIS grid disappeared awhile back. Stopped logging, pulled off line, restarted SIS

- 10:58: Back online and restarted logging. Last portions of previous line, line change file, and first file of current line are not displayed in SIS grid. These problems likely stem from not beginning a new SIS survey project after arriving on site in the Gulf of Alaska after long transit from Hawai'i.

- 11:04: At turn off point when restarted SIS

JD 198 - July 17, 2018

- 0250: Turn from Line HYPACK Line 6 to Line 7. Stop logging on KM1811-Transit 1 and Start new project KM1811 in order to minimize load of data volume on SIS

- 0315: Load gridded background data from Lines 2-6 and crossline

- 0320: Start Line 7 (GOA_Line_275). Gap between previous line and current line. Line coverage is only $12-13.5 \mathrm{~km}$. Came over $1.5 \mathrm{~km}$ to port.

- 0400: Change file to look at overlap between new data and previous lines. No gaps seen, so problem was caused by offset between background grid and real-time data.

- 20845: EM 122 port side array gone wacky, system locked on to false topography or overcompensating while traversing flank of high relief seamount

- 0901: EM 122 cleared itself, back on track

- 1125: Checked last line file in Qimera, overlapping >10\%. Close to middle of line now. Have been seeing wider gap with background image in SIS than at SOL.

- 2303: Start HYPACK Line 8 (GOA_Line_280)

JD 199 - July 18, 2018

- 0730: Maintaining 20\% overlap in middle of line 08

- 1130: Overlap 10\% beginning final third of line 08

- 19:07: Start HYPACK Line 9 (GOA_Line_284)

JD200 - July 19, 2018

- 0608: XBT \#0676 failed. Not transferred to SIS/SSM/NAS.

- 1400: Start HYPACK Line 10 (GOA_Line_288).

- Change survey plan to exclude western triangle, due to consistent $13.5 \mathrm{~km}$ swath coverage and time constraints

- 17:40: Moved line $550 \mathrm{~m}$ to port because of excessive overlap.

JD201 - July 20, 2018

- 0603: EOL HYPACK Line 10

- 0610: SOL turn line 10 to 11a.

- 0641: EOL turn line 10 to 11a

- 0646: SOL HYPACK Line 11a, Hdg $120^{\circ}$

- 2124: SIS crashed at EOL turn

- 2227: SOL HYPACK Line 12a, (GOA_Line_292), Bridge's ECDIS Line 11 
JD202 - July 21, 2018

- 0900: Passed over two narrow, steep spires or pinnacles with $\sim 300 \mathrm{~m}$ relief

- 1358: Started HYPACK line 13a; ECDIS line 12 / SIS Line 300 (GOA_Lines_296)

JD 203 - July 22, 2018

- 0401: EOL turn line 13a to 14a

- 0406: Started HYPACK line 14a / ECDIS line 13 / SIS Line 304 (GOA_line_300), Hdg $297^{\circ}$

- 0715: Getting almost 25\% overlap at $65 \mathrm{~km}$ downline, $3450 \mathrm{~m}$ w.d., $13-14 \mathrm{~km}$ swath width

- 1740 Start HYPACK line 15a / ECDIS line 14 / SIS line 0308 (GOA_line_304); Hdg $115^{\circ}$

JD 204 - July 23, 2018

- 0525: EOL HYPACK Line 15a

- 0531: SOL turn line 15a to $16 \mathrm{a}$

- 0619: EOL turn line 15a to 16a

- 0625: SOL HYPACK Line 16a / SIS line 0308 (GOA_line_307); Hdg 295 [12.5, 12.5 km spacing]

- 1000: >20\% overlap at SOL now reduced to minimal near middle of line, $\sim 65 \mathrm{~km}$ downline, $3545 \mathrm{~m}$ w.d., 12.5-13+ km swath width

- 1030: Overlap has increased back to previous levels at $80 \mathrm{~km}$ downline, $3500 \mathrm{~m}$ w.d., $\sim 13.5 \mathrm{~km}$ swath width

- 1805: SOL HYPACK Line 17a / SIS line 0315 (GOA_line_310)

JD 205 - July 24, 2018

- 0502: EOL HYPACK Line 17a

- 0509: SOL turn line 17a to $18 \mathrm{a}$

- 0548: EOL turn line 17a to $18 \mathrm{a}$

- 0551: SOL HYPACK Line 18a / ECDIS line 17 / SIS line 0318 (GOA_line_313), Hdg $297^{\circ}$ [12.5, $12.5 \mathrm{~km}$ spacing]

- 0654: XBT \#708 failed, \#709 good

- 0838: Auto-pilot went wacky when switched hydraulic pumps $\sim 60 \mathrm{~km}$ downline. Spinning around to redo coverage.

- 0851: Resume line 18a

- 1657: SOL HYPACK Line 19a / ECDIS line 18 / SIS line 0322 (GOA_line_317)

JD 206 - July 25, 2018

- 0326: SOL HYPACK Line 20a / ECDIS line 19 / SIS line 0326 (GOA_line_320), Hdg $297^{\circ}[12.25,12.25 \mathrm{~km}$ spacing]

- 1130: Achieving 20\% overlap for the entire line

- 1300: SOL SIS Line 329 / HYPACK Line 21a (switched to 22a because of closer proximity) (GOA_Line_323) 
- 2155: SOL SIS Line 332 / HYPACK Line 23a

JD 207 - July 26, 2018

- 0500: EOL HYPACK Line 23a

- 0507: SOL turn line 23a to 24a

- 0538: EOL turn line 23a to 24a

- 0546: SOL HYPACK Line 24a / SIS Line 0334 (GOA_line_328), Hdg $115^{\circ}$

- 1315: SOL HYPACK Line 25a / SIS Line 0336 (GOA_Line_330), Hdg $298^{\circ}$

- 1917: SOL HYPACK Line 26a / SIS Line 0338 (GOA_Line_332), Hdg $115^{\circ}$

JD 208 - July 27, 2018

- 0049: SOL HYPACK Line 27a / SIS Line 0340 (GOA_Line_334), Hdg. $294^{\circ}$

- 0431: EOL HYPACK Line 27a

- 0439: SOL turn line 27a to $28 \mathrm{a}$

- 0510: EOL turn line 27a to 28a

- 0518: SOL HYPACK Line 28a / SIS Line 0342 (GOA_Line_336), Hdg. $115^{\circ}$

- 0804: EOL HYPACK Line 28a

- 0811: SOL turn line 28a to 29a

- 0858: EOL turn line 28a to 29a

- 0905: SOL HYPACK Line 29a / SIS Line 0344 (GOA_Line_338), Hdg. $297^{\circ}$

- 1059: EOL HYPACK Line 29a

- 1105: SOL turn line 29a to 30a

- 1139: EOL turn line 29a to 30a

- 1145: SOL HYPACK Line 30a / SIS Line 0346 (GOA_Line_340), Hdg. $115^{\circ}$

- 1248: EOL SOL HYPACK Line 30a / SIS Line 0346 (GOA_Line_340), Hdg. $115^{\circ}$

- 1305: SOL HYPACK Line 31a / SIS Line 0347 (GOA_Line_341), Hdg. $115^{\circ}$

- 1410-1424: Short segment lines after finishing point HYPACK 31a; SIS lines 0348 and 0349 (GOA_line_342).

- 1430: SOL HYPACK Line W1 / SIS Line 0350 (GOA_Line_343) Hdg. 9. Western edge of survey.

- 1831: Did both ASV and XBT - almost identical results

JD 209 - July 28, 2018

- 0355: EOL HYPACK Line W1 (W=west)

- 0402: SOL turn line W1 to W2

- 0431: EOL turn line W1 to W2

- 0437: SOL HYPACK Line W2 / SIS Line 0353 (GOA_Line_346), Hdg $188^{\circ}$

- 0703: Moving $500 \mathrm{~m}$ to port to increase overlap

- 1825: EOL HYPACK Line W2

- 1834: SOL turn W2 to W3

- 1903: EOL turn W2 to W3 
- 1909: SOL HYPACK Line W3 / SIS Line 0358 (GOA_Line_350), Hdg $10^{\circ}$

JD 210 - July 29, 2018

- 0853: EOL HYPACK Line W3

- 0901: SOL turn line W3 to W4

- 0927: EOL turn line W3 to W4

- 0938: SOL HYPACK Line W4 / SIS Line 0362 (GOA_Line_354), Hdg $188^{\circ}$

JD 211 - July 30, 2018

- 0004: EOL W4

- 0014: SOL HYPACK Line S5 / SIS Line 0365 (GOA_Line_357), Hdg. 91

- 0440: Moving another $500 \mathrm{~m}$ to port to avoid gapping the corner pocket. Hdg $069^{\circ}$.

- 0505: Moving another $200 \mathrm{~m}$ port. Total will be $1200 \mathrm{~m}$ offset to port.

- 0510: Moving another $100 \mathrm{~m}$ to port

- 0522: Kept moving over to $1470 \mathrm{~m}$ off, now coming back to $1400 \mathrm{~m}$ off for future pockets

- 0616: Moving $100 \mathrm{~m}$ to port for a total of $1500 \mathrm{~m}$ off

- 0640: Incrementally increasing offset, now $\sim 1850 \mathrm{~m}$ off to port

- 0715: Gap filled

- 0800: Next gap filled

- 0900: Left small gap to avoid distorted survey geometry

- 0941: SIS crashed for no apparent reason on SIS line 366. Stopped SBP logging.

- 0945: SIS back up and logging on same line 366, different timestamp. Resumed SBP logging.

- 1001: Stopped logging and spun around to reboot computer, SIS, and Data Distrib Mgr

- 1017: Restart survey, SIS Line 367. Determined it was not worth it to go all the way back to gap.

- 1108: EOL HYPACK Line S5

- 1112: SOL HYPACK Line SBP6 / SIS Line 0368 (GOA_Line_361), Hdg. 13. Knudsen SBP on $200 \mathrm{~m}$ scale, internal sync. EM 122 pinging and logging, seeing intermittent $3.5-\mathrm{kHz}$ interference.

- 2102: SOL HYPACK Line SBP7 / SIS Line 0370 (GOA_Line_363), Hdg 50, Continue priority sub-bottom survey.

JD 212 - July 31, 2018

- 0038: EOL SBP7

- 0040: Start transit to Seattle; continue logging sub-bottom and multibeam until reaching Canadian EEZ. SIS Line 371 (GOA_Line_364), Hdg 135

- 1029: EOL transit to Canadian EEZ, end of KM1811 sonar data acquisition. Also turned off ADCP.

- Transit to Seattle through Canadian EEZ. 
JD 213 - JD 214 Aug 1 -2, 2018

- Transit to Seattle through Canadian EEZ

JD 216 - August 3, 2018

- $1600 Z$ (0800L) Arrive at Pier 91 Seattle

\section{Personnel List}

The RV Kilo Moana provided deck officers, crew, and support personnel as appropriate for the safe operation of the ship. Two resident technicians were provided by University of Hawai' $i$ to provide assistance in operating the computer and survey equipment on the ship, and to train the science party in their correct usage. The ship and scientific party are listed in Table 6.1.

Table 6.1: Ship and science party personnel during KM1811.

\begin{tabular}{|l|l|l|}
\hline Name & Organization & Role \\
\hline Joyce Miller & CCOM-JHC/ UH & Chief Scientist \\
\hline Capt. David Martin & University of Hawai'i & Ship's Master \\
\hline Brian Wehmeyer & University of Hawai'i & Chief Mate \\
\hline Luke Barker & University of Hawai'i & Second Mate \\
\hline Drew Steiger & University of Hawai'i & Third Mate \\
\hline Ted Kane & University of Hawai'i & Chief Engineer \\
\hline Jonathan Tree & University of Hawai'i & Gravity \\
\hline Dr. John R. Smith & University of Hawai'i & Watch Lead/Scientist \\
\hline Tiziana Munene & CCOM-JHC & $\begin{array}{l}\text { Watch Lead/Graduate } \\
\text { Student }\end{array}$ \\
\hline Emmanuel Omayajowo & $\begin{array}{l}\text { Univ. of Southern } \\
\text { Mississippi }\end{array}$ & $\begin{array}{l}\text { Watchstander/Graduate } \\
\text { Student }\end{array}$ \\
\hline Treyson Gillespie & College of Charleston & Watchstander/Student \\
\hline Victoria Gitto & College of Charleston & Watchstander/ Student \\
\hline Michaela Barnes & Memorial University & Watchstander/ Student \\
\hline Rob Palomares & University of Hawaii & Lead Marine Technician \\
\hline Juliana Diehl & University of Hawaii & Marine Technician \\
\hline
\end{tabular}

\section{References}

Mayer, L.A., Jakobsson, M., and Armstrong, A.A., 2002. The compilation and analysis of data relevant to a U.S. claim under the United Nations Law of the Sea Article 76. Technical report, Center for Coastal and Ocean Mapping and NOAA-UNH Joint Hydrographic Center, $75 \mathrm{p}$.

Gardner , J.V. and Mayer, L.A., 2005 US Law of the Sea Cruise to Map the Foot of the Slope and the 2500-m Isobath of the Gulf of Alaska Continental Margin. Cruises 0514-1 and 05142. June 24-Sept. 1, 2005. Technical Report, Center for Coastal and Ocean Mapping and NOAA-UNH Joint Hydrographic Center, 110p. 


\section{Appendix A: File Name Translations}

In order to maintain compatibility with previous UNH/CCOM-JHC Gulf of Alaska cruises, lines numbers from the SIS and Knudsen Engineering data were renamed to provide a sequential line numbering scheme. The SIS renaming is detailed in Table A.1 and that for the Knudsen is detailed in Table A.2.

Table A.1: Conversion table of Kongsberg SIS .all file names to UNH .all file names by Julian Day

\begin{tabular}{|c|c|c|c|c|}
\hline JD & $\begin{array}{l}\text { Data } \\
\text { Folder }\end{array}$ & $\begin{array}{c}\text { Kongsberg .all file name } \\
\text { Line_yyyymmdd_time_Ship.all }\end{array}$ & UNH file name .all & Notes \\
\hline 183 & 180702 & 0200_20180702_193430_KM_EM122 & GOA_Line_200tran & \\
\hline 184 & 180703 & 0201_20180703_000049_KM_EM122 & GOA_Line_201tran & \\
\hline 184 & 180703 & 0202_20180703_060027_KM_EM122 & GOA_Line_202tran & \\
\hline 184 & 180703 & 0203_20180703_120008_KM_EM122 & GOA_Line_203tran & \\
\hline 184 & 180703 & 0204_20180703_180018_KM_EM122 & GOA_Line_204tran & \\
\hline 185 & 180704 & 0205_20180704_000036_KM_EM122 & GOA_Line_205tran & \\
\hline 185 & 180704 & 0206_20180704_060054_KM_EM122 & GOA_Line_206tran & \\
\hline 185 & 180704 & 0207_20180704_120021_KM_EM122 & GOA_Line_207tran & \\
\hline 185 & 180704 & 0208_20180704_195934_KM_EM122 & GOA_Line_208tran & SIS crash \\
\hline 186 & 180705 & 0209_20180705_000033_KM_EM122 & GOA_Line_209tran & \\
\hline 186 & 180705 & 0210_20180705_060017_KM_EM122 & GOA_Line_210tran & \\
\hline 186 & 180705 & 0211_20180705_120021_KM_EM122 & GOA_Line_211tran & \\
\hline 186 & 180705 & 0212_20180705_180015_KM_EM122 & GOA_Line_212tran & \\
\hline 187 & 180706 & 0213_20180706_000810_KM_EM122 & GOA_Line_213tran & \\
\hline 187 & 180706 & 0214_20180706_060021_KM_EM122 & GOA_Line_214tran & \\
\hline 187 & 180706 & 0215_20180706_120028_KM_EM122 & GOA_Line_215tran & \\
\hline 187 & 180706 & 0216_20180706_181910_KM_EM122 & GOA_Line_216tran & \\
\hline 188 & 180707 & 0217_20180707_000014_KM_EM122 & GOA_Line_217atran & $\begin{array}{l}0530 \text { Port side } \\
\text { beam blanked } \\
\text { out. SIS } \\
\text { restarted }\end{array}$ \\
\hline 188 & 180707 & 0218_20180707_054759_KM_EM122 & GOA_Line_217btran & $\begin{array}{l}\text { Appended logging } \\
\text { to } \\
\text { GOA_Line_217tr } \\
\text { an }\end{array}$ \\
\hline 188 & 180707 & 0219_20180707_060039_KM_EM122 & GOA_Line_218tran & \\
\hline 188 & 180707 & 0220_20180707_120013_KM_EM122 & GOA_Line_219tran & \\
\hline 188 & 180707 & 0221_20180707_180010_KM_EM122 & GOA_Line_220tran & \\
\hline 188 & 180707 & 0222_20180707_000034_KM_EM122 & GOA_Line_221tran & \\
\hline 189 & 180708 & 0223_20180708_060022_KM_EM122 & GOA_Line_222tran & \\
\hline 189 & 180708 & 0224_20180708_120013_KM_EM122 & GOA_Line_223tran & \\
\hline 189 & 180708 & 0225_20180708_180019_KM_EM122 & GOA_Line_224tran & \\
\hline 190 & 180709 & 0226_20180709_000018_KM_EM122 & GOA_Line_225tran & \\
\hline 190 & 180709 & 0227_20180709_060100_KM_EM122 & GOA_Line_226tran & \\
\hline 190 & 180709 & 0228_20180709_120017_KM_EM122 & GOA_Line_227tran & \\
\hline 190 & 180709 & 0229_20180709_180011_KM_EM122 & GOA_Line_228tran & \\
\hline 190 & 180709 & 0230_20180709_000024_KM_EM122 & GOA_Line_229tran & \\
\hline 191 & 180710 & 0231_20180710_043339_KM_EM122 & GOA_Line_230 & Crossline \\
\hline 191 & 180710 & 0232_20180710_103335_KM_EM122 & GOA_Line_231 & Crossline \\
\hline 191 & 180710 & 0233_20180710_163527_KM_EM122 & GOA_Line_232 & Crossline \\
\hline 191 & 180710 & 0234_20180710_223540_KM_EM122 & GOA_Line_233 & Crossline \\
\hline
\end{tabular}




\begin{tabular}{|c|c|c|c|c|}
\hline 192 & 180711 & 0235_20180711_000840_KM_EM122 & GOA_Line_234atran & $\begin{array}{l}\text { SIS crashed, } \\
\text { Transit to Sitka }\end{array}$ \\
\hline 192 & 180711 & 0236_20180711_003602_KM_EM122 & GOA_Line_234btran & $\begin{array}{l}\text { SIS restarted, } \\
\text { Transit to Sitka }\end{array}$ \\
\hline 192 & 180711 & 0237_20180711_061036_KM_EM122 & GOA_Line_235tran & $\begin{array}{l}\text { SIS crashed, } \\
\text { Transit to Sitka }\end{array}$ \\
\hline 192 & 180711 & 0238_20180711_093308_KM_EM122 & GOA_Line_236tran & $\begin{array}{l}\text { SIS restarted, } \\
\text { Transit to Sitka }\end{array}$ \\
\hline 193 & 180712 & 0239_20180712_062406_KM_EM122 & $\begin{array}{l}\text { GOA_Line_237patchte } \\
\text { st }\end{array}$ & Pitch \\
\hline 193 & 180712 & 0240_20180712_074949_KM_EM122 & GOA_Line_238patchtest & Pitch \\
\hline 193 & 180712 & 0241_20180712_102236_KM_EM122 & GOA_Line_239patchtest & Roll \\
\hline 193 & 180712 & 0242_20180712_112230_KM_EM122 & GOA_Line_240patchtest & Roll \\
\hline 193 & 180712 & 0243_20180712_130746_KM_EM122 & GOA_Line_241patchtest & Yaw / Pitch \\
\hline 193 & 180712 & 0244_20180712_143301_KM_EM122 & GOA_Line_242patchtest & Pitch \\
\hline 193 & 180712 & 0245_20180712_161444_KM_EM122 & GOA_Line_243patchtest & Yaw \\
\hline 193 & 180712 & 0246_20180712_174831_KM_EM122 & GOA_Line_244atran & $\begin{array}{l}\text { SIS crash, transit } \\
\text { to survey area }\end{array}$ \\
\hline 193 & 180712 & 0246_20180712_175911_KM_EM122 & GOA_Line_244btran & $\begin{array}{l}\text { SIS crash, transit } \\
\text { to survey area }\end{array}$ \\
\hline 193 & 180712 & 0247_20180712_185013_KM_EM122 & GOA_Line_245tran & \\
\hline 193 & 180712 & 0248_20180712_192313_KM_EM122 & GOA_Line_246 & \\
\hline 193 & 180712 & 0249_20180712_230041_KM_EM122 & GOA_Line_247 & \\
\hline 194 & 180713 & 0250_20180713_050107_KM_EM122 & GOA_Line_248 & \\
\hline 194 & 180713 & 0251_20180713_110013_KM_EM122 & GOA_Line_249 & \\
\hline 194 & 180713 & 0252_20180713_132808_KM_EM122 & GOA_Line_250turn & \\
\hline 194 & 180713 & 0253_20180713_135834_KM_EM122 & GOA_Line_251 & \\
\hline 194 & 180713 & 0254_20180713_200058_KM_EM122 & GOA_Line_252 & \\
\hline 195 & 180714 & 0255_20180714_020031_KM_EM122 & GOA_Line_253 & \\
\hline 195 & 180714 & 0256_20180714_085138_KM_EM122 & GOA_Line_254turn & \\
\hline 195 & 180714 & 0257_20180714_110550_KM_EM122 & GOA_Line_255 & \\
\hline 195 & 180714 & 0258_20180714_170012_KM_EM122 & GOA_Line_256 & \\
\hline 195 & 180714 & 0259_20180714_232708_KM_EM122 & GOA_Line_257 & \\
\hline 196 & 180715 & 0260_20180715_052806_KM_EM122 & GOA_Line_258 & \\
\hline 196 & 180715 & 0261_20180715_081038_KM_EM122 & GOA_Line_259turn & \\
\hline 196 & 180715 & 0262_20180715_084835_KM_EM122 & GOA_Line_260 & \\
\hline 196 & 180715 & 0263_20180715_144903_KM_EM122 & GOA_Line_261 & \\
\hline 196 & 180715 & 0264_20180715_204812_KM_EM122 & GOA_Line_262 & \\
\hline 197 & 180716 & 0265_20180716_024806_KM_EM122 & GOA_Line_263 & \\
\hline 197 & 180716 & 0266_20180716_051202_KM_EM122 & GOA_Line_264turn & \\
\hline 197 & 180716 & 0267_20180716_060410_KM_EM122 & GOA_Line_265 & SIS restarted \\
\hline 197 & 180716 & 0268_20180716_105813_KM_EM122 & GOA_Line_266 & \\
\hline 197 & 180716 & 0269_20180716_165819_KM_EM122 & GOA_Line_267 & \\
\hline 197 & 180716 & 0270_20180716_231209_KM_EM122 & GOA_Line_268 & \\
\hline 198 & 180717 & 0271_20180717_031301_KM_EM122 & GOA_Line_269 & \\
\hline 198 & 180717 & 0272_20180717_035943_KM_EM122 & GOA_Line_270 & \\
\hline 198 & 180717 & 0273_20180717_095909_KM_EM122 & GOA_Line_271 & \\
\hline 198 & 180717 & 0274_20180717_155918_KM_EM122 & GOA_Line_272 & \\
\hline 198 & 180717 & 0275_20180717_222007_KM_EM122 & GOA_Line_273turn & \\
\hline 198 & 180717 & 0276_20180717_225216_KM_EM122 & GOA_Line_274turn & \\
\hline 198 & 180717 & 0277_20180717_230328_KM_EM122 & GOA_Line_275 & \\
\hline 199 & 180718 & 0278_20180718_050325_KM_EM122 & GOA_Line_276 & \\
\hline 199 & 180718 & 0279_20180718_110325_KM_EM122 & GOA_Line_277 & \\
\hline 199 & 180718 & 0280_20180718_170335_KM_EM122 & GOA_Line_278a & \\
\hline
\end{tabular}




\begin{tabular}{|c|c|c|c|c|}
\hline 199 & 180718 & 0281_20180718_174709_KM_EM122 & GOA_Line_278b & \\
\hline 199 & 180718 & 028220180718183310 KM EM122 & GOA Line 279turn & \\
\hline 199 & 180718 & 0283_20180718_190753_KM_EM122 & GOA_Line_280 & \\
\hline 199 & 180718 & 0284_20180718_183310_KM_EM122 & GOA_Line_281 & \\
\hline 200 & 180719 & 0285_20180719_071519_KM_EM122 & GOA_Line_282 & \\
\hline 200 & 180719 & 0287_20180719_130741_KM_EM122 & GOA_Line_283turn & \\
\hline 200 & 180719 & 0288_20180719_140029_KM_EM122 & GOA_Line_284 & \\
\hline 200 & 180719 & 0289_20180719_200013_KM_EM122 & GOA_Line_285 & \\
\hline 201 & 180720 & 0290_20180720_020326_KM_EM122 & GOA_Line_286 & \\
\hline 201 & 180720 & 0291_20180720_061101_KM_EM122 & GOA_Line_287turn & \\
\hline 201 & 180720 & 0292_20180720_064617_KM_EM122 & GOA_Line_288 & \\
\hline 201 & 180720 & 0293_20180720_124724_KM_EM122 & GOA_Line_289 & \\
\hline 201 & 180720 & 0294_20180720_184642_KM_EM122 & GOA_Line_290 & \\
\hline 201 & 180720 & 0295_20180720_213024_KM_EM122 & GOA_Line_291turn & \\
\hline 201 & 180720 & 0296_20180720_222338_KM_EM122 & GOA_Line_292 & \\
\hline 202 & 180721 & 0297_20180721_042802_KM_EM122 & GOA_Line_293 & \\
\hline 202 & 180721 & 0298_20180721_102755_KM_EM122 & GOA_Line_294 & \\
\hline 202 & 180721 & 0299_20180721_132142_KM_EM122 & GOA_Line_295turn & \\
\hline 202 & 180721 & 0300_20180721_135841_KM_EM122 & GOA_Line_296 & \\
\hline 202 & 180721 & 0301_20180721_195437_KM_EM122 & GOA_Line_297 & \\
\hline 203 & 180722 & 0302_20180722_015723_KM_EM122 & GOA_Line_298 & \\
\hline 203 & 180722 & 0303_20180722_031611_KM_EM122 & GOA_Line_299turn & \\
\hline 203 & 180722 & 0304_20180722_040617_KM_EM122 & GOA_Line_300 & \\
\hline 203 & 180722 & 0305_20180722_100612_KM_EM122 & GOA_Line_301 & \\
\hline 203 & 180722 & 0306_20180722_160701_KM_EM122 & GOA_Line_302 & \\
\hline 203 & 180722 & 0307_20180722_165426_KM_EM122 & GOA_Line_303turn & \\
\hline 203 & 180722 & 0308_20180722_173536_KM_EM122 & GOA_Line_304 & \\
\hline 203 & 180722 & 0309_20180722_234026_KM_EM122 & GOA_Line_305 & \\
\hline 204 & 180723 & 0310_20180723_053133_KM_EM122 & GOA_Line_306turn & \\
\hline 204 & 180723 & 0311_20180723_062445_KM_EM122 & GOA_Line_307 & \\
\hline 204 & 180723 & 0312_20180723_122514_KM_EM122 & GOA_Line_308a & \\
\hline 204 & 180723 & 0313_20180723_125723_KM_EM122 & GOA_Line_308b & \\
\hline 204 & 180723 & 0314_20180723_172714_KM_EM122 & GOA_Line_309turn & \\
\hline 204 & 180723 & 0315_20180723_180534_KM_EM122 & GOA_Line_310 & \\
\hline 205 & 180724 & 0316_20180724_000539_KM_EM122 & GOA_Line_311 & \\
\hline 205 & 180724 & 0317_20180724_051008_KM_EM122 & GOA_Line_312turn & \\
\hline 205 & 180724 & 0318_20180724_055203_KM_EM122 & GOA_Line_313 & \\
\hline 205 & 180724 & 0319_20180724_085116_KM_EM122 & GOA_Line_314 & \\
\hline 205 & 180724 & 0320_20180724_145107_KM_EM122 & GOA_Line_315 & \\
\hline 205 & 180724 & 0321_20180724_162243_KM_EM122 & GOA_Line_316turn & \\
\hline 205 & 180724 & 0322_20180724_165726_KM_EM122 & GOA_Line_317 & \\
\hline 205 & 180724 & 0323_20180724_224509_KM_EM122 & GOA_Line_318 & \\
\hline 206 & 180725 & 0324_20180725_024121_KM_EM122 & GOA_Line_319aturn & \\
\hline 206 & 180725 & 0325_20180725_031657_KM_EM122 & GOA_Line_319bturn & \\
\hline 206 & 180725 & 0326_20180725_032626_KM_EM122 & GOA_Line_320 & \\
\hline 206 & 180725 & 0327_20180725_092411_KM_EM122 & GOA_Line_321 & \\
\hline 206 & 180725 & 0328_20180725_122138_KM_EM122 & GOA_Line_322turn & \\
\hline 206 & 180725 & 0329_20180725_130056_KM_EM122 & GOA_Line_323 & \\
\hline 206 & 180725 & 0330_20180725_190003_KM_EM122 & GOA_Line_324 & \\
\hline 206 & 180725 & 0331_20180725_210134_KM_EM122 & GOA_Line_325turn & \\
\hline 206 & 180725 & 0332_20180725_215533_KM_EM122 & GOA_Line_326 & \\
\hline 207 & 180726 & 0333_20180726_050726_KM_EM122 & GOA_Line_327turn & \\
\hline 207 & 180726 & 0334_20180726_054631_KM_EM122 & GOA_Line_328 & \\
\hline
\end{tabular}




\begin{tabular}{|c|c|c|c|c|}
\hline 207 & 180726 & 0335_20180726_121518_KM_EM122 & GOA_Line_329turn & \\
\hline 207 & 180726 & 0336_20180726_131311_KM_EM122 & GOA_Line_330 & \\
\hline 207 & 180726 & 0337_20180726_183753_KM_EM122 & GOA_Line_331turn & \\
\hline 207 & 180726 & 0338_20180726_191720_KM_EM122 & GOA_Line_332 & \\
\hline 207 & 180726 & 0339_20180726_235906_KM_EM122 & GOA_Line_333turn & \\
\hline 208 & 180727 & 0340_20180727_004912_KM_EM122 & GOA_Line_334 & \\
\hline 208 & 180727 & 0341_20180727_043952_KM_EM122 & GOA_Line_335turn & \\
\hline 208 & 180727 & 0342_20180727_051819_KM_EM122 & GOA_Line_336 & \\
\hline 208 & 180727 & 0343_20180727_081133_KM_EM122 & GOA_Line_337turn & \\
\hline 208 & 180727 & 0344_20180727_090304_KM_EM122 & GOA_Line_338 & \\
\hline 208 & 180727 & 0345_20180727_110539_KM_EM122 & GOA_Line_339turn & \\
\hline 208 & 180727 & 0346_20180727_114436_KM_EM122 & GOA_Line_340 & \\
\hline 208 & 180727 & 0347_20180727_125815_KM_EM122 & GOA_Line_341 & \\
\hline 208 & 180727 & 0348_20180727_140431_KM_EM122 & GOA_Line_342a & \\
\hline 208 & 180727 & 0349_20180727_141355_KM_EM122 & GOA_Line_342b & \\
\hline 208 & 180727 & 0350_20180727_143017_KM_EM122 & GOA_Line_343 & \\
\hline 208 & 180727 & 0351_20180727_203651_KM_EM122 & GOA_Line_344 & \\
\hline 209 & 180728 & 0352_20180728_043718_KM_EM122 & GOA_Line_345turn & \\
\hline 209 & 180728 & 0353_20180728_043718_KM_EM122 & GOA_Line_346 & \\
\hline 209 & 180728 & 0354_20180728_103705_KM_EM122 & GOA_Line_347a & \\
\hline 209 & 180728 & 0355_20180728_121237_KM_EM122 & GOA_Line_347b & \\
\hline 209 & 180728 & 0356_20180728_173343_KM_EM122 & GOA_Line_348 & \\
\hline 209 & 180728 & 0357_20180728_183122_KM_EM122 & GOA_Line_349turn & \\
\hline 209 & 180728 & 0358_20180728_190842_KM_EM122 & GOA_Line_350 & \\
\hline 210 & 180729 & 0359_20180729_011006_KM_EM122 & GOA_Line_351 & \\
\hline 210 & 180729 & 0360_20180729_071016_KM_EM122 & GOA_Line_352 & \\
\hline 210 & 180729 & 0361_20180729_090141_KM_EM122 & GOA_Line_353turn & \\
\hline 210 & 180729 & 0362_20180729_093610_KM_EM122 & GOA_Line_354 & \\
\hline 210 & 180729 & 0363_20180729_153811_KM_EM122 & GOA_Line_355 & \\
\hline 210 & 180729 & 0364_20180729_213910_KM_EM122 & GOA_Line_356 & \\
\hline 211 & 180730 & 0365_20180730_001449_KM_EM122 & GOA_Line_357 & \\
\hline 211 & 180730 & 0366_20180730_061618_KM_EM122 & GOA_Line_358 & SIS crash \\
\hline 211 & 180730 & 0366_20180730_094515_KM_EM122 & GOA_Line_359 & \\
\hline 211 & 180730 & 0367_20180730_101723_KM_EM122 & GOA_Line_360 & \\
\hline 211 & 180730 & 0368_20180730_111253_KM_EM122 & GOA_Line_361 & $\begin{array}{l}\text { Subbottom } \\
\text { Preferred Line }\end{array}$ \\
\hline 211 & 180730 & 0369_20180730_171824_KM_EM122 & GOA_Line_362 & $\begin{array}{l}\text { Subbottom } \\
\text { Preferred Line }\end{array}$ \\
\hline 211 & 180730 & 0370_20180730_210206_KM_EM122 & GOA_Line_363 & $\begin{array}{l}\text { Subbottom } \\
\text { Preferred Line }\end{array}$ \\
\hline 212 & 180731 & 0371_20180731_004137_KM_EM122 & GOA_Line_364 & $\begin{array}{l}\text { Subbottom } \\
\text { Preferred Line }\end{array}$ \\
\hline 212 & 180731 & 0372_20180731_064042_KM_EM122 & GOA_Line_365 & $\begin{array}{l}\text { Subbottom } \\
\text { Preferred Line }\end{array}$ \\
\hline
\end{tabular}


Table A.2: Conversion table of Knudsen-assigned sgy file names to UNH file names by Julian Day.

\begin{tabular}{|c|c|c|c|c|}
\hline JD & $\begin{array}{l}\text { Data } \\
\text { Folder }\end{array}$ & $\begin{array}{c}\text { Knudsen file name } \\
\text {.sgy }\end{array}$ & $\begin{array}{l}\text { UNH file name } \\
\text {.sgy }\end{array}$ & Notes \\
\hline 183 & 180702 & km1811_70884_CHP3.5_RAW_007 & GOA_Line_200tran & \\
\hline 184 & 180703 & km1811_70884_CHP3.5_RAW_008 & GOA_Line_201atran & \\
\hline 184 & 180703 & km1811_70884_CHP3.5_RAW_009 & GOA_Line_201btran & \\
\hline 184 & 180703 & km1811_70884_CHP3.5_RAW_010 & GOA_Line_202atran & \\
\hline 184 & 180703 & km1811_70884_CHP3.5_RAW_011 & GOA_Line_202btran & \\
\hline 184 & 180703 & km1811_70884_CHP3.5_RAW_012 & GOA_Line_203atran & \\
\hline 184 & 180703 & km1811_70884_CHP3.5_RAW_013 & GOA_Line_203btran & \\
\hline 184 & 180703 & km1811_70884_CHP3.5_RAW_014 & GOA_Line_203ctran & \\
\hline 184 & 180703 & km1811_70884_CHP3.5_RAW_015 & GOA_Line_203dtran & \\
\hline 184 & 180703 & km1811_70884_CHP3.5_RAW_016 & GOA_Line_204atran & \\
\hline 184 & 180703 & km1811_70884_CHP3.5_RAW_017 & GOA_Line_204btran & \\
\hline 185 & 180704 & km1811_70884_CHP3.5_RAW_018 & GOA_Line_205tran & \\
\hline 185 & 180704 & km1811_70884_CHP3.5_RAW_019 & GOA_Line_206tran & \\
\hline 185 & 180704 & km1811_70884_CHP3.5_RAW_020 & GOA_Line_207tran & \\
\hline 185 & 180704 & km1811_70884_CHP3.5_RAW_021 & GOA_Line_208tran & \\
\hline 186 & 180705 & km1811_70884_CHP3.5_RAW_022 & GOA_Line_209tran & \\
\hline 186 & 180705 & km1811_70884_CHP3.5_RAW_023 & GOA_Line_210tran & \\
\hline 186 & 180705 & km1811_70884_CHP3.5_RAW_024 & GOA_Line_211atran & \\
\hline 186 & 180705 & km1811_70884_CHP3.5_RAW_025 & GOA_Line_211btran & \\
\hline 186 & 180705 & km1811_70884_CHP3.5_RAW_026 & GOA_Line_211ctran & \\
\hline 186 & 180705 & km1811_70884_CHP3.5_RAW_027 & GOA_Line_212tran & \\
\hline 187 & 180706 & km1811_70884_CHP3.5_RAW_028 & GOA_Line_213tran & \\
\hline 187 & 180706 & km1811_70884_CHP3.5_RAW_029 & GOA_Line_214atran & \\
\hline 187 & 180706 & km1811_70884_CHP3.5_RAW_030 & GOA_Line_214btran & \\
\hline 187 & 180706 & km1811_70884_CHP3.5_RAW_031 & GOA_Line_215tran & \\
\hline 187 & 180706 & km1811_70884_CHP3.5_RAW_032 & GOA_Line_216tran & \\
\hline 188 & 180707 & km1811_70884_CHP3.5_RAW_033 & GOA_Line_217atran & \\
\hline 188 & 180707 & km1811_70884_CHP3.5_FLT_033 & GOA_Line_217btran & $\begin{array}{l}\text { SEG-Y } \\
\text { Carrier Type } \\
\text { was changed } \\
\text { to filtered }\end{array}$ \\
\hline 188 & 180707 & km1811_70884_CHP3.5_FLT_034 & GOA_Line_217ctran & $\begin{array}{l}\text { Knudsen } \\
\text { workstation } \\
\text { had to be } \\
\text { restarted }\end{array}$ \\
\hline 188 & 180707 & km1811_70884_CHP3.5_FLT_035 & GOA_Line_217dtran & \\
\hline 188 & 180707 & km1811_70884_CHP3.5_FLT_036 & GOA_Line_218tran & \\
\hline 188 & 180707 & km1811_70884_CHP3.5_FLT_037 & GOA_Line_219tran & \\
\hline 188 & 180707 & km1811_70884_CHP3.5_FLT_038 & GOA_Line_220atran & \\
\hline 188 & 180707 & km1811_70884_CHP3.5_FLT_039 & GOA_Line_220btran & \\
\hline 188 & 180707 & km1811_70884_CHP3.5_FLT_040 & GOA_Line_220ctran & \\
\hline 188 & 180707 & km1811_70884_CHP3.5_FLT_041 & GOA_Line_220dtran & \\
\hline 188 & 180707 & km1811_70884_CHP3.5_FLT_042 & GOA_Line_220etran & \\
\hline 188 & 180707 & km1811_70884_CHP3.5_FLT_043 & GOA_Line_220ftran & \\
\hline 188 & 180707 & km1811_70884_CHP3.5_FLT_044 & GOA_Line_221tran & \\
\hline 189 & 180708 & km1811_70884_CHP3.5_FLT_045 & GOA_Line_222tran & \\
\hline 189 & 180708 & km1811_70884_CHP3.5_FLT_046 & GOA_Line_223atran & \\
\hline 189 & 180708 & km1811_70884_CHP3.5_FLT_047 & GOA_Line_223btran & \\
\hline
\end{tabular}




\begin{tabular}{|c|c|c|c|c|}
\hline 189 & 180708 & km1811_70884_CHP3.5_FLT_048 & GOA_Line_224atran & \\
\hline 189 & 180708 & km1811_70884_CHP3.5_FLT_049 & GOA_Line_224btran & \\
\hline 189 & 180708 & km1811_70884_CHP3.5_FLT_050 & GOA_Line_224ctran & \\
\hline 189 & 180708 & km1811_70884_CHP3.5_FLT_051 & GOA_Line_224dtran & \\
\hline 190 & 180709 & km1811_70884_CHP3.5_FLT_052 & GOA_Line_225tran & \\
\hline 190 & 180709 & km1811_70884_CHP3.5_FLT_053 & GOA_Line_226tran & \\
\hline 190 & 180709 & km1811_70884_CHP3.5_FLT_054 & GOA_Line_227tran & \\
\hline 190 & 180709 & km1811_70884_CHP3.5_FLT_055 & GOA_Line_228atran & \\
\hline 190 & 180709 & km1811_70884_CHP3.5_FLT_056 & GOA_Line_228btran & \\
\hline 190 & 180709 & km1811_70884_CHP3.5_FLT_057 & GOA_Line_229tran & \\
\hline 191 & 180710 & km1811_70884_CHP3.5_FLT_058 & GOA_Line_230 & \\
\hline 191 & 180710 & km1811_70884_CHP3.5_FLT_059 & GOA_Line_231 & \\
\hline 191 & 180710 & km1811_70884_CHP3.5_FLT_060 & GOA_Line_232 & \\
\hline 191 & 180710 & km1811_70884_CHP3.5_FLT_061 & GOA_Line_233 & \\
\hline 192 & 180711 & km1811_70884_CHP3.5_FLT_062 & GOA_Line_234tran & \\
\hline 192 & 180711 & km1811_70884_CHP3.5_FLT_064 & GOA_Line_235atran & \\
\hline 192 & 180711 & km1811_70884_CHP3.5_FLT_065 & GOA_Line_235btran & \\
\hline 192 & 180711 & km1811_70884_CHP3.5_FLT_066 & GOA_Line_235ctran & \\
\hline 192 & 180711 & km1811_70884_CHP3.5_FLT_067 & GOA_Line_235dtran & \\
\hline 192 & 180711 & km1811_70884_CHP3.5_FLT_068 & GOA_Line_236tran & \\
\hline 193 & 180712 & km1811_70884_CHP3.5_FLT_069 & GOA_Line_244btran & $\begin{array}{l}\text { *Patch test } \\
\text { lines were } \\
\text { not logged, } \\
\text { transit to } \\
\text { survey area }\end{array}$ \\
\hline 193 & 180712 & km1811_70884_CHP3.5_FLT_070 & GOA_Line_245tran & \\
\hline 193 & 180712 & km1811_70884_CHP3.5_FLT_071 & GOA_Line_246 & \\
\hline 193 & 180712 & km1811_70884_CHP3.5_FLT_072 & GOA_Line_247 & \\
\hline 194 & 180713 & km1811_70884_CHP3.5_FLT_073 & GOA_Line_248 & \\
\hline 194 & 180713 & km1811_70884_CHP3.5_FLT_074 & GOA_Line_249 & \\
\hline 194 & 180713 & km1811_70884_CHP3.5_FLT_075 & GOA_Line_250turn & \\
\hline 194 & 180713 & km1811_70884_CHP3.5_FLT_076 & GOA_Line_251 & \\
\hline 194 & 180713 & km1811_70884_CHP3.5_FLT_077 & GOA_Line_252 & \\
\hline 195 & 180714 & km1811_70884_CHP3.5_FLT_078 & GOA_Line_253 & \\
\hline 195 & 180714 & km1811_70884_CHP3.5_FLT_079 & GOA_Line_254turn & \\
\hline 195 & 180714 & km1811_70884_CHP3.5_FLT_080 & GOA_Line_255 & \\
\hline 195 & 180714 & km1811_70884_CHP3.5_FLT_081 & GOA_Line_256 & \\
\hline 195 & 180714 & km1811_70884_CHP3.5_FLT_082 & GOA_Line_257 & \\
\hline 196 & 180715 & km1811_70884_CHP3.5_FLT_083 & GOA_Line_258 & \\
\hline 196 & 180715 & km1811_70884_CHP3.5_FLT_084 & GOA_Line_259turn & \\
\hline 196 & 180715 & km1811_70884_CHP3.5_FLT_085 & GOA_Line_260 & \\
\hline 196 & 180715 & km1811_70884_CHP3.5_FLT_086 & GOA_Line_261 & \\
\hline 196 & 180715 & km1811_70884_CHP3.5_FLT_087 & GOA_Line_262 & \\
\hline 197 & 180716 & km1811_70884_CHP3.5_FLT_088 & GOA_Line_263 & \\
\hline 197 & 180716 & km1811_70884_CHP3.5_FLT_089 & GOA_Line_264turn & \\
\hline 197 & 180716 & km1811_70884_CHP3.5_FLT_090 & GOA_Line_265 & \\
\hline 197 & 180716 & km1811_70884_CHP3.5_FLT_091 & GOA_Line_266 & \\
\hline 197 & 180716 & km1811_70884_CHP3.5_FLT_092 & GOA_Line_267 & \\
\hline 197 & 180716 & km1811_70884_CHP3.5_FLT_093 & GOA_Line_268 & \\
\hline 198 & 180717 & km1811_70884_CHP3.5_FLT_094 & GOA_Line_269 & \\
\hline 198 & 180717 & km1811_70884_CHP3.5_FLT_095 & GOA_Line_270 & \\
\hline 198 & 180717 & km1811_70884_CHP3.5_FLT_096 & GOA_Line_271 & \\
\hline 198 & 180717 & km1811_70884_CHP3.5_FLT_097 & GOA_Line_272 & \\
\hline
\end{tabular}




\begin{tabular}{|c|c|c|c|c|}
\hline 198 & 180717 & km1811_70884_CHP3.5_FLT_098 & GOA_Line_273turn & \\
\hline 198 & 180717 & km1811_70884_CHP3.5_FLT_099 & GOA_Line_274turn & \\
\hline 198 & 180717 & km1811_70884_CHP3.5_FLT_100 & GOA_Line_275 & \\
\hline 199 & 180718 & km1811_70884_CHP3.5_FLT_101 & GOA_Line_276 & \\
\hline 199 & 180718 & km1811_70884_CHP3.5_FLT_102 & GOA_Line_277 & \\
\hline 199 & 180718 & km1811_70884_CHP3.5_FLT_103 & GOA_Line_278 & \\
\hline 199 & 180718 & km1811_70884_CHP3.5_FLT_104 & GOA_Line_279turn & \\
\hline 199 & 180718 & km1811_70884_CHP3.5_FLT_105 & GOA_Line_280 & \\
\hline 199 & 180718 & km1811_70884_CHP3.5_FLT_106 & GOA_Line_281 & \\
\hline 200 & 180719 & km1811_70884_CHP3.5_FLT_107 & GOA_Line_282 & \\
\hline 200 & 180719 & km1811_70884_CHP3.5_FLT_108 & GOA_Line_284 & $\begin{array}{l}\text { No Sub- } \\
\text { bottom } \\
\text { collected on } \\
\text { turn }\end{array}$ \\
\hline 200 & 180719 & km1811_70884_CHP3.5_FLT_109 & GOA_Line_285 & \\
\hline 201 & 180720 & km1811_70884_CHP3.5_FLT_110 & GOA_Line_286 & \\
\hline 201 & 180720 & km1811_70884_CHP3.5_FLT_111 & GOA_Line_287turn & \\
\hline 201 & 180720 & km1811_70884_CHP3.5_FLT_112 & GOA_Line_288 & \\
\hline 201 & 180720 & km1811_70884_CHP3.5_FLT_113 & GOA_Line_289 & \\
\hline 201 & 180720 & km1811_70884_CHP3.5_FLT_114 & GOA_Line_290 & \\
\hline 201 & 180720 & km1811_70884_CHP3.5_FLT_115 & GOA_Line_291turn & \\
\hline 201 & 180720 & km1811_70884_CHP3.5_FLT_116 & GOA_Line_292 & \\
\hline 202 & 180721 & km1811_70884_CHP3.5_FLT_117 & GOA_Line_293 & \\
\hline 202 & 180721 & km1811_70884_CHP3.5_FLT_118 & GOA_Line_294 & \\
\hline 202 & 180721 & km1811_70884_CHP3.5_FLT_119 & GOA_Line_295turn & \\
\hline 202 & 180721 & km1811_70884_CHP3.5_FLT_120 & GOA_Line_296 & \\
\hline 202 & 180721 & km1811_70884_CHP3.5_FLT_121 & GOA_Line_297 & \\
\hline 203 & 180722 & km1811_70884_CHP3.5_FLT_122 & GOA_Line_298 & \\
\hline 203 & 180722 & km1811_70884_CHP3.5_FLT_123 & GOA_Line_299turn & \\
\hline 203 & 180722 & km1811_70884_CHP3.5_FLT_124 & GOA_Line_300 & \\
\hline 203 & 180722 & km1811_70884_CHP3.5_FLT_125 & GOA_Line_301 & \\
\hline 203 & 180722 & km1811_70884_CHP3.5_FLT_126 & GOA_Line_302 & \\
\hline 203 & 180722 & km1811_70884_CHP3.5_FLT_127 & GOA_Line_303turn & \\
\hline 203 & 180722 & km1811_70884_CHP3.5_FLT_128 & GOA_Line_304 & \\
\hline 203 & 180722 & km1811_70884_CHP3.5_FLT_129 & GOA_Line_305 & \\
\hline 204 & 180723 & km1811_70884_CHP3.5_FLT_130 & GOA_Line_306turn & \\
\hline 204 & 180723 & km1811_70884_CHP3.5_FLT_131 & GOA_Line_307 & \\
\hline 204 & 180723 & km1811_70884_CHP3.5_FLT_132 & GOA_Line_308 & \\
\hline 204 & 180723 & km1811_70884_CHP3.5_FLT_133 & GOA_Line_309turn & \\
\hline 204 & 180723 & km1811_70884_CHP3.5_FLT_134 & GOA_Line_310 & \\
\hline 205 & 180724 & km1811_70884_CHP3.5_FLT_135 & GOA_Line_311 & \\
\hline 205 & 180724 & km1811_70884_CHP3.5_FLT_136 & GOA_Line_312turn & \\
\hline 205 & 180724 & km1811_70884_CHP3.5_FLT_137 & GOA_Line_313 & \\
\hline 205 & 180724 & km1811_70884_CHP3.5_FLT_138 & GOA_Line_314 & \\
\hline 204 & 180724 & km1811_70884_CHP3.5_FLT_139 & GOA_Line_315 & \\
\hline 205 & 180724 & km1811_70884_CHP3.5_FLT_140 & GOA_Line_316turn & \\
\hline 205 & 180724 & km1811_70884_CHP3.5_FLT_141 & GOA_Line_317 & \\
\hline 205 & 180724 & km1811_70884_CHP3.5_FLT_142 & GOA_Line_318 & \\
\hline 206 & 180725 & km1811_70884_CHP3.5_FLT_143 & GOA_Line_319turn & \\
\hline 206 & 180725 & km1811_70884_CHP3.5_FLT_144 & GOA_Line_320 & \\
\hline 206 & 180725 & km1811_70884_CHP3.5_FLT_145 & GOA_Line_321 & \\
\hline 206 & 180725 & km1811_70884_CHP3.5_FLT_146 & GOA_Line_322turn & \\
\hline 206 & 180725 & km1811_70884_CHP3.5_FLT_147 & GOA_Line_323 & \\
\hline
\end{tabular}




\begin{tabular}{|c|c|c|c|c|}
\hline 206 & 180725 & km1811_70884_CHP3.5_FLT_148 & GOA_Line_324 & \\
\hline 206 & 180725 & km1811_70884_CHP3.5_FLT_149 & GOA_Line_325turn & \\
\hline 206 & 180725 & km1811_70884_CHP3.5_FLT_150 & GOA_Line_326 & \\
\hline 207 & 180726 & km1811_70884_CHP3.5_FLT_151 & GOA_Line_327turn & \\
\hline 207 & 180726 & km1811_70884_CHP3.5_FLT_152 & GOA_Line_328 & \\
\hline 207 & 180726 & km1811_70884_CHP3.5_FLT_153 & GOA_Line_329turn & \\
\hline 207 & 180726 & km1811_70884_CHP3.5_FLT_154 & GOA_Line_330 & \\
\hline 207 & 180726 & km1811_70884_CHP3.5_FLT_155 & GOA_Line_331turn & \\
\hline 207 & 180726 & km1811_70884_CHP3.5_FLT_156 & GOA_Line_332 & \\
\hline 207 & 180726 & km1811_70884_CHP3.5_FLT_157 & GOA_Line_333turn & \\
\hline 208 & 180727 & km1811_70884_CHP3.5_FLT_158 & GOA_Line_334 & \\
\hline 208 & 180727 & km1811_70884_CHP3.5_FLT_159 & GOA_Line_335turn & \\
\hline 208 & 180727 & km1811_70884_CHP3.5_FLT_160 & GOA_Line_336 & \\
\hline 208 & 180727 & km1811_70884_CHP3.5_FLT_161 & GOA_Line_337turn & \\
\hline 208 & 180727 & km1811_70884_CHP3.5_FLT_162 & GOA_Line_338 & \\
\hline 208 & 180727 & km1811_70884_CHP3.5_FLT_163 & GOA_Line_339turn & \\
\hline 208 & 180727 & km1811_70884_CHP3.5_FLT_164 & GOA_Line_340 & \\
\hline 208 & 180727 & km1811_70884_CHP3.5_FLT_165 & GOA_Line_341 & \\
\hline 208 & 180727 & km1811_70884_CHP3.5_FLT_166 & GOA_Line_342a & \\
\hline 208 & 180727 & km1811_70884_CHP3.5_FLT_167 & GOA_Line_342b & \\
\hline 208 & 180727 & km1811_70884_CHP3.5_FLT_168 & GOA_Line_343 & \\
\hline 208 & 180727 & km1811_70884_CHP3.5_FLT_169 & GOA_Line_344 & \\
\hline 209 & 180728 & km1811_70884_CHP3.5_FLT_170 & GOA_Line_345turn & \\
\hline 209 & 180728 & km1811_70884_CHP3.5_FLT_171 & GOA_Line_346 & \\
\hline 209 & 180728 & km1811_70884_CHP3.5_FLT_172 & GOA_Line_347 & \\
\hline 209 & 180728 & km1811_70884_CHP3.5_FLT_173 & GOA_Line_348 & \\
\hline 209 & 180728 & km1811_70884_CHP3.5_FLT_174 & GOA_Line_349turn & \\
\hline 209 & 180728 & km1811_70884_CHP3.5_FLT_175 & GOA_Line_350 & \\
\hline 210 & 180729 & km1811_70884_CHP3.5_FLT_176 & GOA_Line_351 & \\
\hline 210 & 180729 & km1811_70884_CHP3.5_FLT_177 & GOA_Line_352 & \\
\hline 210 & 180729 & km1811_70884_CHP3.5_FLT_178 & GOA_Line_353turn & \\
\hline 210 & 180729 & km1811_70884_CHP3.5_FLT_179 & GOA_Line_354 & \\
\hline 210 & 180729 & km1811_70884_CHP3.5_FLT_180 & GOA_Line_355 & \\
\hline 210 & 180729 & km1811_70884_CHP3.5_FLT_181 & GOA_Line_356 & \\
\hline 211 & 180730 & km1811_70884_CHP3.5_FLT_182 & GOA_Line_357 & \\
\hline 211 & 180730 & km1811_70884_CHP3.5_FLT_183 & GOA_Line_358 & \\
\hline 211 & 180730 & km1811_70884_CHP3.5_FLT_184 & GOA_Line_359 & \\
\hline 211 & 180730 & km1811_70884_CHP3.5_FLT_185 & GOA_Line_360 & \\
\hline 211 & 180730 & km1811_70884_CHP3.5_FLT_186 & GOA_Line_361 & $\begin{array}{l}\text { Subbottom } \\
\text { Preferred Line }\end{array}$ \\
\hline 211 & 180730 & km1811_70884_CHP3.5_FLT_187 & GOA_Line_362 & $\begin{array}{l}\text { Subbottom } \\
\text { Preferred Line }\end{array}$ \\
\hline 211 & 180730 & km1811_70884_CHP3.5_FLT_188 & GOA_Line_363 & $\begin{array}{l}\text { Subbottom } \\
\text { Preferred Line }\end{array}$ \\
\hline 212 & 180731 & km1811_70884_CHP3.5_FLT_186 & GOA_Line_364 & $\begin{array}{l}\text { Subbottom } \\
\text { Preferred } \\
\text { Line }\end{array}$ \\
\hline 212 & 180731 & km1811_70884_CHP3.5_FLT_190 & GOA_Line_365 & $\begin{array}{l}\text { Subbottom } \\
\text { Preferred Line }\end{array}$ \\
\hline
\end{tabular}




\section{Appendix B: XBT and XSV Casts Metadata}

A total of 139 XBTs and two XSV-01s were cast in the main KM1811 survey area (Fig. B.1). During transit 11 XBTs were cast; the Sound Speed Manager database was used after the XBT launcher failed until a new launcher was available. Sixteen XBTs (12.3\%) failed on or after launch, or were not used for processing. The composite spread of sound speed from all profiles is shown in Fig. B.2. The metadata associated with these launches are given in Table B..

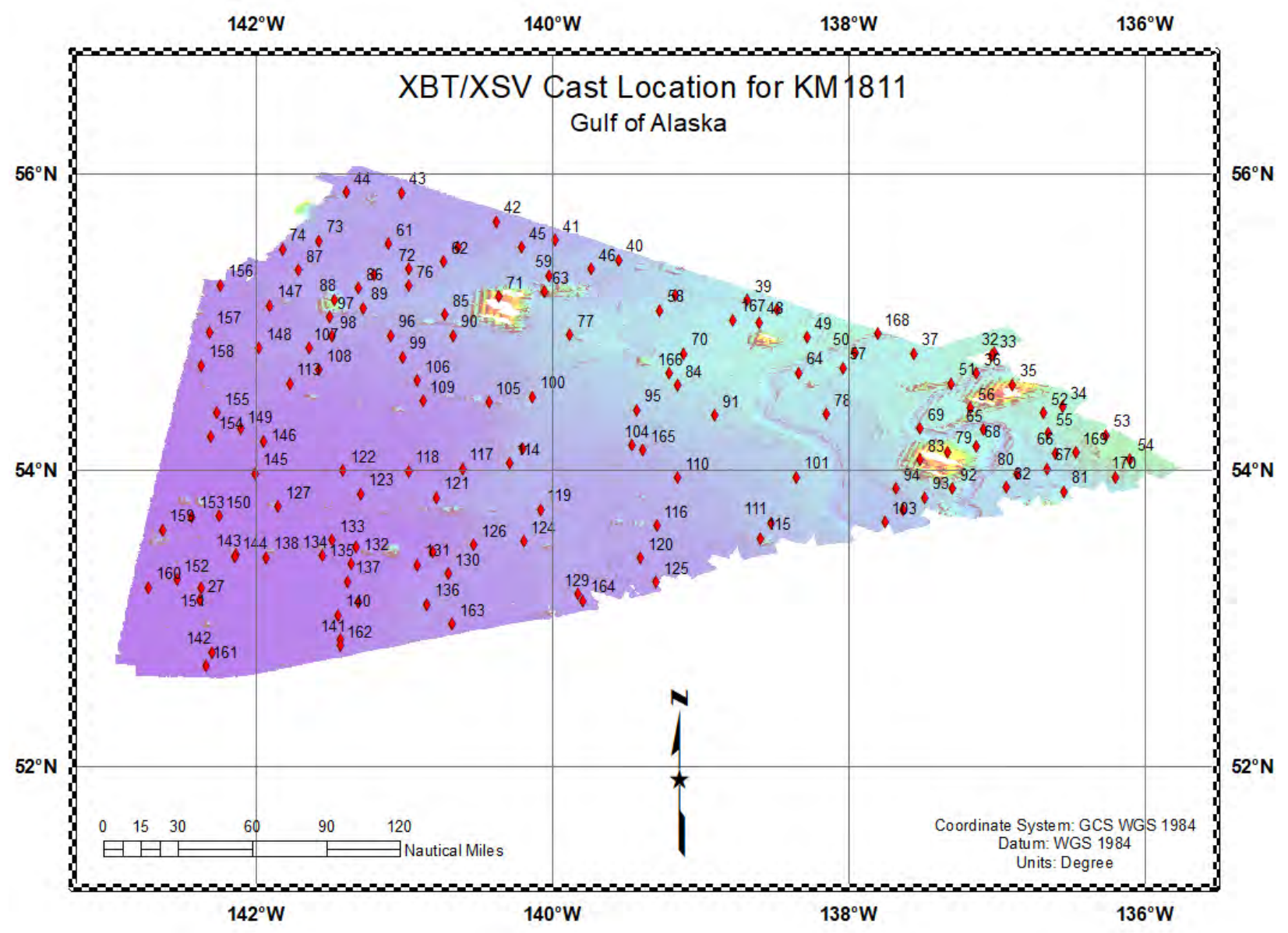

Fig. B.1: Locations of the XBTs launched during the course of the KM1811. 


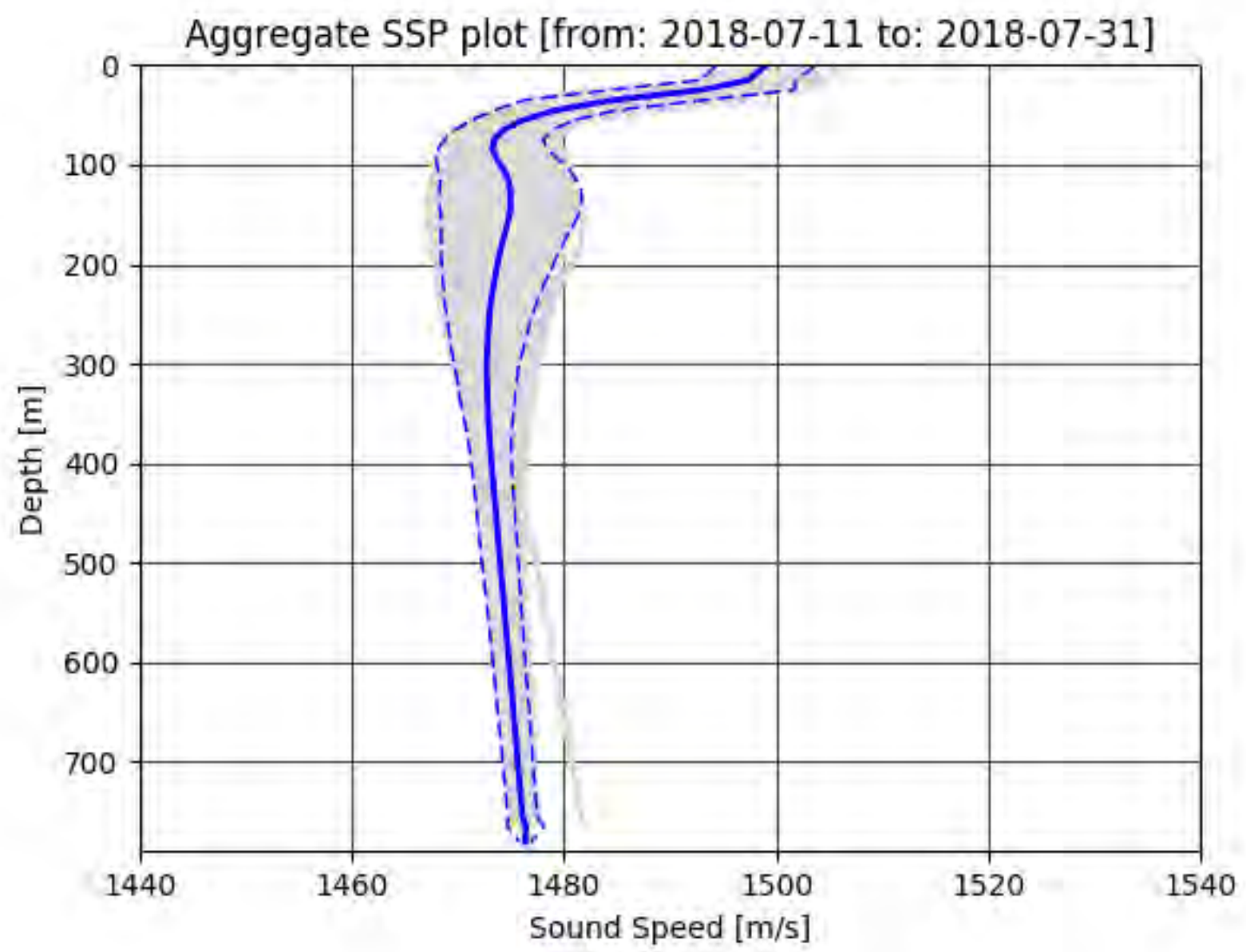

Fig. B.2: Aggregate of all XBT and XSV-derived sound speed profiles for KM1811, with mean value (solid blue) and 95\% CI (dashed blue) lines.

Table B.1: Log of XBT and ASVP Launches during KM1811

\begin{tabular}{|c|l|l|c|c|}
\hline Probe Number & Longitude & Latitude & Serial Number & Type \\
\hline 1 & $157^{\circ} 12.02442^{\prime} \mathrm{W}$ & $21^{\circ} 51.23022^{\prime} \mathrm{N}$ & 01301347 & Deep Blue \\
\hline 2 & $156^{\circ} 17.7588^{\prime} \mathrm{W}$ & $24^{\circ} 50.8086^{\prime} \mathrm{N}$ & 01178890 & Deep Blue \\
\hline 3 & $156^{\circ} 8.92482^{\prime} \mathrm{W}$ & $25^{\circ} 19.53954^{\prime} \mathrm{N}$ & 01301336 & Deep Blue \\
\hline 4 & $156^{\circ} 5.88186^{\prime} \mathrm{W}$ & $25^{\circ} 29.70582^{\prime} \mathrm{N}$ & 01301340 & Deep Blue \\
\hline 5 & $155^{\circ} 55.25388^{\prime} \mathrm{W}$ & $26^{\circ} 4.0674^{\prime} \mathrm{N}$ & 01178897 & Deep Blue \\
\hline 6 & $155^{\circ} 37.17288^{\prime} \mathrm{W}$ & $27^{\circ} 2.04492^{\prime} \mathrm{N}$ & 01178893 & Deep Blue \\
\hline 7 & $155^{\circ} 26.19726^{\prime} \mathrm{W}$ & $27^{\circ} 37.23996^{\prime} \mathrm{N}$ & 01178896 & Deep Blue \\
\hline 8 & $155^{\circ} 7.50198^{\prime} \mathrm{W}$ & $28^{\circ} 36.3528^{\prime} \mathrm{N}$ & 01178892 & Deep Blue \\
\hline 9 & $154^{\circ} 46.48242^{\prime} \mathrm{W}$ & $29^{\circ} 34.197^{\prime} \mathrm{N}$ & 01301337 & Deep Blue \\
\hline 10 & $154^{\circ} 32.418^{\prime} \mathrm{W}$ & $30^{\circ} 9.34812^{\prime} \mathrm{N}$ & 01301338 & Deep Blue \\
\hline 11 & $154^{\circ} 16.11426^{\prime} \mathrm{W}$ & $30^{\circ} 49.88382^{\prime} \mathrm{N}$ & 01301339 & Deep Blue \\
\hline
\end{tabular}




\begin{tabular}{|c|c|c|c|c|}
\hline 12 & $153^{\circ} 52.12206^{\prime} \mathrm{W}$ & $31^{\circ} 47.91528^{\prime} \mathrm{N}$ & 01178891 & Deep Blue \\
\hline 13 & $153^{\circ} 29.4375^{\prime} \mathrm{W}$ & $32^{\circ} 41.6487^{\prime} \mathrm{N}$ & 01301341 & Deep Blue \\
\hline 14 & $153^{\circ} 26.0127^{\prime} \mathrm{W}$ & $32^{\circ} 49.67652^{\prime} \mathrm{N}$ & 01301342 & Deep Blue \\
\hline 15 & $153^{\circ} 16.07616^{\prime} \mathrm{W}$ & $33^{\circ} 12.90186^{\prime} \mathrm{N}$ & 01301344 & Deep Blue \\
\hline 16 & $153^{\circ} 1.02834^{\prime} \mathrm{W}$ & $33^{\circ} 47.40846^{\prime} \mathrm{N}$ & 01301345 & Deep Blue \\
\hline 17 & $153^{\circ} 53.31936^{\prime} \mathrm{W}$ & $34^{\circ} 4.68822^{\prime} \mathrm{N}$ & 01301346 & Deep Blue \\
\hline 18 & $152^{\circ} 27.77538^{\prime} \mathrm{W}$ & $35^{\circ} 1.78956^{\prime} \mathrm{N}$ & 01301343 & Deep Blue \\
\hline 19 & $150^{\circ} 22.5^{\prime} \mathrm{W}$ & $39^{\circ} 37.5^{\prime} \mathrm{N}$ & & WOA13 \\
\hline 20 & $150^{\circ} 7.5^{\prime} \mathrm{W}$ & $39^{\circ} 37.5^{\prime} \mathrm{N}$ & & WOA13 \\
\hline 21 & $150^{\circ} 7.5^{\prime} \mathrm{W}$ & $39^{\circ} 52.5^{\prime} \mathrm{N}$ & & WOA13 \\
\hline 22 & $149^{\circ} 52.5^{\prime} \mathrm{W}$ & $40^{\circ} 7.5^{\prime} \mathrm{N}$ & & WOA13 \\
\hline 23 & $149^{\circ} 52.5^{\prime} \mathrm{W}$ & $40^{\circ} 22.5^{\prime} \mathrm{N}$ & & WOA13 \\
\hline 24 & $149^{\circ} 37.5^{\prime} \mathrm{W}$ & $40^{\circ} 37.5^{\prime} \mathrm{N}$ & & WOA13 \\
\hline 25 & $148^{\circ} 22.5^{\prime} \mathrm{W}$ & $42^{\circ} 52.5^{\prime} \mathrm{N}$ & & WOA13 \\
\hline 26 & $148^{\circ} 22.5^{\prime} \mathrm{W}$ & $43^{\circ} 7.5^{\prime} \mathrm{N}$ & & WOA13 \\
\hline 27 & $142^{\circ} 22.5^{\prime} \mathrm{W}$ & $53^{\circ} 7.5^{\prime} \mathrm{N}$ & & WOA13 \\
\hline 28 & $-222^{\circ}-30^{\prime} \mathrm{W}$ & $54^{\circ} 30^{\prime} \mathrm{N}$ & & WOA09 \\
\hline 29 & $-223^{\circ}-30^{\prime} \mathrm{W}$ & $55^{\circ} 30^{\prime} \mathrm{N}$ & & WOA09 \\
\hline 30 & $135^{\circ} 50.3379^{\prime} \mathrm{W}$ & $56^{\circ} 37.56006^{\prime} \mathrm{N}$ & 01234532 & Deep Blue \\
\hline 31 & $136^{\circ} 39.72756^{\prime} \mathrm{W}$ & $55^{\circ} 16.96434^{\prime} \mathrm{N}$ & 01234528 & Deep Blue \\
\hline 32 & $137^{\circ} 0.64746^{\prime} \mathrm{W}$ & $54^{\circ} 47.46192^{\prime} \mathrm{N}$ & 032693 & XSV-01 \\
\hline 33 & $137^{\circ} 1.49904^{\prime} \mathrm{W}$ & $54^{\circ} 46.62696^{\prime} \mathrm{N}$ & 01234523 & Deep Blue \\
\hline 34 & $136^{\circ} 32.87304^{\prime} \mathrm{W}$ & $54^{\circ} 25.7925^{\prime} \mathrm{N}$ & 01234524 & Deep Blue \\
\hline 35 & $136^{\circ} 53.10936^{\prime} \mathrm{W}$ & $54^{\circ} 34.74612^{\prime} \mathrm{N}$ & 01179159 & Deep Blue \\
\hline 36 & $137^{\circ} 7.61526^{\prime} \mathrm{W}$ & $54^{\circ} 39.38916^{\prime} \mathrm{N}$ & 01179163 & Deep Blue \\
\hline 37 & $137^{\circ} 32.95998^{\prime} \mathrm{W}$ & $54^{\circ} 47.4531^{\prime} \mathrm{N}$ & 01179164 & Deep Blue \\
\hline 38 & $138^{\circ} 28.76076^{\prime} \mathrm{W}$ & $55^{\circ} 5.1582^{\prime} \mathrm{N}$ & 01179160 & Deep Blue \\
\hline 39 & $138^{\circ} 40.66506^{\prime} \mathrm{W}$ & $55^{\circ} 8.87598^{\prime} \mathrm{N}$ & 01179156 & Deep Blue \\
\hline 40 & $139^{\circ} 32.55174^{\prime} \mathrm{W}$ & $55^{\circ} 25.17432^{\prime} \mathrm{N}$ & 01179165 & Deep Blue \\
\hline 41 & $139^{\circ} 58.3389^{\prime} \mathrm{W}$ & $55^{\circ} 33.23634^{\prime} \mathrm{N}$ & 01179161 & Deep Blue \\
\hline 42 & $140^{\circ} 22.5039^{\prime} \mathrm{W}$ & $55^{\circ} 40.7544^{\prime} \mathrm{N}$ & 01179157 & Deep Blue \\
\hline 43 & $141^{\circ} 0.52248^{\prime} \mathrm{W}$ & $55^{\circ} 52.55076^{\prime} \mathrm{N}$ & 01160530 & Deep Blue \\
\hline 44 & $141^{\circ} 23.10648^{\prime} \mathrm{W}$ & $55^{\circ} 52.6533^{\prime} \mathrm{N}$ & 01160531 & Deep Blue \\
\hline 45 & $140^{\circ} 12.02736^{\prime} \mathrm{W}$ & $55^{\circ} 30.4473^{\prime} \mathrm{N}$ & 01160532 & Deep Blue \\
\hline 46 & $139^{\circ} 43.833^{\prime} \mathrm{W}$ & $55^{\circ} 21.57714^{\prime} \mathrm{N}$ & 01160533 & Deep Blue \\
\hline 47 & $139^{\circ} 9.99024^{\prime} \mathrm{W}$ & $55^{\circ} 10.90722^{\prime} \mathrm{N}$ & 01160537 & Deep Blue \\
\hline 48 & $138^{\circ} 35.62014^{\prime} \mathrm{W}$ & $54^{\circ} 59.97996^{\prime} \mathrm{N}$ & 01160536 & Deep Blue \\
\hline 49 & $138^{\circ} 16.15626^{\prime} \mathrm{W}$ & $54^{\circ} 53.82762^{\prime} \mathrm{N}$ & 01160535 & Deep Blue \\
\hline 50 & $137^{\circ} 56.84766^{\prime} \mathrm{W}$ & $54^{\circ} 47.6997^{\prime} \mathrm{N}$ & 01160534 & Deep Blue \\
\hline 51 & $137^{\circ} 17.8242^{\prime} \mathrm{W}$ & $54^{\circ} 35.1714^{\prime} \mathrm{N}$ & 01160541 & Deep Blue \\
\hline 52 & $136^{\circ} 40.54296^{\prime} \mathrm{W}$ & $54^{\circ} 23.16408^{\prime} \mathrm{N}$ & 01160540 & Deep Blue \\
\hline
\end{tabular}




\begin{tabular}{|c|c|c|c|c|}
\hline 53 & $136^{\circ} 15.33984^{\prime} \mathrm{W}$ & $54^{\circ} 14.40186^{\prime} \mathrm{N}$ & 01160539 & Deep Blue \\
\hline 54 & $136^{\circ} 5.38968^{\prime} \mathrm{W}$ & $54^{\circ} 4.47558^{\prime} \mathrm{N}$ & 01160538 & Deep Blue \\
\hline 55 & $136^{\circ} 38.56836^{\prime} \mathrm{W}$ & $54^{\circ} 15.12792^{\prime} \mathrm{N}$ & 01303964 & Deep Blue \\
\hline 56 & $137^{\circ} 10.29102^{\prime} \mathrm{W}$ & $54^{\circ} 25.1997^{\prime} \mathrm{N}$ & 01303960 & Deep Blue \\
\hline 57 & $138^{\circ} 2.02344^{\prime} \mathrm{W}$ & $54^{\circ} 41.60886^{\prime} \mathrm{N}$ & 01303956 & Deep Blue \\
\hline 58 & $139^{\circ} 16.13478^{\prime} \mathrm{W}$ & $55^{\circ} 4.91454^{\prime} \mathrm{N}$ & 01303953 & Deep Blue \\
\hline 59 & $140^{\circ} 1.14846^{\prime} \mathrm{W}$ & $55^{\circ} 18.95994^{\prime} \mathrm{N}$ & 01303955 & Deep Blue \\
\hline 60 & $140^{\circ} 37.70706^{\prime} \mathrm{W}$ & $55^{\circ} 30.29346^{\prime} \mathrm{N}$ & 01303957 & Deep Blue \\
\hline 61 & $141^{\circ} 6.08202^{\prime} \mathrm{W}$ & $55^{\circ} 31.73928^{\prime} \mathrm{N}$ & 01303959 & Deep Blue \\
\hline 62 & $140^{\circ} 43.60056^{\prime} \mathrm{W}$ & $55^{\circ} 24.49416^{\prime} \mathrm{N}$ & 01303958 & Deep Blue \\
\hline 63 & $140^{\circ} 2.6592^{\prime} \mathrm{W}$ & $55^{\circ} 12.27882^{\prime} \mathrm{N}$ & 01303963 & Deep Blue \\
\hline 64 & $138^{\circ} 19.58214^{\prime} \mathrm{W}$ & $54^{\circ} 39.67578^{\prime} \mathrm{N}$ & 01303961 & Deep Blue \\
\hline 65 & $137^{\circ} 5.00388^{\prime} \mathrm{W}$ & $54^{\circ} 16.5^{\prime} \mathrm{N}$ & 01303962 & Deep Blue \\
\hline 66 & $136^{\circ} 35.55564^{\prime} \mathrm{W}$ & $54^{\circ} 7.03614^{\prime} \mathrm{N}$ & 01301312 & Deep Blue \\
\hline 67 & $136^{\circ} 39.26562^{\prime} \mathrm{W}$ & $54^{\circ} 0.70458^{\prime} \mathrm{N}$ & 01301313 & Deep Blue \\
\hline 68 & $137^{\circ} 7.89648^{\prime} \mathrm{W}$ & $54^{\circ} 9.81396^{\prime} \mathrm{N}$ & 01301315 & Deep Blue \\
\hline 69 & $137^{\circ} 30.78612^{\prime} \mathrm{W}$ & $54^{\circ} 17.07228^{\prime} \mathrm{N}$ & 01301314 & Deep Blue \\
\hline 70 & $139^{\circ} 6.59082^{\prime} \mathrm{W}$ & $54^{\circ} 47.22462^{\prime} \mathrm{N}$ & 01301319 & Deep Blue \\
\hline 71 & $140^{\circ} 21.48144^{\prime} \mathrm{W}$ & $55^{\circ} 10.53126^{\prime} \mathrm{N}$ & 01301316 & Deep Blue \\
\hline 72 & $140^{\circ} 57.72168^{\prime} \mathrm{W}$ & $55^{\circ} 21.7197^{\prime} \mathrm{N}$ & 01301318 & Deep Blue \\
\hline 73 & $141^{\circ} 34.36428^{\prime} \mathrm{W}$ & $55^{\circ} 32.96238^{\prime} \mathrm{N}$ & 01301320 & Deep Blue \\
\hline 74 & $141^{\circ} 49.05762^{\prime} \mathrm{W}$ & $55^{\circ} 29.56248^{\prime} \mathrm{N}$ & 01301321 & Deep Blue \\
\hline 75 & $141^{\circ} 11.91312^{\prime} \mathrm{W}$ & $55^{\circ} 19.15626^{\prime} \mathrm{N}$ & 01301322 & Deep Blue \\
\hline 76 & $140^{\circ} 57.67968^{\prime} \mathrm{W}$ & $55^{\circ} 14.80908^{\prime} \mathrm{N}$ & 01301323 & Deep Blue \\
\hline 77 & $139^{\circ} 52.57128^{\prime} \mathrm{W}$ & $54^{\circ} 54.92238^{\prime} \mathrm{N}$ & 01301405 & Deep Blue \\
\hline 78 & $138^{\circ} 8.77734^{\prime} \mathrm{W}$ & $54^{\circ} 22.88526^{\prime} \mathrm{N}$ & 01301406 & Deep Blue \\
\hline 79 & $137^{\circ} 19.53318^{\prime} \mathrm{W}$ & $54^{\circ} 7.51854^{\prime} \mathrm{N}$ & 01301406 & Deep Blue \\
\hline 80 & $136^{\circ} 51.24024^{\prime} \mathrm{W}$ & $53^{\circ} 58.64304^{\prime} \mathrm{N}$ & 01301296 & Deep Blue \\
\hline 81 & $136^{\circ} 32.1738^{\prime} \mathrm{W}$ & $53^{\circ} 51.45018^{\prime} \mathrm{N}$ & 01301297 & Deep Blue \\
\hline 82 & $136^{\circ} 55.458^{\prime} \mathrm{W}$ & $53^{\circ} 53.20458^{\prime} \mathrm{N}$ & 01301298 & Deep Blue \\
\hline 83 & $137^{\circ} 30.792^{\prime} \mathrm{W}$ & $54^{\circ} 4.22952^{\prime} \mathrm{N}$ & 01301299 & Deep Blue \\
\hline 84 & $139^{\circ} 8.99124^{\prime} \mathrm{W}$ & $54^{\circ} 34.46532^{\prime} \mathrm{N}$ & 01301403 & Deep Blue \\
\hline 85 & $140^{\circ} 43.30176^{\prime} \mathrm{W}$ & $55^{\circ} 3.15186^{\prime} \mathrm{N}$ & 01301402 & Deep Blue \\
\hline 86 & $141^{\circ} 18.2373^{\prime} \mathrm{W}$ & $55^{\circ} 13.7388^{\prime} \mathrm{N}$ & 01301401 & Deep Blue \\
\hline 87 & $141^{\circ} 42.59376^{\prime} \mathrm{W}$ & $55^{\circ} 21.07176^{\prime} \mathrm{N}$ & 01301400 & Deep Blue \\
\hline 88 & $141^{\circ} 28.06152^{\prime} \mathrm{W}$ & $55^{\circ} 9.33252^{\prime} \mathrm{N}$ & 01303917 & Deep Blue \\
\hline 89 & $141^{\circ} 16.0449^{\prime} \mathrm{W}$ & $55^{\circ} 5.71242^{\prime} \mathrm{N}$ & 01303918 & Deep Blue \\
\hline 90 & $140^{\circ} 39.71388^{\prime} \mathrm{W}$ & $54^{\circ} 54.72948^{\prime} \mathrm{N}$ & 01303919 & Deep Blue \\
\hline 91 & $138^{\circ} 53.82912^{\prime} \mathrm{W}$ & $54^{\circ} 22.38186^{\prime} \mathrm{N}$ & 01303921 & Deep Blue \\
\hline 92 & $137^{\circ} 17.43456^{\prime} \mathrm{W}$ & $53^{\circ} 52.55076^{\prime} \mathrm{N}$ & 01303924 & Deep Blue \\
\hline 93 & $137^{\circ} 28.82028^{\prime} \mathrm{W}$ & $53^{\circ} 48.9468^{\prime} \mathrm{N}$ & 01303928 & Deep Blue \\
\hline
\end{tabular}




\begin{tabular}{|c|c|c|c|c|}
\hline 94 & $137^{\circ} 40.4121^{\prime} \mathrm{W}$ & $53^{\circ} 52.52736^{\prime} \mathrm{N}$ & 01303927 & Deep Blue \\
\hline 95 & $139^{\circ} 25.50294^{\prime} \mathrm{W}$ & $54^{\circ} 24.50538^{\prime} \mathrm{N}$ & 01303925 & Deep Blue \\
\hline 96 & $141^{\circ} 5.0166^{\prime} \mathrm{W}$ & $54^{\circ} 54.71238^{\prime} \mathrm{N}$ & 01303926 & Deep Blue \\
\hline 97 & $141^{\circ} 29.83008^{\prime} \mathrm{W}$ & $55^{\circ} 2.18064^{\prime} \mathrm{N}$ & 01301360 & Deep Blue \\
\hline 98 & $141^{\circ} 28.7217^{\prime} \mathrm{W}$ & $54^{\circ} 54.41406^{\prime} \mathrm{N}$ & 01301361 & Deep Blue \\
\hline 99 & $141^{\circ} 0.44826^{\prime} \mathrm{W}$ & $54^{\circ} 45.91848^{\prime} \mathrm{N}$ & 01301362 & Deep Blue \\
\hline 100 & $140^{\circ} 7.58886^{\prime} \mathrm{W}$ & $54^{\circ} 29.9409^{\prime} \mathrm{N}$ & 01301363 & Deep Blue \\
\hline 101 & $138^{\circ} 20.83008^{\prime} \mathrm{W}$ & $53^{\circ} 57.3657^{\prime} \mathrm{N}$ & 01301364 & Deep Blue \\
\hline 102 & $137^{\circ} 37.51854^{\prime} \mathrm{W}$ & $53^{\circ} 44.03076^{\prime} \mathrm{N}$ & 01301365 & Deep Blue \\
\hline 103 & $137^{\circ} 44.99904^{\prime} \mathrm{W}$ & $53^{\circ} 38.96238^{\prime} \mathrm{N}$ & 01301366 & Deep Blue \\
\hline 104 & $139^{\circ} 27.39258^{\prime} \mathrm{W}$ & $54^{\circ} 10.188^{\prime} \mathrm{N}$ & 01301367 & Deep Blue \\
\hline 105 & $140^{\circ} 25.45218^{\prime} \mathrm{W}$ & $54^{\circ} 27.68556^{\prime} \mathrm{N}$ & 01301368 & Deep Blue \\
\hline 106 & $140^{\circ} 54.19626^{\prime} \mathrm{W}$ & $54^{\circ} 36.34374^{\prime} \mathrm{N}$ & 01301369 & Deep Blue \\
\hline 107 & $141^{\circ} 38.12988^{\prime} \mathrm{W}$ & $54^{\circ} 49.46292^{\prime} \mathrm{N}$ & 01301370 & Deep Blue \\
\hline 108 & $141^{\circ} 34.27638^{\prime} \mathrm{W}$ & $54^{\circ} 40.7334^{\prime} \mathrm{N}$ & 01301371 & Deep Blue \\
\hline 109 & $140^{\circ} 52.07322^{\prime} \mathrm{W}$ & $54^{\circ} 28.19238^{\prime} \mathrm{N}$ & 01301383 & Deep Blue \\
\hline 110 & $139^{\circ} 8.66502^{\prime} \mathrm{W}$ & $53^{\circ} 57.11964^{\prime} \mathrm{N}$ & 01301372 & Deep Blue \\
\hline 111 & $138^{\circ} 31.16112^{\prime} \mathrm{W}$ & $53^{\circ} 38.69382^{\prime} \mathrm{N}$ & 01301373 & Deep Blue \\
\hline 112 & $140^{\circ} 11.49414^{\prime} \mathrm{W}$ & $54^{\circ} 8.70264^{\prime} \mathrm{N}$ & 01301374 & Deep Blue \\
\hline 113 & $141^{\circ} 45.77538^{\prime} \mathrm{W}$ & $54^{\circ} 35.29494^{\prime} \mathrm{N}$ & 01301382 & Deep Blue \\
\hline 114 & $140^{\circ} 16.92288^{\prime} \mathrm{W}$ & $54^{\circ} 2.7759^{\prime} \mathrm{N}$ & 01301375 & Deep Blue \\
\hline 115 & $138^{\circ} 35.25588^{\prime} \mathrm{W}$ & $53^{\circ} 32.57178^{\prime} \mathrm{N}$ & 01301376 & Deep Blue \\
\hline 116 & $139^{\circ} 17.25294^{\prime} \mathrm{W}$ & $53^{\circ} 37.49124^{\prime} \mathrm{N}$ & 01301381 & Deep Blue \\
\hline 117 & $140^{\circ} 35.74218^{\prime} \mathrm{W}$ & $54^{\circ} 0.75096^{\prime} \mathrm{N}$ & 01301380 & Deep Blue \\
\hline 118 & $140^{\circ} 57.76464^{\prime} \mathrm{W}$ & $53^{\circ} 59.73144^{\prime} \mathrm{N}$ & 01301377 & Deep Blue \\
\hline 119 & $140^{\circ} 4.15332^{\prime} \mathrm{W}$ & $53^{\circ} 44.24904^{\prime} \mathrm{N}$ & 01301378 & Deep Blue \\
\hline 120 & $139^{\circ} 23.77248^{\prime} \mathrm{W}$ & $53^{\circ} 24.39402^{\prime} \mathrm{N}$ & 01303965 & Deep Blue \\
\hline 121 & $140^{\circ} 46.55274^{\prime} \mathrm{W}$ & $53^{\circ} 48.92382^{\prime} \mathrm{N}$ & 01303969 & Deep Blue \\
\hline 122 & $141^{\circ} 24.37206^{\prime} \mathrm{W}$ & $54^{\circ} 0.05178^{\prime} \mathrm{N}$ & 01303973 & Deep Blue \\
\hline 123 & $141^{\circ} 17.05764^{\prime} \mathrm{W}$ & $53^{\circ} 50.42772^{\prime} \mathrm{N}$ & 01303974 & Deep Blue \\
\hline 124 & $140^{\circ} 11.28612^{\prime} \mathrm{W}$ & $53^{\circ} 31.19094^{\prime} \mathrm{N}$ & 01303966 & Deep Blue \\
\hline 125 & $139^{\circ} 17.47752^{\prime} \mathrm{W}$ & $53^{\circ} 14.77344^{\prime} \mathrm{N}$ & 01303967 & Deep Blue \\
\hline 126 & $140^{\circ} 31.51758^{\prime} \mathrm{W}$ & $53^{\circ} 29.71194^{\prime} \mathrm{N}$ & 01303968 & Deep Blue \\
\hline 127 & $141^{\circ} 50.80956^{\prime} \mathrm{W}$ & $53^{\circ} 45.44238^{\prime} \mathrm{N}$ & 01303970 & Deep Blue \\
\hline 128 & $140^{\circ} 48.12888^{\prime} \mathrm{W}$ & $53^{\circ} 27.17142^{\prime} \mathrm{N}$ & 01303971 & Deep Blue \\
\hline 129 & $139^{\circ} 49.36428^{\prime} \mathrm{W}$ & $53^{\circ} 9.959466^{\prime} \mathrm{N}$ & 01303972 & Deep Blue \\
\hline 130 & $140^{\circ} 41.97168^{\prime} \mathrm{W}$ & $53^{\circ} 18.05226^{\prime} \mathrm{N}$ & 01303975 & Deep Blue \\
\hline 131 & $140^{\circ} 54.417^{\prime} \mathrm{W}$ & $53^{\circ} 21.69042^{\prime} \mathrm{N}$ & 01303977 & Deep Blue \\
\hline 132 & $141^{\circ} 19.14258^{\prime} \mathrm{W}$ & $53^{\circ} 21.69042^{\prime} \mathrm{N}$ & 01303978 & Deep Blue \\
\hline 133 & $141^{\circ} 28.93752^{\prime} \mathrm{W}$ & $53^{\circ} 31.67772^{\prime} \mathrm{N}$ & 01303979 & Deep Blue \\
\hline 134 & $141^{\circ} 32.69922^{\prime} \mathrm{W}$ & $53^{\circ} 25.33884^{\prime} \mathrm{N}$ & 01303980 & Deep Blue \\
\hline
\end{tabular}




\begin{tabular}{|c|c|c|c|c|}
\hline 135 & $141^{\circ} 21.00588^{\prime} \mathrm{W}$ & $53^{\circ} 21.94092^{\prime} \mathrm{N}$ & 01303984 & Deep Blue \\
\hline 136 & $140^{\circ} 50.5449^{\prime} \mathrm{W}$ & $53^{\circ} 5.6655^{\prime} \mathrm{N}$ & 01303983 & Deep Blue \\
\hline 137 & $141^{\circ} 22.37304^{\prime} \mathrm{W}$ & $53^{\circ} 14.95458^{\prime} \mathrm{N}$ & 01303981 & Deep Blue \\
\hline 138 & $141^{\circ} 55.60644^{\prime} \mathrm{W}$ & $53^{\circ} 24.58398^{\prime} \mathrm{N}$ & 01303988 & Deep Blue \\
\hline 139 & $141^{\circ} 18.33594^{\prime} \mathrm{W}$ & $53^{\circ} 6.41994^{\prime} \mathrm{N}$ & 01303986 & Deep Blue \\
\hline 140 & $141^{\circ} 26.4912^{\prime} \mathrm{W}$ & $53^{\circ} 1.44924^{\prime} \mathrm{N}$ & 01303987 & Deep Blue \\
\hline 141 & $141^{\circ} 25.46292^{\prime} \mathrm{W}$ & $52^{\circ} 51.32814^{\prime} \mathrm{N}$ & 01301324 & Deep Blue \\
\hline 142 & $142^{\circ} 17.60058^{\prime} \mathrm{W}$ & $52^{\circ} 46.24074^{\prime} \mathrm{N}$ & 01301325 & Deep Blue \\
\hline 143 & $142^{\circ} 7.93554^{\prime} \mathrm{W}$ & $53^{\circ} 25.96242^{\prime} \mathrm{N}$ & 01301326 & Deep Blue \\
\hline 144 & $142^{\circ} 8.18652^{\prime} \mathrm{W}$ & $53^{\circ} 24.94044^{\prime} \mathrm{N}$ & 032697 & XSV-01 \\
\hline 145 & $141^{\circ} 59.8203^{\prime} \mathrm{W}$ & $53^{\circ} 58.80468^{\prime} \mathrm{N}$ & 01301327 & Deep Blue \\
\hline 146 & $141^{\circ} 56.67282^{\prime} \mathrm{W}$ & $54^{\circ} 11.59422^{\prime} \mathrm{N}$ & 01301328 & Deep Blue \\
\hline 147 & $141^{\circ} 54.1494^{\prime} \mathrm{W}$ & $55^{\circ} 6.77442^{\prime} \mathrm{N}$ & 01301329 & Deep Blue \\
\hline 148 & $141^{\circ} 58.5117^{\prime} \mathrm{W}$ & $54^{\circ} 49.42188^{\prime} \mathrm{N}$ & 01301330 & Deep Blue \\
\hline 149 & $142^{\circ} 6.04494^{\prime} \mathrm{W}$ & $54^{\circ} 17.08602^{\prime} \mathrm{N}$ & 01301331 & Deep Blue \\
\hline 150 & $142^{\circ} 14.74314^{\prime} \mathrm{W}$ & $53^{\circ} 41.42286^{\prime} \mathrm{N}$ & 01301335 & Deep Blue \\
\hline 151 & $142^{\circ} 21.81738^{\prime} \mathrm{W}$ & $53^{\circ} 12.28272^{\prime} \mathrm{N}$ & 01301334 & Deep Blue \\
\hline 152 & $142^{\circ} 31.81248^{\prime} \mathrm{W}$ & $53^{\circ} 15.74514^{\prime} \mathrm{N}$ & 01301332 & Deep Blue \\
\hline 153 & $142^{\circ} 25.76952^{\prime} \mathrm{W}$ & $53^{\circ} 41.19432^{\prime} \mathrm{N}$ & 01301333 & Deep Blue \\
\hline 154 & $142^{\circ} 17.97948^{\prime} \mathrm{W}$ & $54^{\circ} 13.53906^{\prime} \mathrm{N}$ & 01301348 & Deep Blue \\
\hline 155 & $142^{\circ} 15.62892^{\prime} \mathrm{W}$ & $54^{\circ} 23.1699^{\prime} \mathrm{N}$ & 01301349 & Deep Blue \\
\hline 156 & $142^{\circ} 14.01858^{\prime} \mathrm{W}$ & $55^{\circ} 14.98782^{\prime} \mathrm{N}$ & 01301350 & Deep Blue \\
\hline 157 & $142^{\circ} 18.62988^{\prime} \mathrm{W}$ & $54^{\circ} 56.11182^{\prime} \mathrm{N}$ & 01301351 & Deep Blue \\
\hline 158 & $142^{\circ} 21.93264^{\prime} \mathrm{W}$ & $54^{\circ} 42.42576^{\prime} \mathrm{N}$ & 01301355 & Deep Blue \\
\hline 159 & $142^{\circ} 37.68654^{\prime} \mathrm{W}$ & $53^{\circ} 35.93652^{\prime} \mathrm{N}$ & 01301353 & Deep Blue \\
\hline 160 & $142^{\circ} 43.13478^{\prime} \mathrm{W}$ & $53^{\circ} 12.63624^{\prime} \mathrm{N}$ & 01301352 & Deep Blue \\
\hline 161 & $142^{\circ} 20.07126^{\prime} \mathrm{W}$ & $52^{\circ} 40.61862^{\prime} \mathrm{N}$ & 01301355 & Deep Blue \\
\hline 162 & $141^{\circ} 25.7412^{\prime} \mathrm{W}$ & $52^{\circ} 49.05666^{\prime} \mathrm{N}$ & 01301357 & Deep Blue \\
\hline 163 & $140^{\circ} 40.10352^{\prime} \mathrm{W}$ & $52^{\circ} 57.7827^{\prime} \mathrm{N}$ & 01301358 & Deep Blue \\
\hline 164 & $139^{\circ} 47.17578^{\prime} \mathrm{W}$ & $53^{\circ} 7.18308^{\prime} \mathrm{N}$ & 01301359 & Deep Blue \\
\hline 165 & $139^{\circ} 22.90428^{\prime} \mathrm{W}$ & $54^{\circ} 8.1948^{\prime} \mathrm{N}$ & 01303992 & Deep Blue \\
\hline 166 & $139^{\circ} 12.2676^{\prime} \mathrm{W}$ & $54^{\circ} 39.31692^{\prime} \mathrm{N}$ & 01303989 & Deep Blue \\
\hline 167 & $138^{\circ} 46.35936^{\prime} \mathrm{W}$ & $55^{\circ} 0.97998^{\prime} \mathrm{N}$ & 01303990 & Deep Blue \\
\hline 168 & $137^{\circ} 47.90916^{\prime} \mathrm{W}$ & $54^{\circ} 55.41504^{\prime} \mathrm{N}$ & 01303991 & Deep Blue \\
\hline 169 & $136^{\circ} 27.6924^{\prime} \mathrm{W}$ & $54^{\circ} 7.18848^{\prime} \mathrm{N}$ & 01303993 & Deep Blue \\
\hline 170 & $136^{\circ} 11.59962^{\prime} \mathrm{W}$ & $53^{\circ} 57.27102^{\prime} \mathrm{N}$ & 01303994 & Deep Blue \\
\hline
\end{tabular}




\section{Appendix C: Shipboard Preliminary Products}

Grids of data collected during the KM1811survey were generated for quality control. A resolution of $100 \mathrm{~m}$ was generally used. The final 100-m composite grid of the data collected in the survey area is shown in Fig. C.1, with vertical exaggeration of 5x for shading, and artificial sun-illumination from the northwest. Acoustic backscatter was also processed as part of the quality control process; the final composite, at a resolution of $50 \mathrm{~m}$ is shown in Fig. C.2.

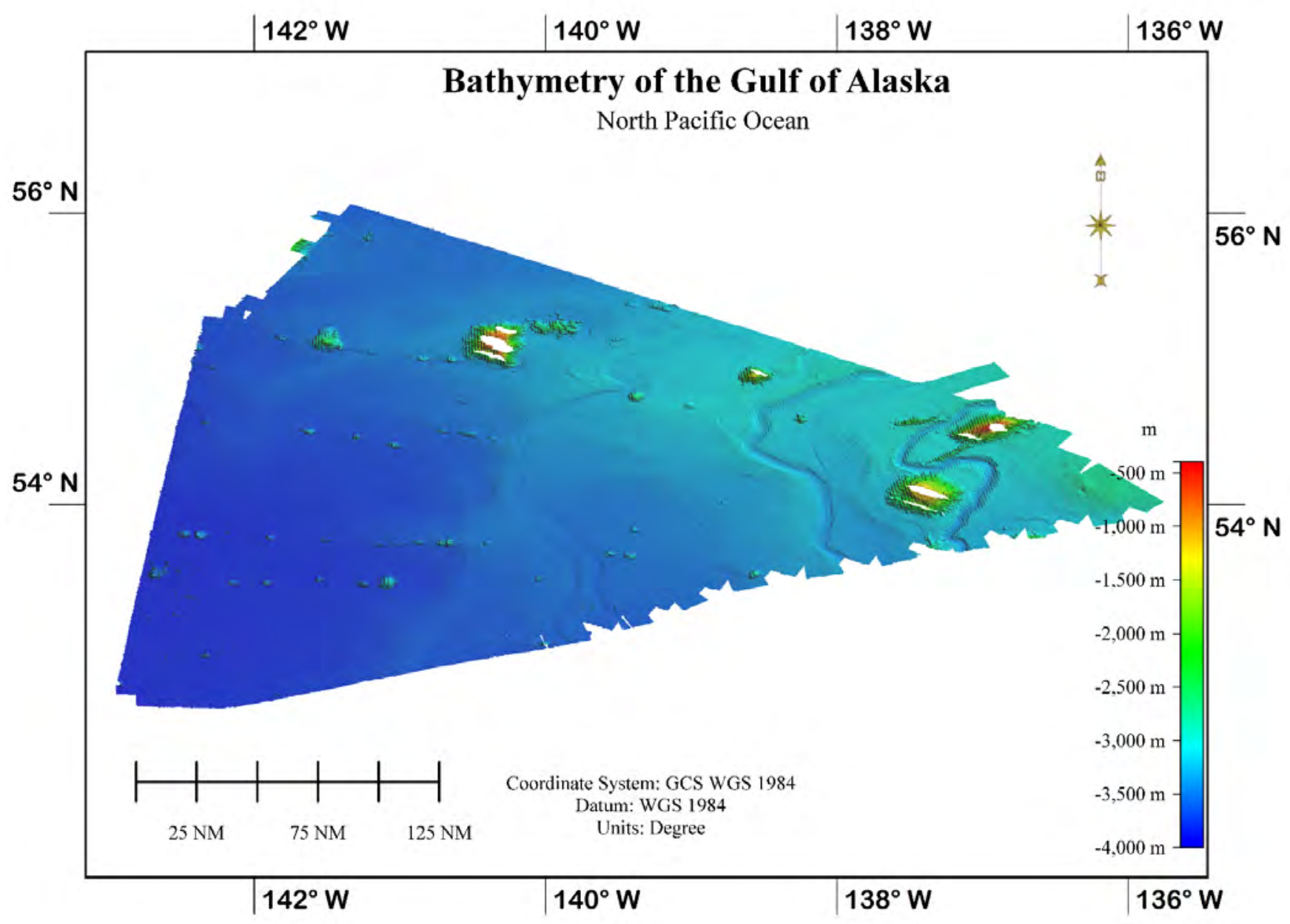

Figure C.1. Bathymetry of the KM1811 survey area in the Gulf of Alaska. Compare with Figure 1.2. 


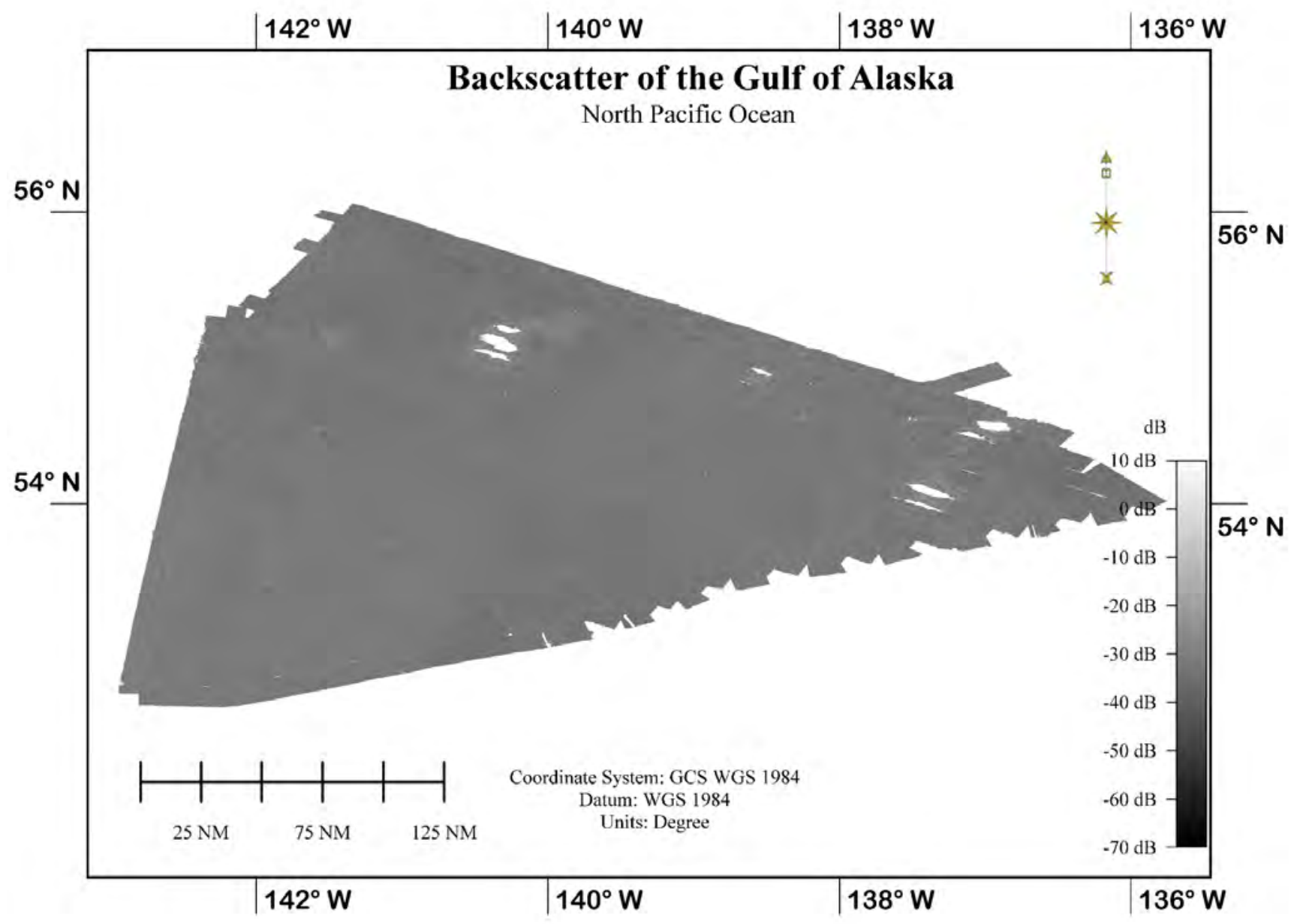

Figure C.2. Acoustic backscatter of the KM1811 survey area in the Gulf of Alaska coregistered to bathymetry in Figure C.1. 


\section{Back-angle Corrected Backscatter}

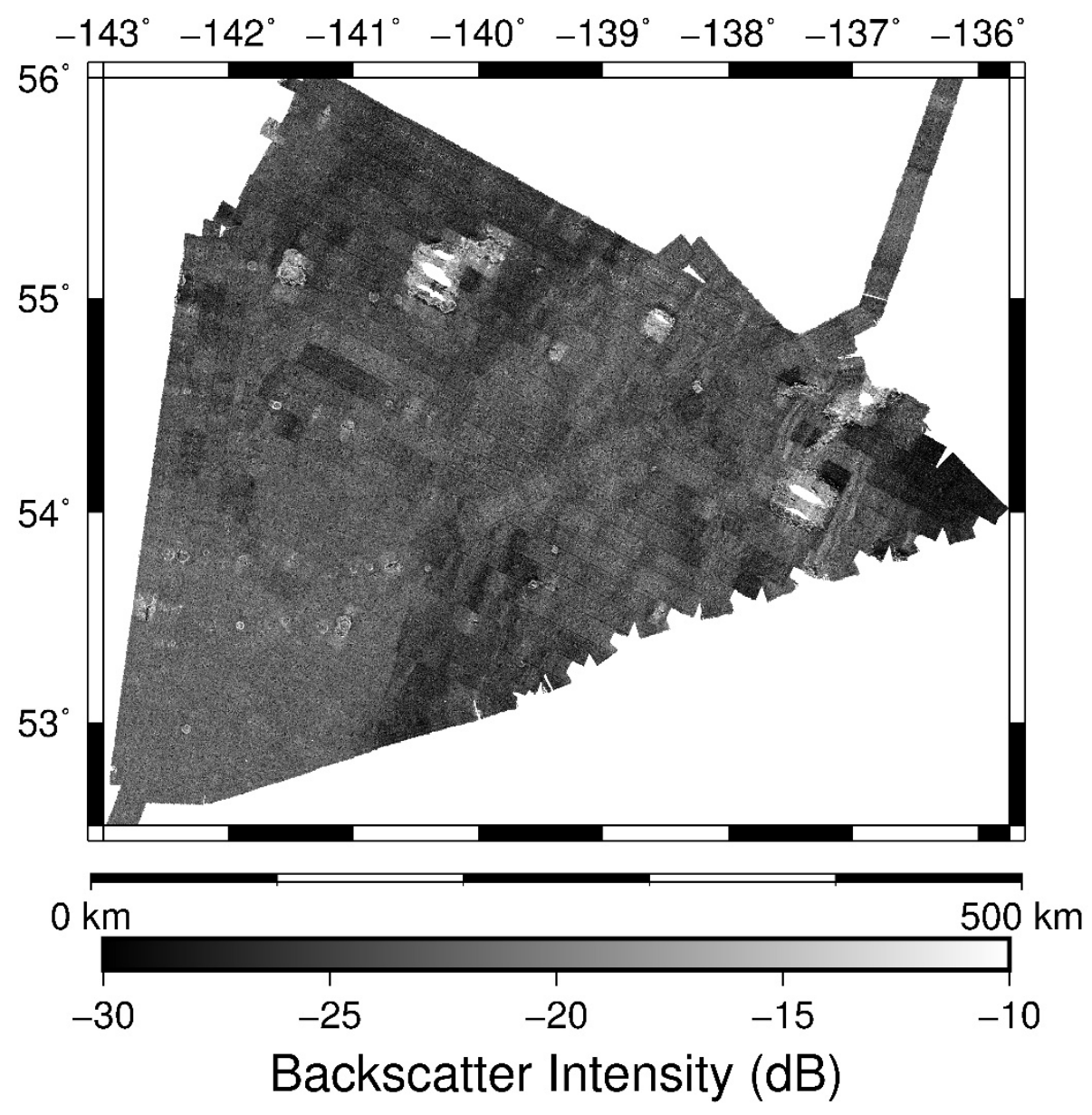

Figure C.3. Back-angle corrected backscatter of the KM1811 survey area iin the Gulf of Alaska processed using MB Systems software and plotted using Generic Mapping Tools. 


\section{Appendix D: Calibration Data}

\section{D.1. Installation Parameters}

The positioning offsets for the EM122 are shown in Fig. D.1, as derived from SIS installation parameters. A graphical outline of the locations of the various sensors is given in Figure D.2.

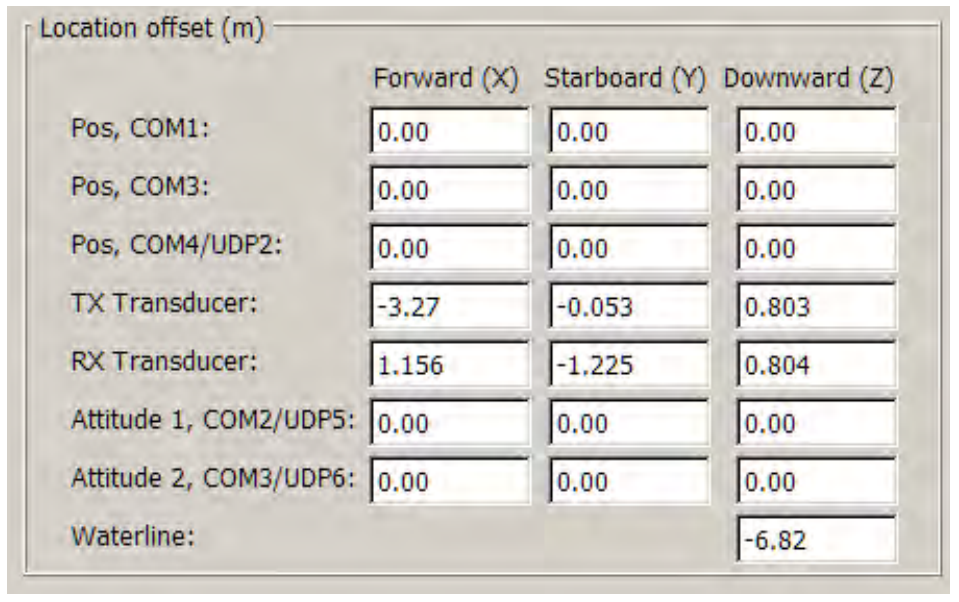

Figure D.1. Installation parameters for the EM122 on the Kilo Moana during KM17-18.

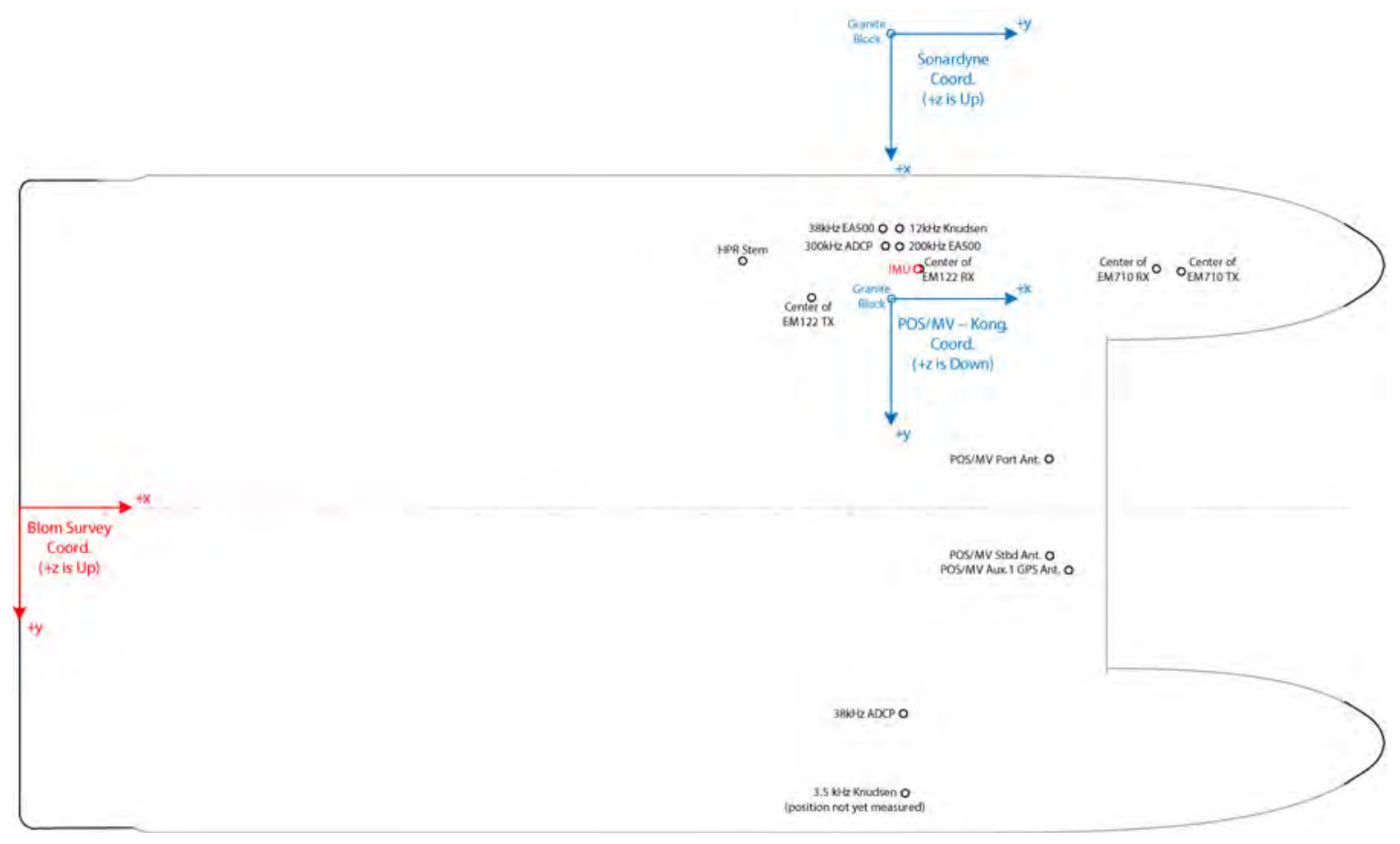

Figure D.2. Graphical layout of RV Kilo Moana instruments for KM17-18. 


\section{D.2 Sound Speed Sensors Certificates}

The certificate of calibration for the AML Oceanographic sound speed (Fig. D.3) the calibration certificate for the temperature sensor is given in Fig. D.4.

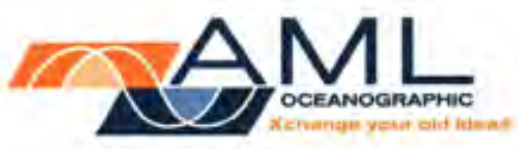

Certificate of Calibration

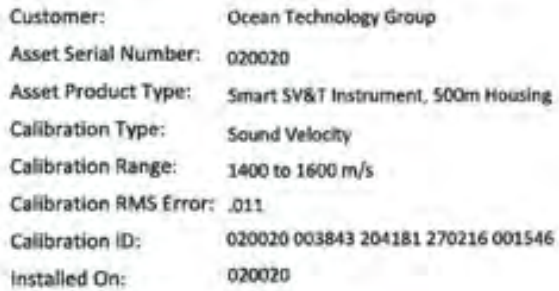

Coefficient A: $7.216886 \varepsilon-4$

Coefficient B: $7,436780 \mathrm{E}-5$

Coefficient C: $1.1392996-6$

Coefficient D: -7.125645E-7

Coefficient $E: \quad 0.000000 E+0$

Coefficient $F: 0.000000 E+0$

Coefficient G: $0,000000 \mathrm{E}+0$
Coefficient H: $0.000000 \mathrm{E}+0$

Coefficient I: $\quad 0.000000 \mathrm{t}+0$

Coefficient f: $\quad 0.000000 e+0$

Coefficient $\mathrm{K}: \quad 0.000000 \mathrm{E}+0$

Coefficient L: $0.000000 E+0$

Coefficient M: $0.000000 E+0$

Coefficient $N: 0.0000006+0$

Calibration Date $(\mathrm{ddd} / \mathrm{mm} / \mathrm{mm})$ ): 27/2/2016 Certified By:

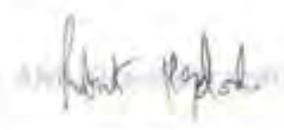

Robert Haydock President, AML Oceanographic

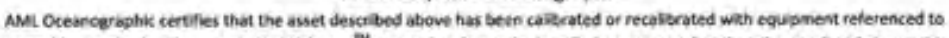
traceable standardx. Please note that Xchange "sensorheadi may be installed on assets other than the one fated above; this calbration certifcate wel still be valid when used on other such assets. It this instrument or semer has beth recelibrated. please be suse to update vour records. Please aso ensure that vow update the instrument's coefficient values in any post. phocessing software that you use, if necessary. Older generation instruments may reoure confliguration flies, which are

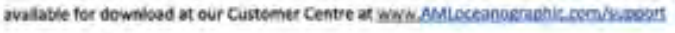

AMt Ockanographic 2071 Molaviow Auenue, Sidney BC. VBe $5 \times 6$ CAMADA

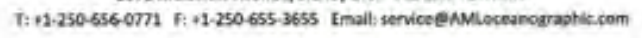

Figure D.3. Certificate of calibration for AML Oceanographic SV\&T sound-velocity sensor. 


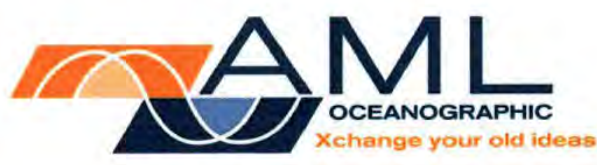

Certificate of Calibration

$\begin{array}{ll}\text { Customer: } & \text { Ocean Technology Group } \\ \text { Asset Serial Number: } & 020020 \\ \text { Asset Product Type: } & \text { Smart SV\&T Instrument, 500m Housing } \\ \text { Calibration Type: } & \text { Temperature } \\ \text { Calibration Range: } & -2 \text { to +32 Dec C } \\ \text { Calibration RMS Error: } & .0012 \\ \text { Calibration ID: } & 020020999999020020250216193333 \\ \text { Installed On: } & 020020\end{array}$

Coefficient A: $\quad-8.271178 E+0$

Coefficient B: $8.840404 E-4$

Coefficient C: $-9.215226 \mathrm{E}-9$

Coefficient D: $1.849194 \mathrm{E}-13$

Coefficient E: - $2.212972 \mathrm{E}-18$

Coefficient F: $1.743399 \mathrm{E}-23$

Coefficient G: $-4.450266 \mathrm{E}-29$

\begin{abstract}
Coefficient $\mathrm{H}: \quad 0.000000 \mathrm{E}+0$
Coefficient I: $\quad 0.000000 \mathrm{E}+0$

Coefficient J: $\quad 0.000000 \mathrm{E}+0$

Coefficient K: $\quad 0.000000 \mathrm{E}+0$

Coefficient L: $\quad 0.000000 E+0$

Coefficient M: $0.000000 E+0$

Coefficient N: $0.000000 \mathrm{E}+0$
\end{abstract}

Calibration Date (dd/mm/yyy): $\quad 25 / 2 / 2016$

Certified By:

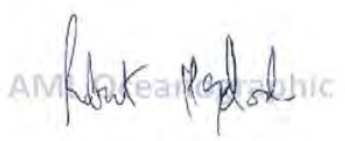

Robert Haydock

President, AML Oceanographic

AML Oceanographic certifies that the asset described above has been calibrated or recalibrated with equipment referenced to traceable standards. Please note that $\mathrm{Xchang} \mathrm{e}^{\mathrm{TM}}$ sensor-heads may be installed on assets other than the one listed above; this calibration certificate will still be valid when used on other such assets. If this instrument or sensor has been recalibrated, please be sure to update your records. Please also ensure that you update the instrument's coefficient values in any postprocessing software that you use, if necessary. Older generation instruments may require configuration files, which are available for download at our Customer Centre at www.AMLoceanographic.com/support

AML Oceanographic

2071 Malaview Avenue, Sidney B.C. V8L 5X6 CANADA

T: +1-250-656-0771 F: +1-250-655-3655 Email: service@AMLoceanographic.com

Figure D.4. Certificate of calibration for AML Oceanographic SV\&T temperature sensor. 


\section{D.3 Gravity Ties}

\section{D.3.1 Calibration}

The gravimeter is installed on the RV Kilo Moana's main deck, slightly to starboard of the centerline and aligned fore/aft approximately with aft-most port hole of Lab 2. The portable land gravimeter was in-line with the aft-most port hole of Lab 2, which is approximately where the gravimeter is installed A bias determination was conducted on the RV Kilo Moana's BGM-3 gravimeter on 2014-06-05, Fig. D.5, and was updated on 2017-03-13. No formal documentation of the re-determination is currently available, but e-mail documentation from Woods Hole Oceanographic Institute (WHOI: Tom Lanagan, tlanagan@whoi.edu) indicates that the scale factor was $5.073184939 \mathrm{mgal} / \mathrm{pps}$, and the bias value was 853493.3941 . The common reference station for all measurements is NGA Gravity Station 'Pier 35 Alpha' at the UH Marine Facility, Honolulu, HI, with description as shown in Fig. D.6; the gravity station monument is shown in Fig. D.7.

\section{D.3.2 Observations}

The opening and closing gravity tie information is provided in Figures D.8. and 9.

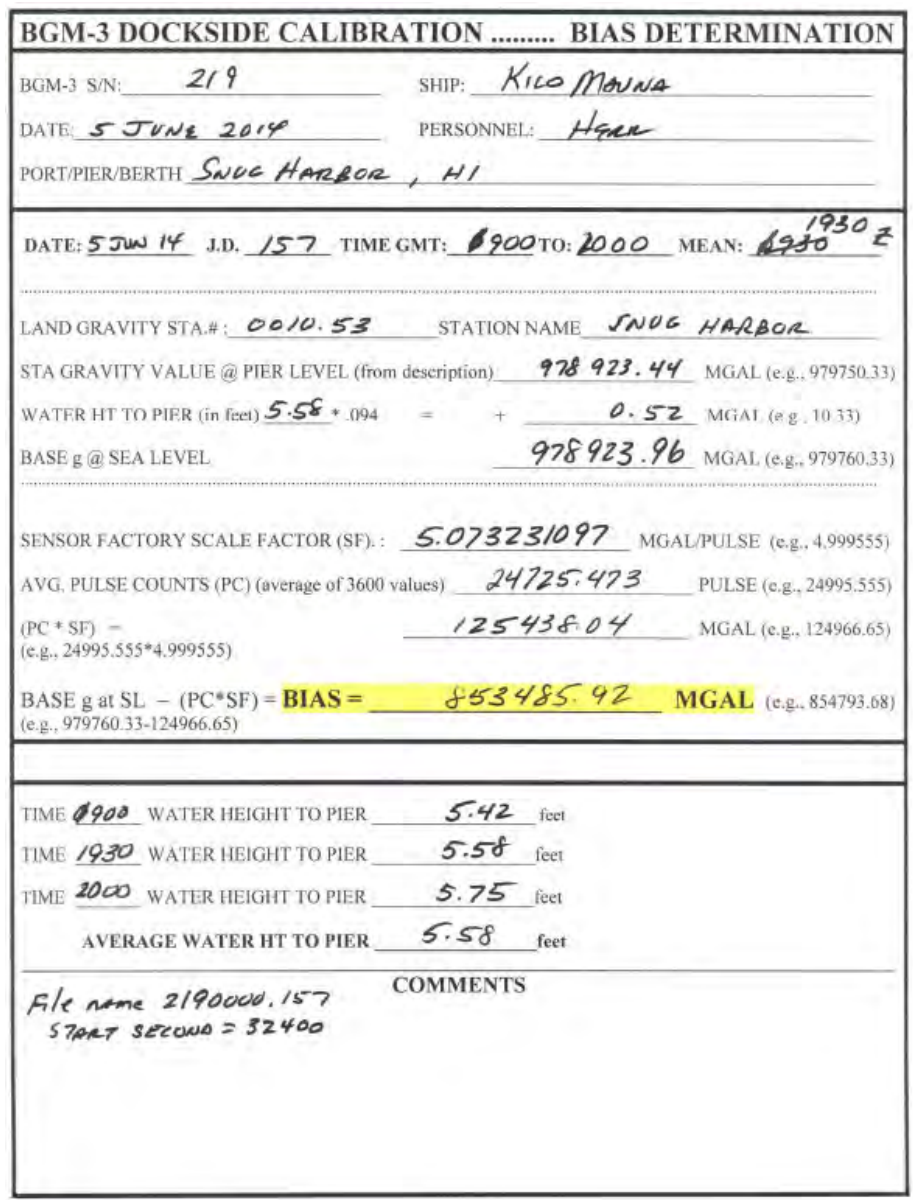

Figure D.5. Dock-side bias determination for the RV Kilo Moana's Bell BCM-3 gravimeter. 


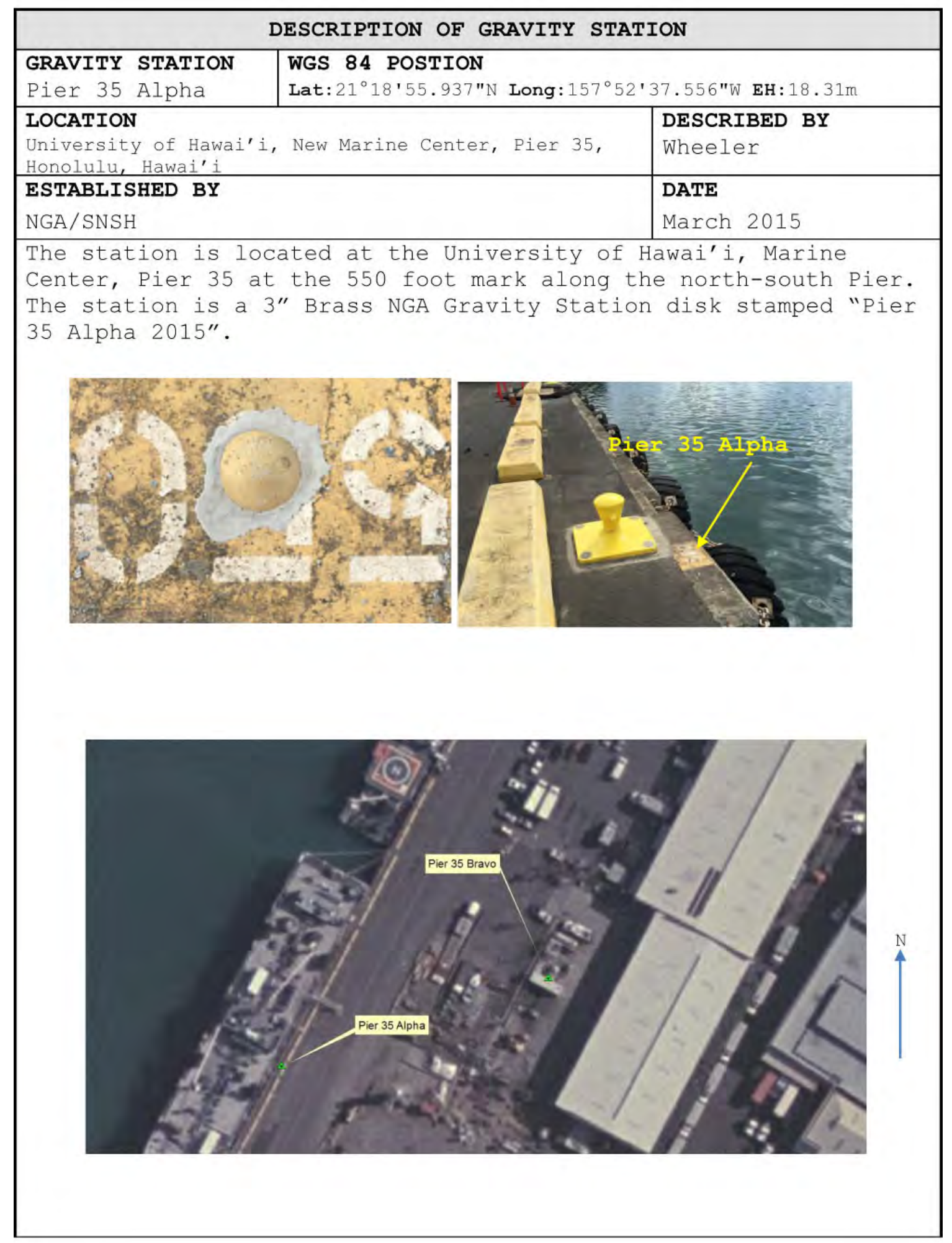

Figure D.6. Description of the gravity reference station at Pier 35, Honolulu, HI used for gravity tie before KM1811. 


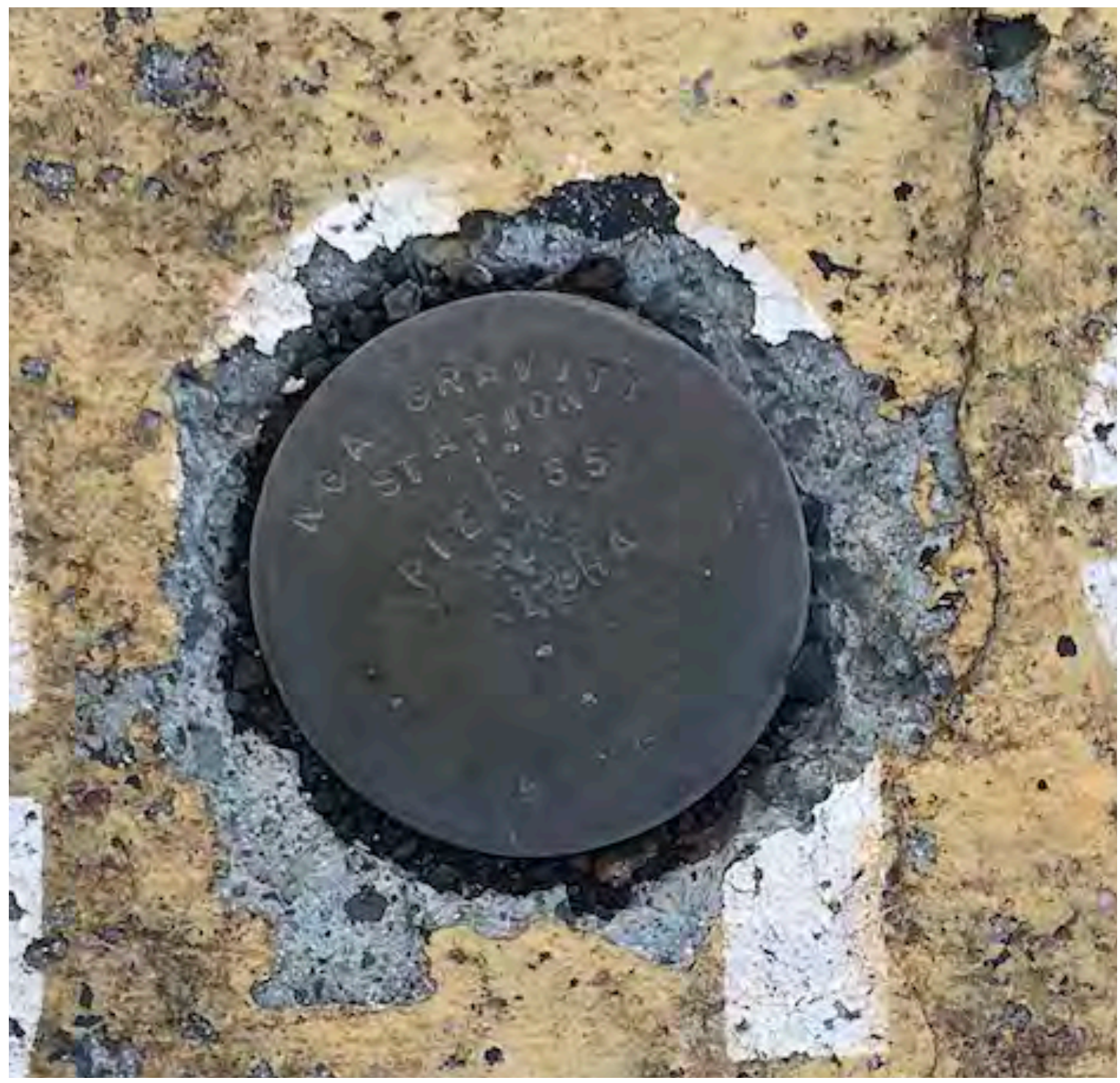

Figure D.7. Gravity station monument at Pier 35, Honolulu, HI that corresponds to the station description in Fig. D.6. 


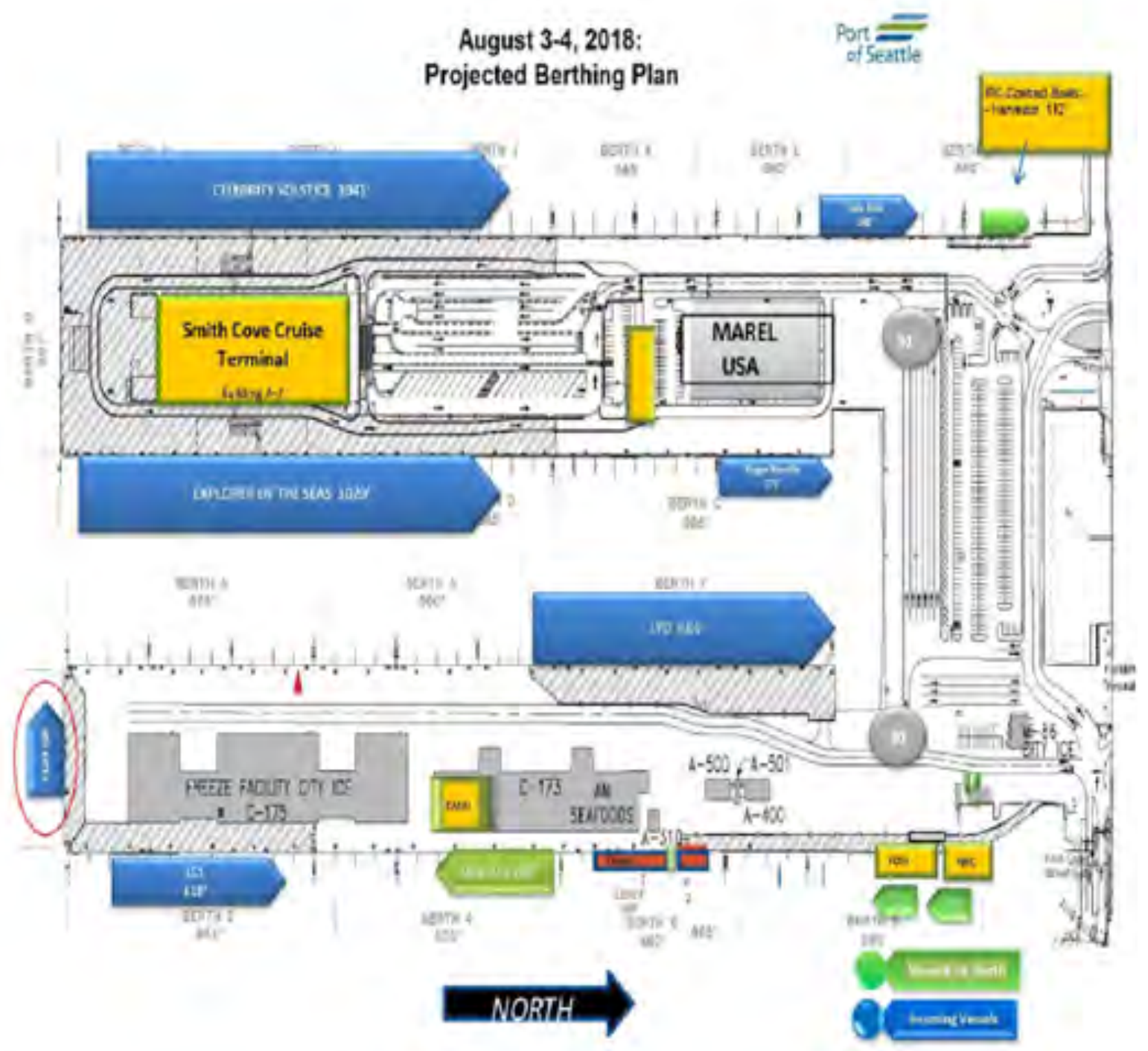

Illustration 2: KM Moored Pier 90 Smith Cove, Seattle WA

Figure D.8. Description of the gravity reference station at Pier 91, Seattle, WA. used for the gravity tie after KM1811. 
D.3.2 Observations

KM18-11 Pre-Cruise Gravity Land-Tie Report

Date:June 29, 2018 HNL; Julian day 182

Gravity Station:Pier 35 Alpha

Port:Honolulu, Hawaii

Cruise: $\mathrm{km} 1811$

Gravity Station Location (lat/lon): $21^{\circ} 18^{\prime} 55.937^{\prime} \mathrm{N} / 157^{\circ} 52^{\prime} 37.556^{\prime} \mathrm{W}$

Gravity Station EH: $18.31 \mathrm{~m}$

Station Description: University of Hawaii Marine Center, Pier 35, Honolulu, Hawaii

Station Adjusted Gravity Value (mGal): $978927.887 \pm 0.0024$

Land Meter ID (Serial No.): LaCoste Romberg, s/n G-1

Ship's Meter ID (Serial Number): BGM-3, s/n 219

\section{Benchmark Tie Details}

\begin{tabular}{|l|l|l|l|}
\hline Location & Time (UTC) & $\begin{array}{l}\text { Portable } \\
\text { Meter } \\
\text { Reading }\end{array}$ & $\begin{array}{l}\text { Ships Meter } \\
\text { Pulse Count }\end{array}$ \\
\hline \multicolumn{2}{|c|}{ Pre-Cruise Pier Measurement } \\
\hline First pier measurement & JD 182 00:25:20 & 2197.20 & 24727 \\
\hline Second pier measurement & JD 182 00:29:23 & 2196.99 & 24692 \\
\hline Third pier measurement & JD 182 00:31:42 & 2196.99 & 24699 \\
\hline Average pier measurement & & $\mathbf{2 1 9 7}$ & $\mathbf{2 4 7 0 6}$ \\
\hline
\end{tabular}

Main deck height above pier: $\mathbf{2 . 6 9 2 m}$

Pier's height above sea surface: $\mathbf{1 . 7 9 0 7 m}$

Main deck above sea surface: $\mathbf{4 . 4 8 3 1 m}$

Distance from port side of ship's main deck: $1.6256 \mathrm{~m}$

Ship's draft mark:Fwd= $7.5692 \mathrm{~m}$ Aft $=\mathbf{7 . 7 2 1 6 m}$

Ship's GPS Location: $21.315062^{\circ} \mathrm{N} /-157.877463^{\circ} \mathrm{W}$

Ship's Heading: $206.9^{\circ} \mathrm{T}$

Operator: Readings taken by T. Young (OTG) and J. Tree (UH). 


\section{KM1811 Post-Cruise Gravity Land-Tie Report}

Date: 07 Aug. 2018 Seattle (Julian DAY 220)

Gravity Station:_MSB-BB

Port:_Smith Cove, Pier 90, Seattle WA

Cruise: KM1811

Gravity Station Location (lat/lon): 4738.9804 N / 12218.7866 W

Gravity Station EH: 88 in.

Station Description: University of Washington Marine Science Building Dock

Station Adjusted Gravity Value (mGal): $\quad 980729.450 \pm 0.002$

Land Meter ID (Serial No.): LaCoste Romberg, s/n G-1

Ship's Meter ID (Serial Number): BGM-3, s/n 219

Ship Tie Details

\begin{tabular}{|c|c|c|c|c|c|}
\hline Ship Location & $\begin{array}{l}\text { Time } \\
\text { (UTC) }\end{array}$ & $\begin{array}{l}\text { L\&R Meter } \\
\text { G-1 Reading }\end{array}$ & $\begin{array}{l}\text { Conversion } \\
\text { Table } \\
\text { milligals }\end{array}$ & $\begin{array}{l}\text { Ship's } \\
\text { Meter Pulse } \\
\text { Count }\end{array}$ & $\begin{array}{l}\text { Ship's } \\
\text { Meter } \\
\text { Gravity }\end{array}$ \\
\hline \multirow[t]{2}{*}{$\begin{array}{l}\text { First pier } \\
\text { measurement } \\
4737.5969 \mathrm{~N} \\
12222.8164 \mathrm{~W}\end{array}$} & $\begin{array}{l}\text { JD } 220 \\
1640\end{array}$ & $\begin{array}{l}3990.36 \\
3990.33 \\
3990.34\end{array}$ & & & \\
\hline & & 3990.34 (avg) & 4148.8 & 25013.9 & 980382.0 \\
\hline \multirow[t]{2}{*}{$\begin{array}{c}\text { Base Station } \\
\text { measurement } \\
4738.9804 \mathrm{~N} \\
12218.7866 \mathrm{~W} \\
\end{array}$} & $\begin{array}{l}\text { JD } 220 \\
1752\end{array}$ & $\begin{array}{l}3988.37 \\
3988.37 \\
3988.37\end{array}$ & & & \\
\hline & & 3988.37 (avg) & 4146.7 & 25079.9 & 980716.6 \\
\hline \multirow[t]{2}{*}{$\begin{array}{l}\text { Third pier } \\
\text { measurement } \\
4737.5969 \mathrm{~N} \\
12222.8164 \mathrm{~W}\end{array}$} & $\begin{array}{l}\text { JD 220 } \\
2036\end{array}$ & $\begin{array}{l}3990.57 \\
3990.55 \\
3990.55\end{array}$ & & & \\
\hline & & 3990.56 (avg) & 4149.0 & 25102.3 & 980830.3 \\
\hline
\end{tabular}

Fig. D.8: KM1811 post-cruise gravity tie information 


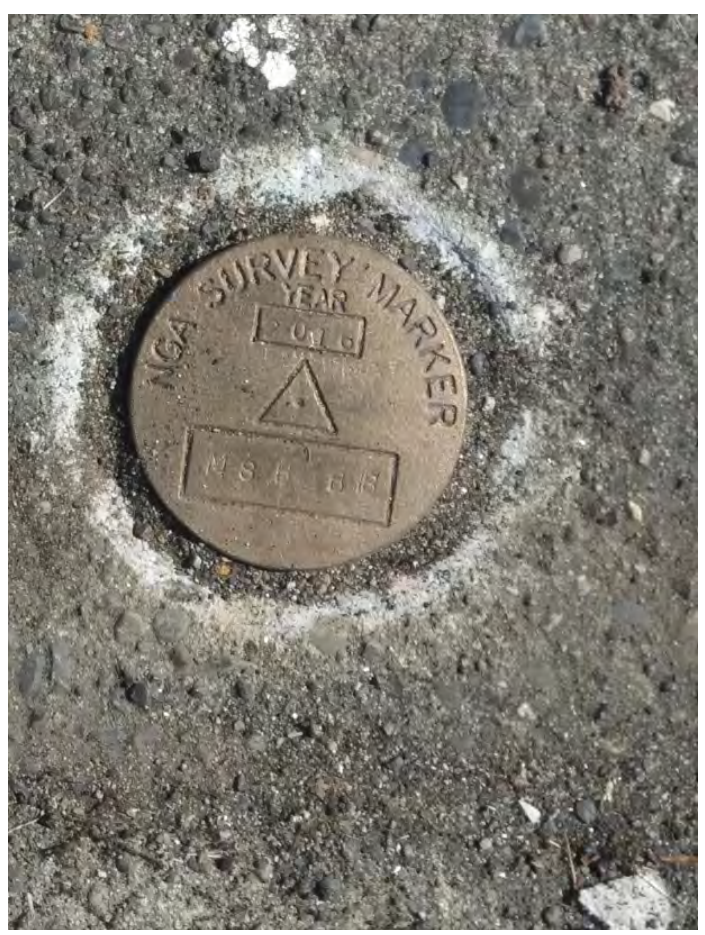

Figure 9a. Post-cruise gravity tie monument at the University of Washington Marine Sciences Bldg. dock, Seattle.

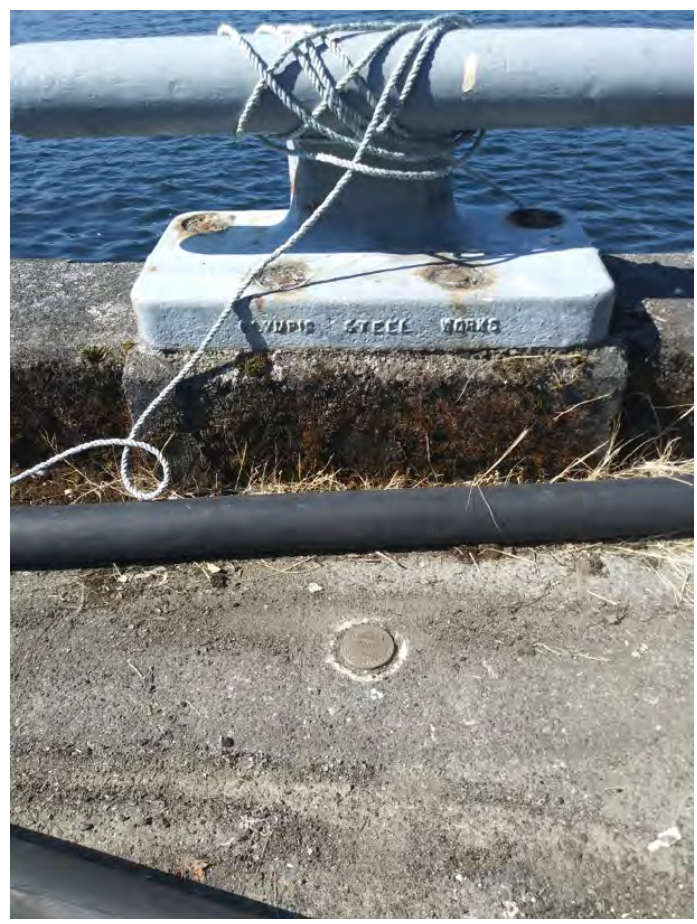

Figure 9b. Location of post-cruise gravity tie station at the University of Washington Marine Sciences Bldg. dock, Seattle. 


\section{D.4 CUBE Algorithm Parameters}

The CUBE algorithm implementation in Qimera was configured with the algorithm deep water parameters and the CUBE hypothesis resolution algorithm was set to number of samples + neighborhood.

\section{D.5 GeoCoder Algorithm Parameters}

The GeoCoder implementation in QPS FMGT was set to the standard configuration for FMGT 7.8.4. This configures the algorithm to carry out transmit and receive power/gain corrections, apply beam pattern corrections, accept all beams, use the absorption coefficients from file, and apply no backscatter bias. The algorithm uses a "flat" AVG correction with window size of 300 pings, computing statistics in logarithmic space. The mosaic used the "blend" method with a 50\% inter-line blending, and dB mean estimation. Navigation was taken from the default source in the input file, with automatically determined sonar defaults. Dualswath compensation was turned off. The default processing pipeline was used.

\section{Appendix E: Gravity Data Consistency Analysis}

Gravity data collected are suspected to be of low accuracy and not valid for further interpretation without RMS minimization and correction factors being applied to the data derived from a cross-over analysis. Suggested further work should use the Generic Mapping Tools 5.4.4 module, X2SYS to obtain correction factors. Scientist, Jonathan Tree, has investigated any sources that may have resulted in these variations such as processing errors or ship dynamic effects (see Fig. F.1 below). The ship's pitch and heave seem to have the least effect on the quality of the gravity data, while hard turns and higher roll magnitudes appear to roughly correlate with magnitude shifts within the data (Fig. F.1). The Eötvös correction is shown in Fig. F.2 for the purpose of highlighting that the correct magnitude of corrections were applied to the free-air gravity reduction. Fig. F.2 shows that the gravity vector calculations are accurate and that they have removed the directional bias present in the filtered raw gravity (Fig. F.1). The gravimeter is suspected to have been locked into a nonvertical gravity component measurement due to gyro stabilizaition failure following turns. This is most obvious in the southern region of the survey following frequent turns of shorter survey lines and the following western margin of chiefly north-south survey lines. 


\section{Shifted Marine Gravity (+200 mgal)}

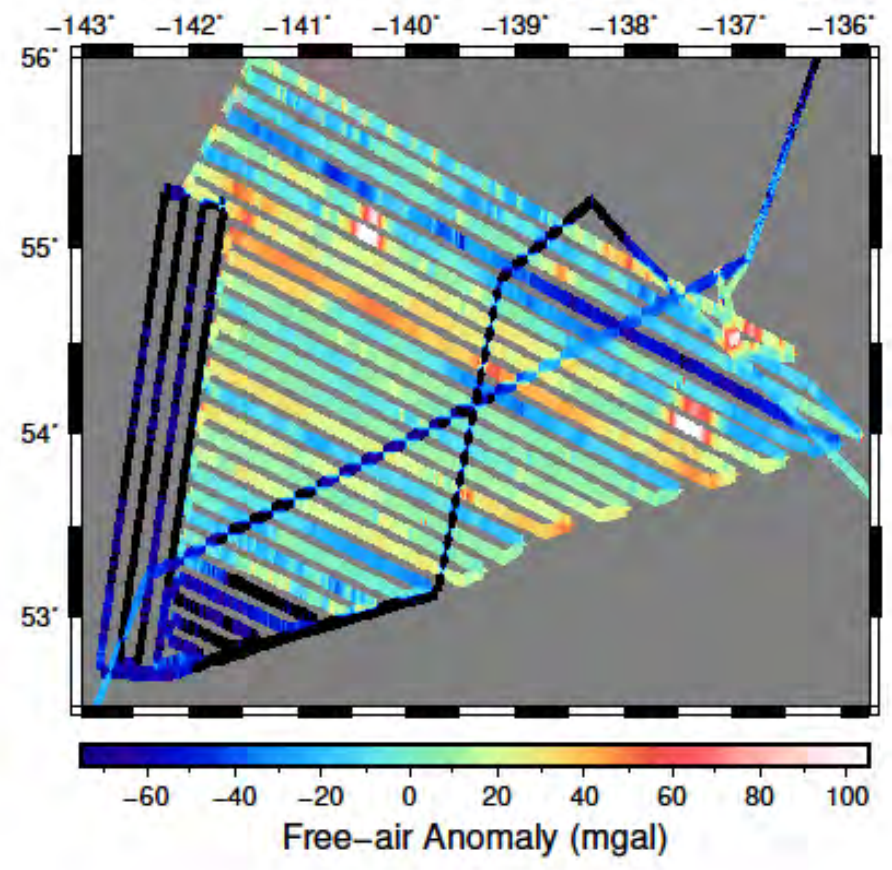

\section{Satellite Gravity FAA}

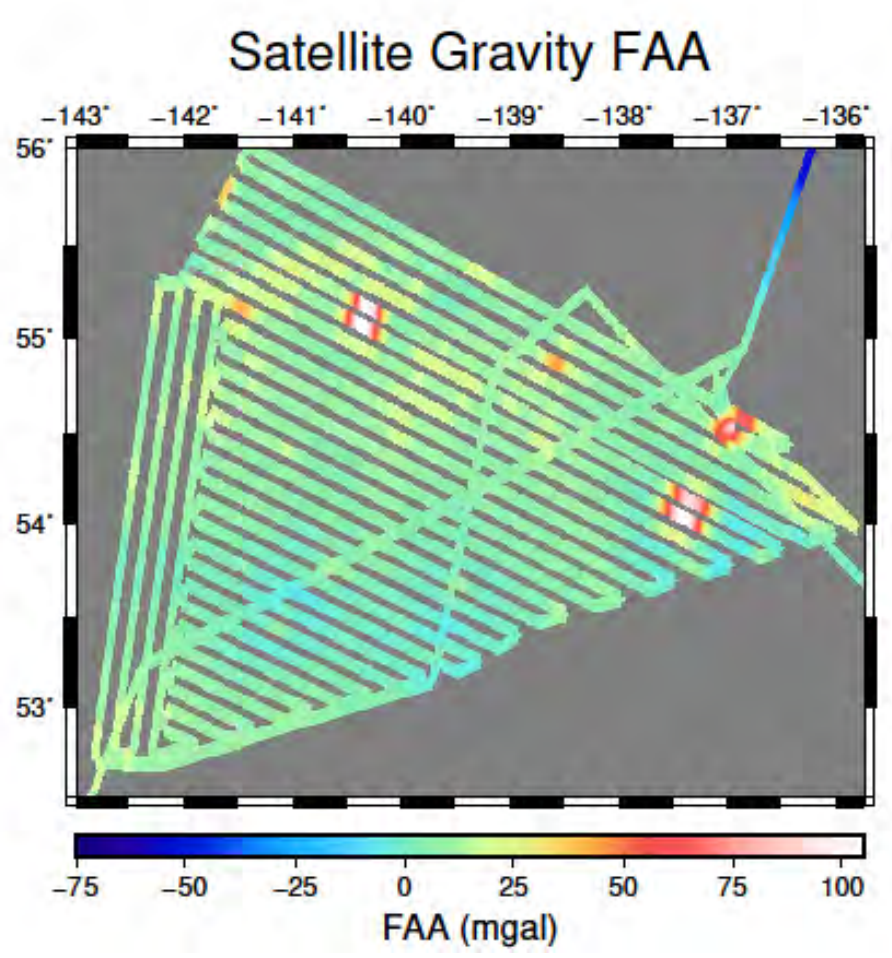

Figure E.1. Comparison of shifted marine gravity to satellite free-air anomoly. The shift of +200 mgal was an estimate to best match magnitudes of the two datasets for visual comparison only. Note the large discepency in most negative values during the last 4 days of the expedition along the southern survey area terminus and the north-northeast / southsouthwest heading lines on the western edge, along with the cross-lines through the survey region. 


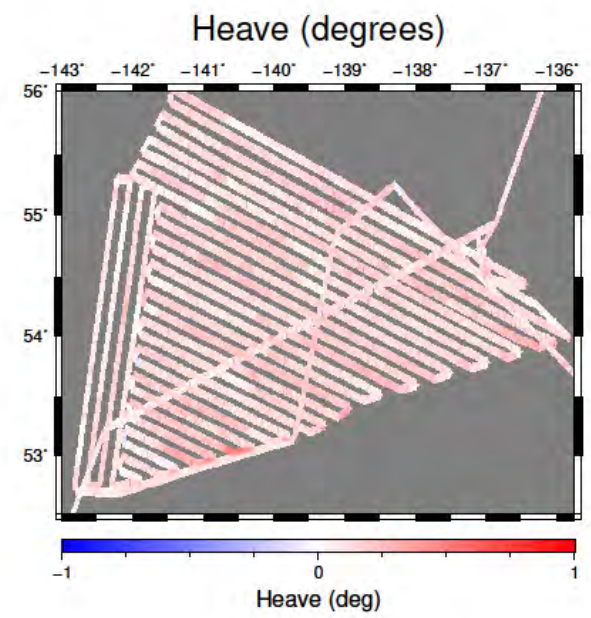

Pitch (degrees)

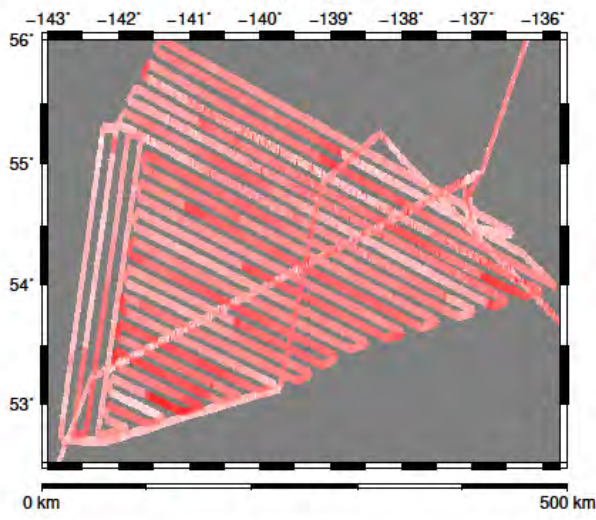

Roll (degrees)

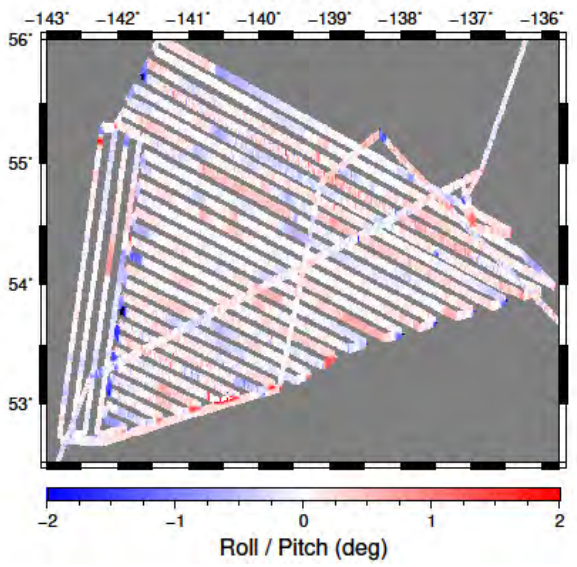

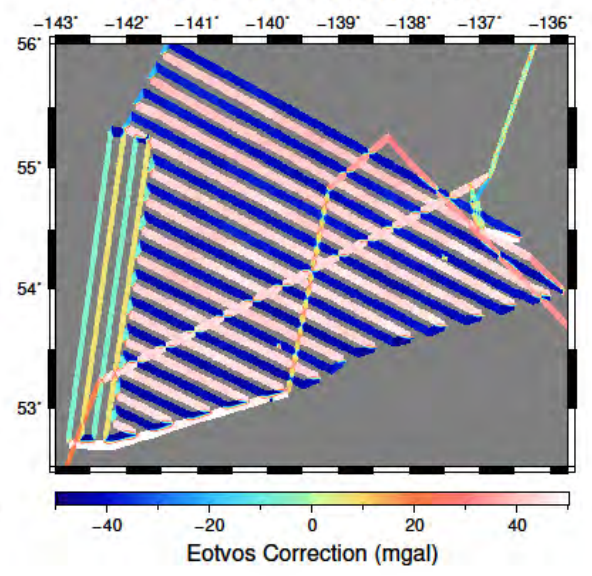

Filtered Absolute Gravity

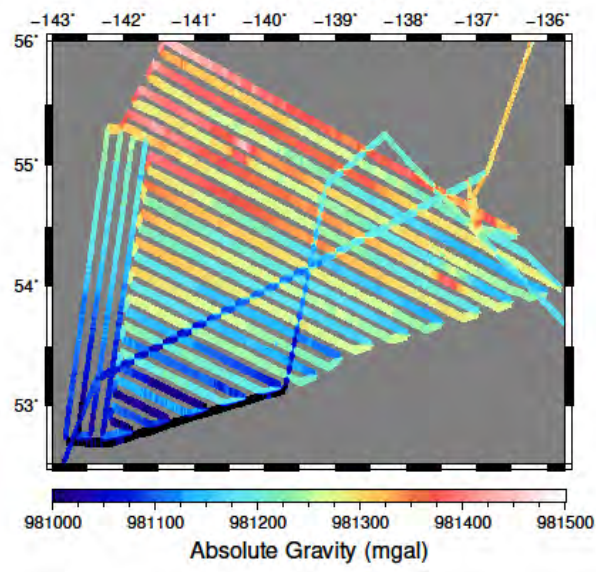

Eotvos Correction Factor

Reduced Gravity

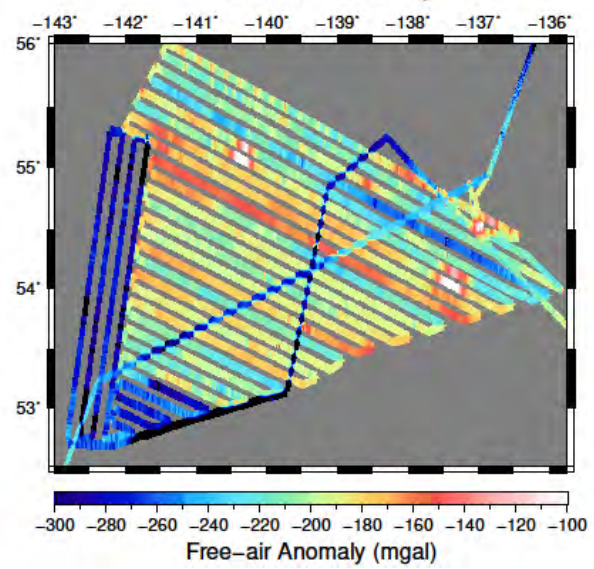

Figure E.2.

Ship

dynamics

plotted on the

left three-

figure panel

show no

correlation to

the quality of

data collected

plotted in the

right side

three-figure

panel. The

right hand

plots show

the filtered

absolute

gravity along

with the

Eötvös

correction

factor to

illustrate that

the erroneous

FAA data

were not an

introduced

artifact of

data

reduction. 


\section{Appendix F: Post-Cruise Cross-Swath Analyses (by Dr. James V. Gardner)}
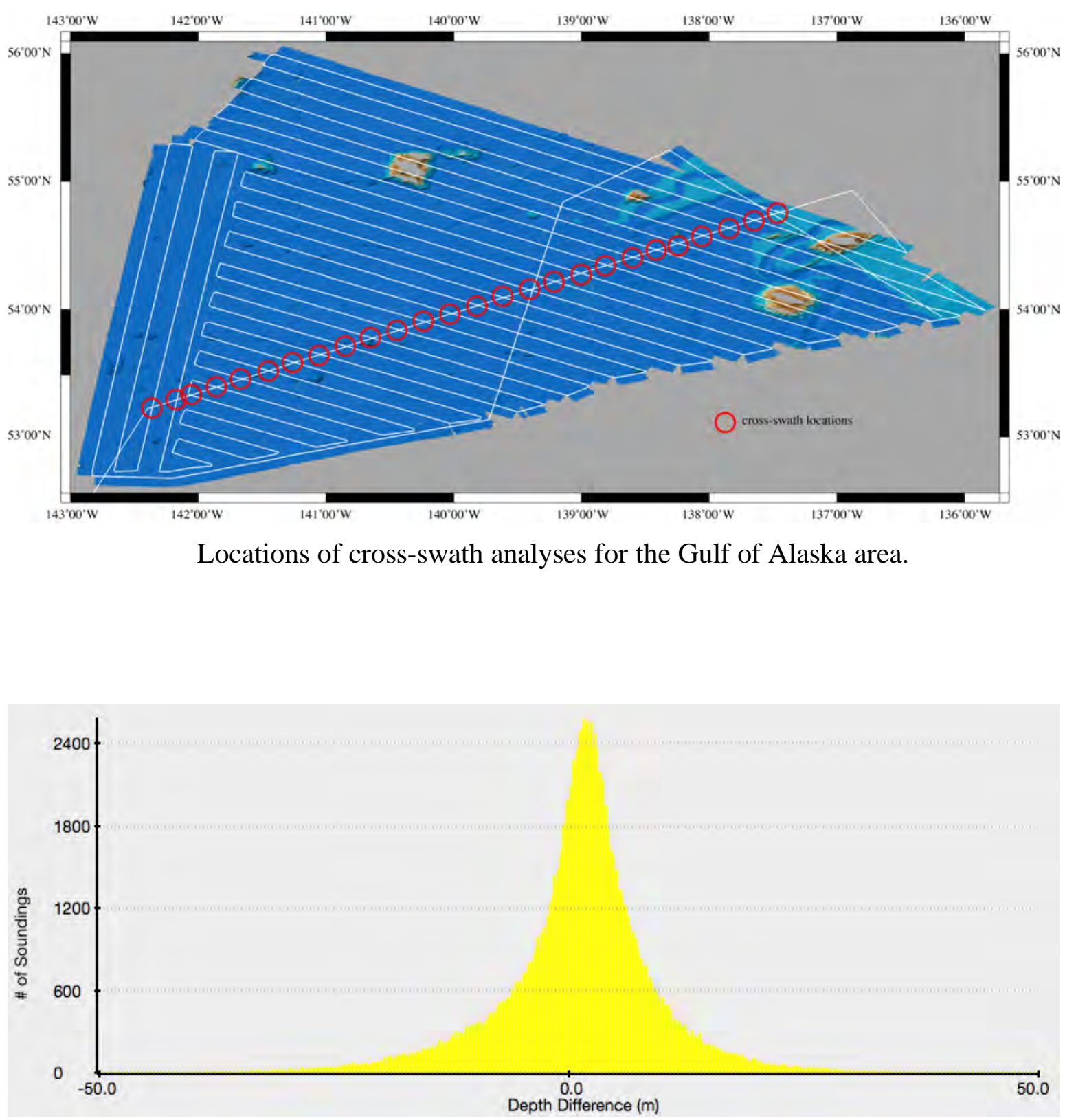

Histogram of sounding-depth differences from cross-line check of Line 343 and dipline 230 (smooth bathymetry). Kongsberg Maritime EM122.

Cross check statistics for the above lines.

\begin{tabular}{|c|c|c|}
\hline Line 343 vs dipline 230 & Mean water depth & $3845 \mathrm{~m}$ \\
\hline & Mean Z difference & $1.21 \mathrm{~m}$ \\
\hline & Standard deviation & $8.70 \mathrm{~m}$ \\
\hline & Number of samples & 150,628 \\
\hline & Percent of water depth & $0.48 \%$ at $2 \sigma$ \\
\hline
\end{tabular}




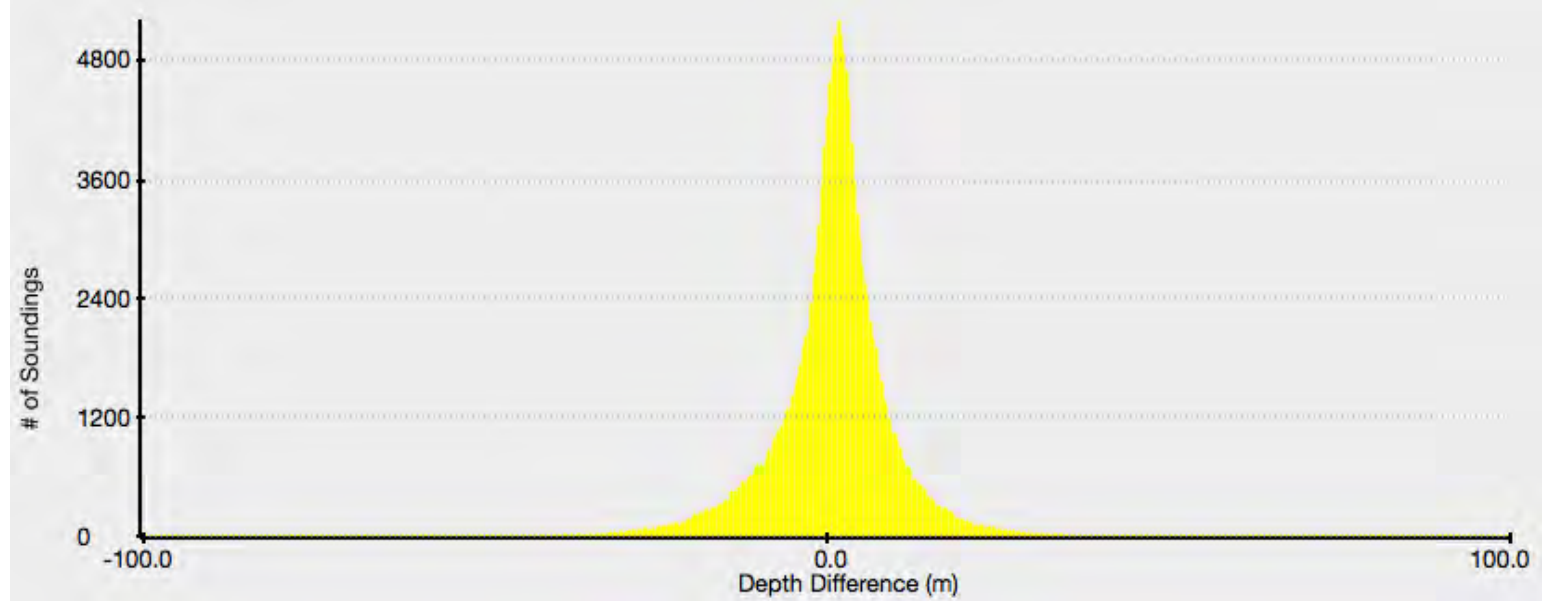

Histogram of sounding-depth differences from cross-line check of Line 328 and dipline 230 (smooth bathymetry). Kongsberg Maritime EM122.

Cross check statistics for the above lines.

\begin{tabular}{|l|c|c|}
\hline Line 328 vs dipline 230 & Mean water depth & $3805 \mathrm{~m}$ \\
\hline & Mean Z difference & $-0.54 \mathrm{~m}$ \\
\hline & Standard deviation & $11.97 \mathrm{~m}$ \\
\hline & Number of samples & 168,805 \\
\hline & Percent of water depth & $0.61 \%$ at $2 \sigma$ \\
\hline
\end{tabular}

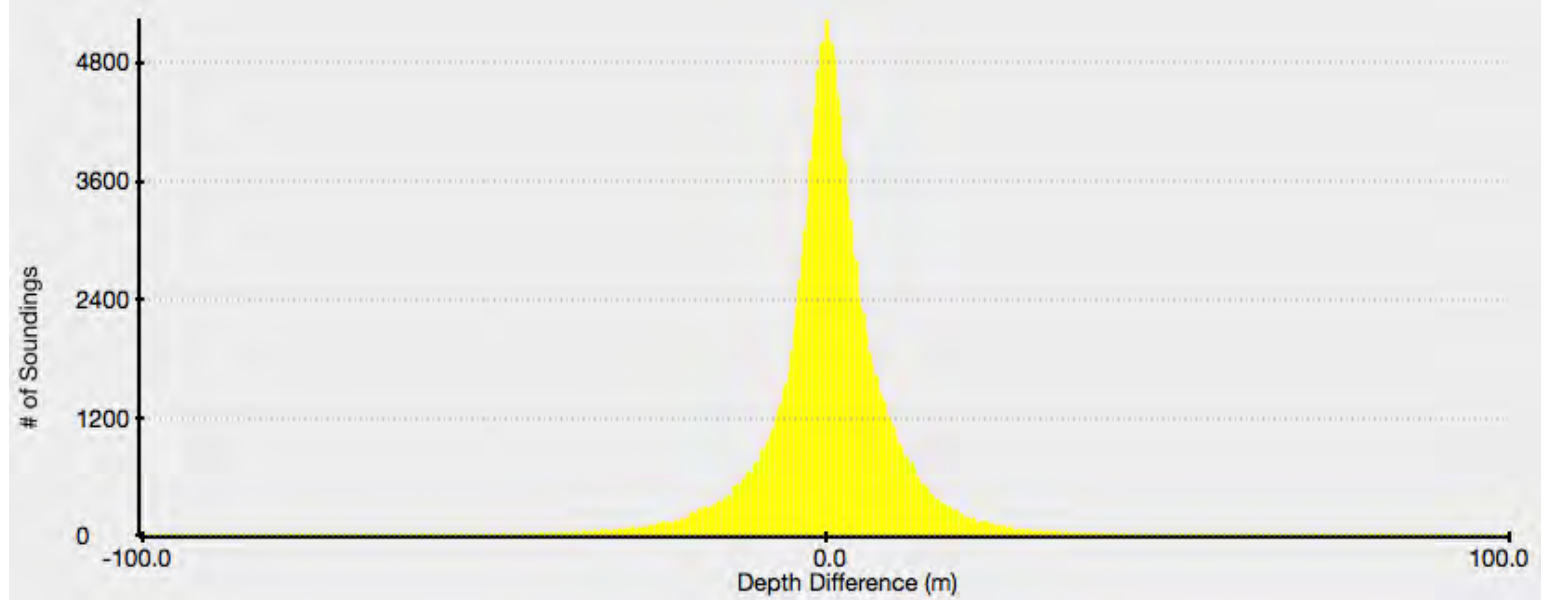

Histogram of sounding-depth differences from cross-line check of Line 330 and dipline 230 (smooth bathymetry). Kongsberg Maritime EM122.

Cross check statistics for the above lines.

\begin{tabular}{|c|c|c|}
\hline Line 330 vs dipline 230 & Mean water depth & $3824 \mathrm{~m}$ \\
\hline & Mean Z difference & $0.50 \mathrm{~m}$ \\
\hline & Standard deviation & $11.06 \mathrm{~m}$ \\
\hline & Number of samples & 165,926 \\
\hline & Percent of water depth & $0.59 \%$ at $2 \sigma$ \\
\hline
\end{tabular}




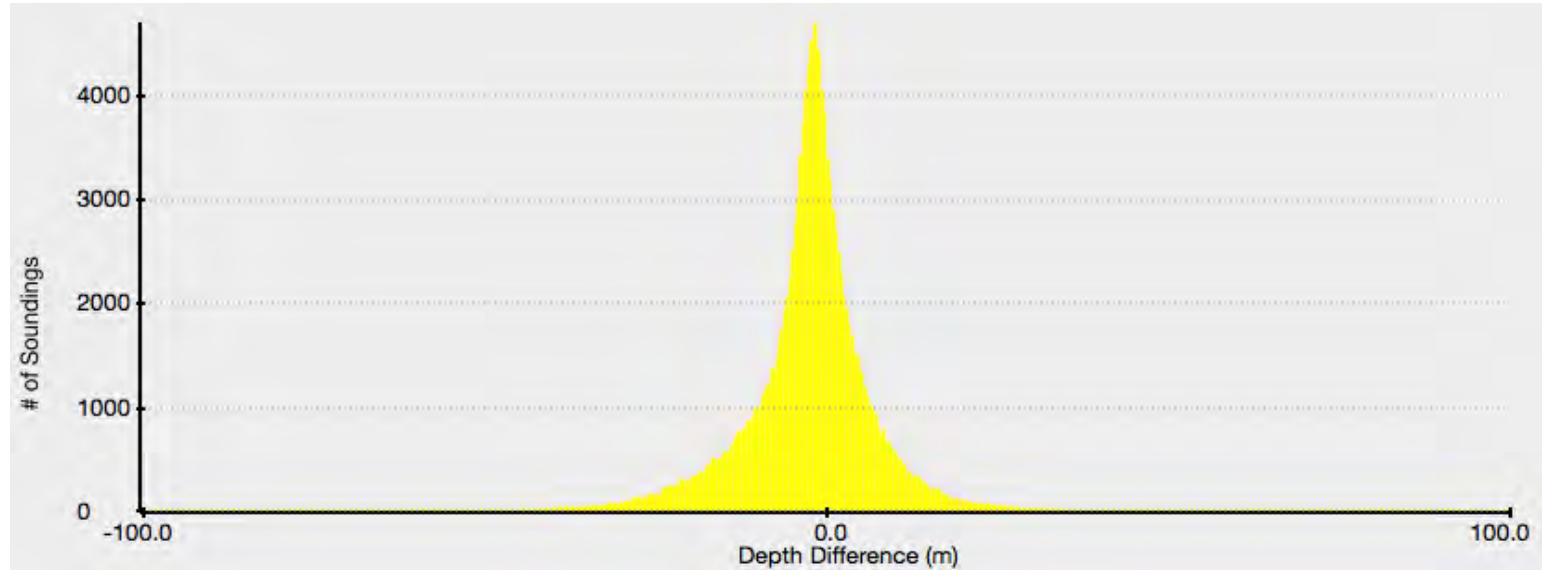

Histogram of sounding-depth differences from cross-line check of Line 320 and dipline 230 (smooth bathymetry). Kongsberg Maritime EM122.

Cross check statistics for the above lines.

\begin{tabular}{|c|c|c|}
\hline Line 320 vs dipline 230 & Mean water depth & $3760 \mathrm{~m}$ \\
\hline & Mean Z difference & $-2.38 \mathrm{~m}$ \\
\hline & Standard deviation & $9.60 \mathrm{~m}$ \\
\hline & Number of samples & 139,884 \\
\hline & Percent of water depth & $0.45 \%$ at $2 \mathrm{\sigma}$ \\
\hline
\end{tabular}

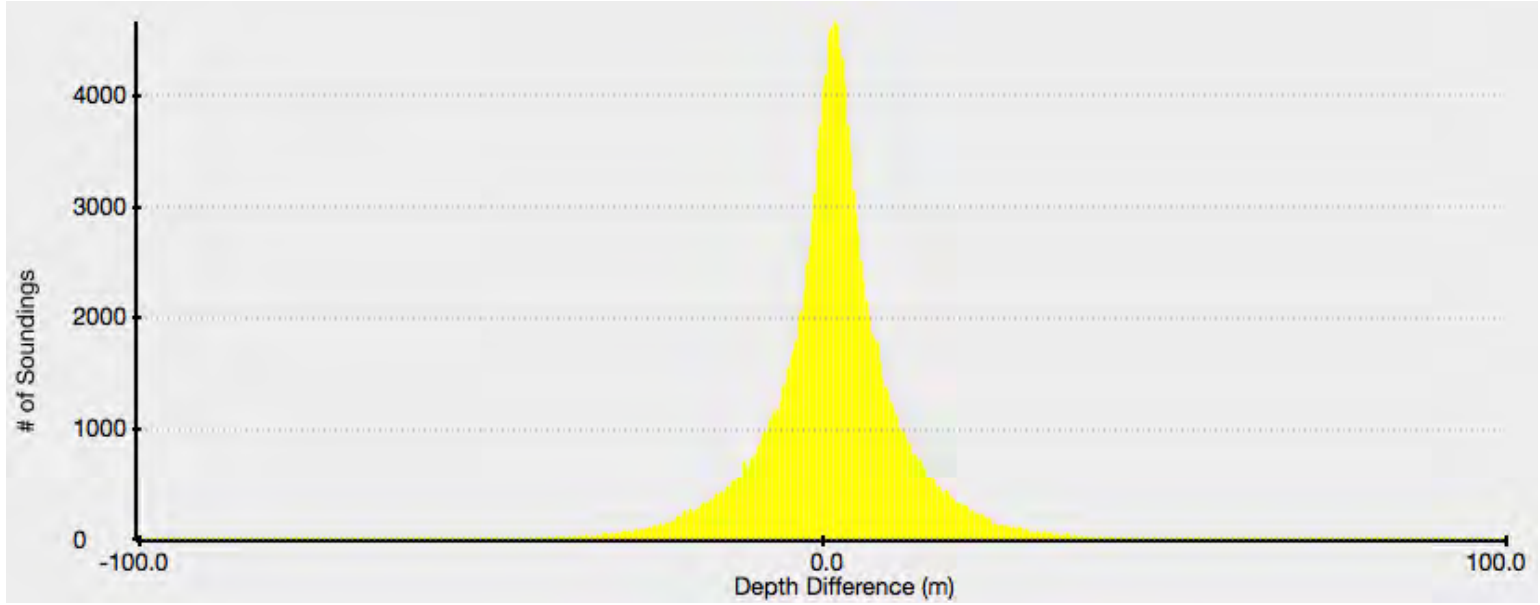

Histogram of sounding-depth differences from cross-line check of Line 323 and dipline 230 (smooth bathymetry). Kongsberg Maritime EM122.

Cross check statistics for the above lines.

\begin{tabular}{|c|c|c|}
\hline Line 323 vs dipline 230 & Mean water depth & $3795 \mathrm{~m}$ \\
\hline & Mean $\mathrm{Z}$ difference & $1.86 \mathrm{~m}$ \\
\hline & Standard deviation & $10.13 \mathrm{~m}$ \\
\hline & Number of samples & 160,300 \\
\hline & Percent of water depth & $0.52 \%$ at $2 \sigma$ \\
\hline
\end{tabular}




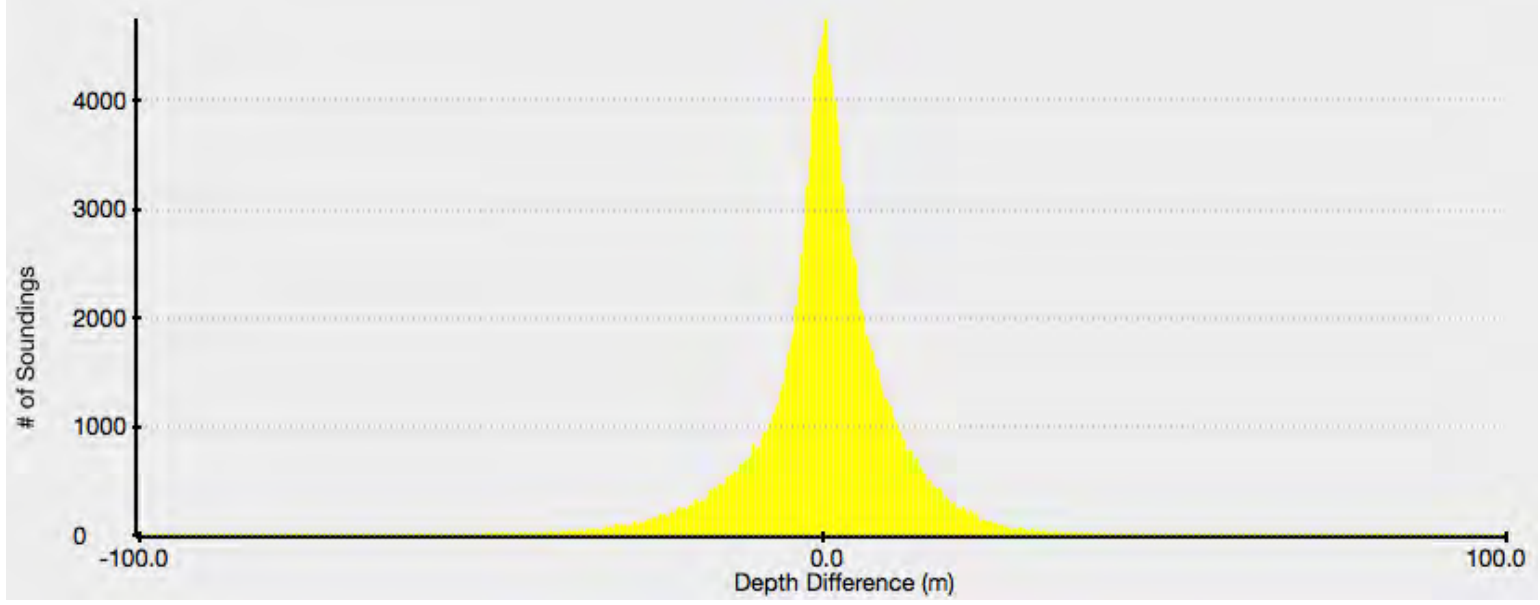

Histogram of sounding-depth differences from cross-line check of Line 326 and dipline 230 (smooth bathymetry). Kongsberg Maritime EM122.

Cross check statistics for the above lines.

\begin{tabular}{|c|c|c|}
\hline Line 326 vs dipline 230 & Mean water depth & $3809 \mathrm{~m}$ \\
\hline & Mean Z difference & $0.37 \mathrm{~m}$ \\
\hline & Standard deviation & $11.26 \mathrm{~m}$ \\
\hline & Number of samples & 158,172 \\
\hline & Percent of water depth & $0.60 \%$ at $2 \sigma$ \\
\hline
\end{tabular}

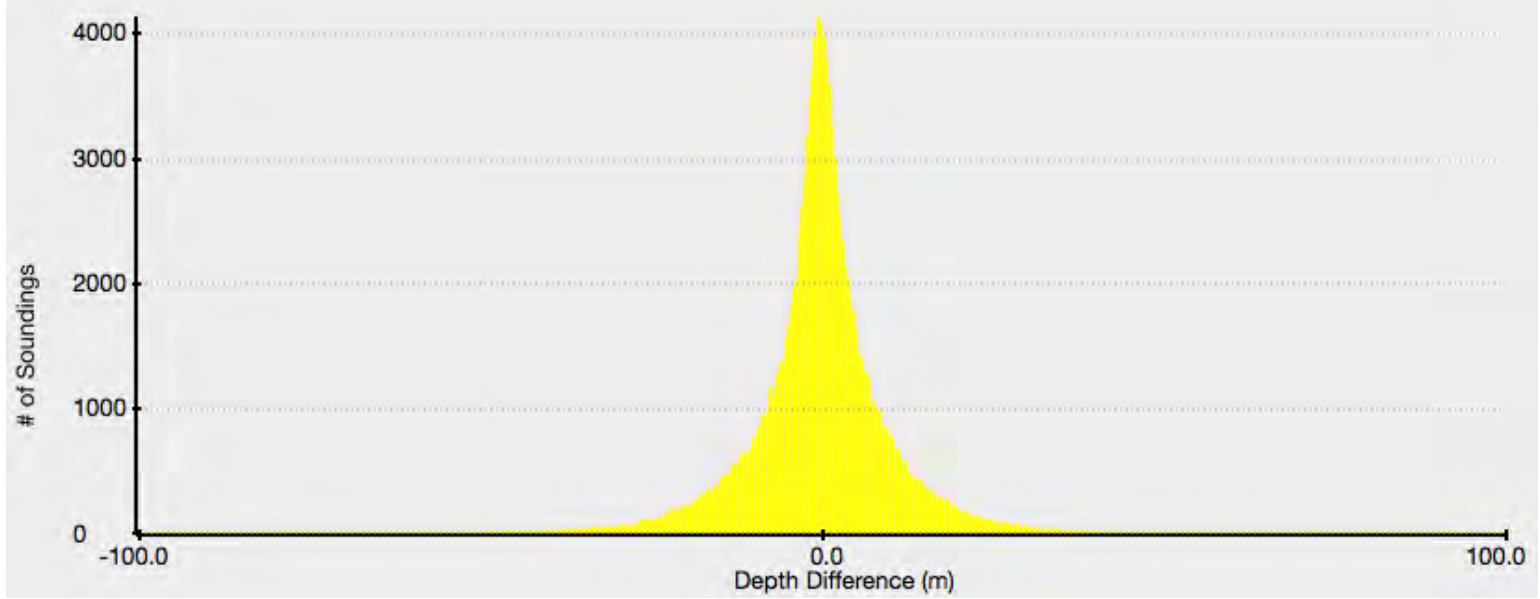

Histogram of sounding-depth differences from cross-line check of Line 314 and dipline 231 (smooth bathymetry). Kongsberg Maritime EM122.

Cross check statistics for the above lines.

\begin{tabular}{|c|c|c|}
\hline Line 314 vs dipline 231 & Mean water depth & $3718 \mathrm{~m}$ \\
\hline & Mean Z difference & $--0.53 \mathrm{~m}$ \\
\hline & Standard deviation & $11.84 \mathrm{~m}$ \\
\hline & Number of samples & 131,847 \\
\hline & Percent of water depth & $0.62 \%$ at $2 \mathrm{\sigma}$ \\
\hline
\end{tabular}




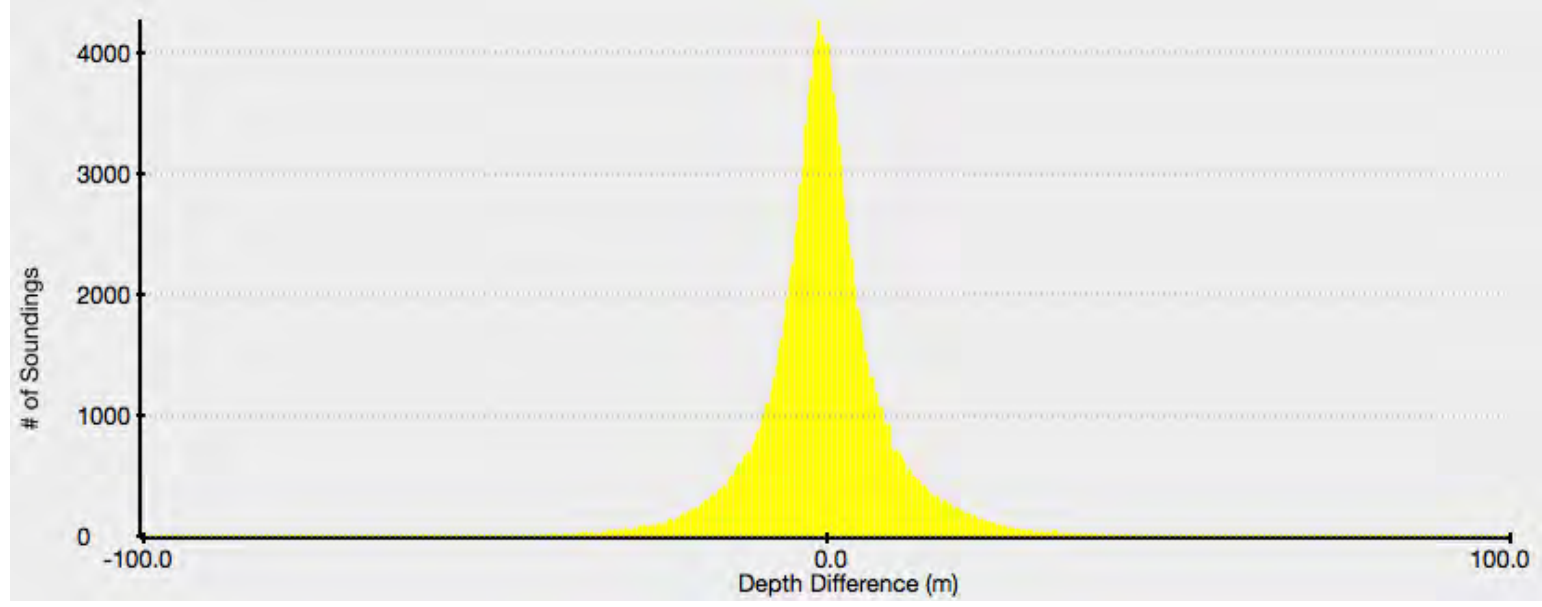

Histogram of sounding-depth differences from cross-line check of Line X307 and dipline 231 (smooth bathymetry). Kongsberg Maritime EM122.

Cross check statistics for the above lines.

\begin{tabular}{|c|c|c|}
\hline Line 307 vs dipline 231 & Mean water depth & $3884 \mathrm{~m}$ \\
\hline & Mean Z difference & $-0.23 \mathrm{~m}$ \\
\hline & Standard deviation & $10.0 \mathrm{~m}$ \\
\hline & Number of samples & 145,241 \\
\hline & Percent of water depth & $0.51 \%$ at $2 \sigma$ \\
\hline
\end{tabular}

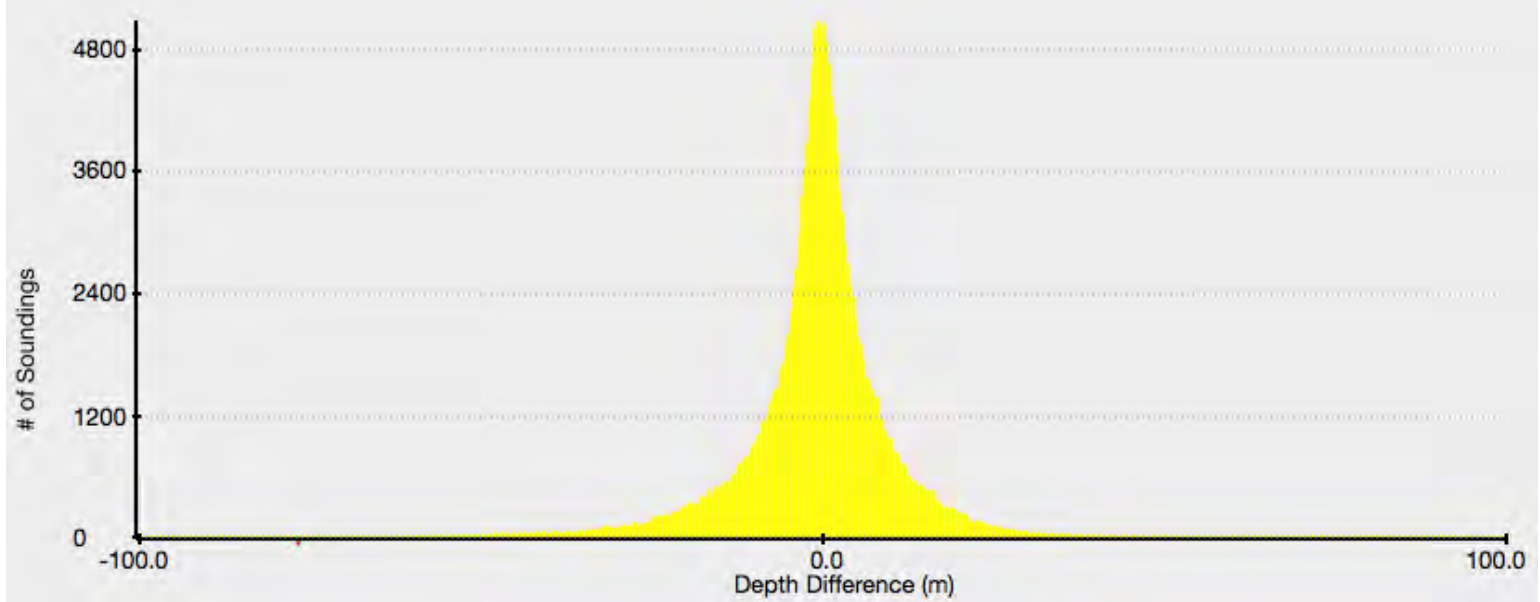

Histogram of sounding-depth differences from cross-line check of Line 310 and dipline 231 (smooth bathymetry). Kongsberg Maritime EM122.

Cross check statistics for the above lines.

\begin{tabular}{|c|c|c|}
\hline Line 310 vs dipline 231 & Mean water depth & $3519 \mathrm{~m}$ \\
\hline & Mean Z difference & $-1.31 \mathrm{~m}$ \\
\hline & Standard deviation & $9.60 \mathrm{~m}$ \\
\hline & Number of samples & 153,927 \\
\hline & Percent of water depth & $0.51 \%$ at $2 \sigma$ \\
\hline
\end{tabular}




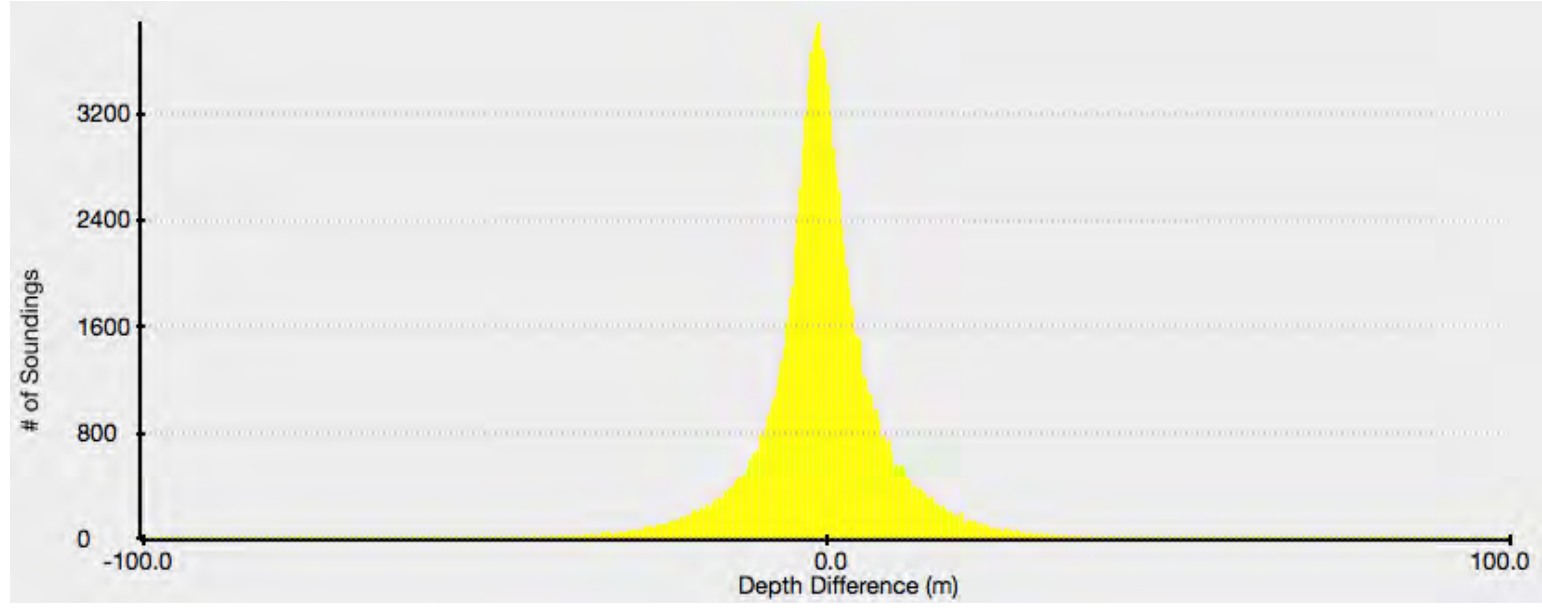

Histogram of sounding-depth differences from cross-line check of Line 300 and dipline 231 (smooth bathymetry). Kongsberg Maritime EM122.

Cross check statistics for the above lines.

\begin{tabular}{|c|c|c|}
\hline Line 300 vs dipline 231 & Mean water depth & $3493 \mathrm{~m}$ \\
\hline & Mean Z difference & $-0.60 \mathrm{~m}$ \\
\hline & Standard deviation & $9.88 \mathrm{~m}$ \\
\hline & Number of samples & 121,782 \\
\hline & Percent of water depth & $0.55 \%$ at $2 \sigma$ \\
\hline
\end{tabular}

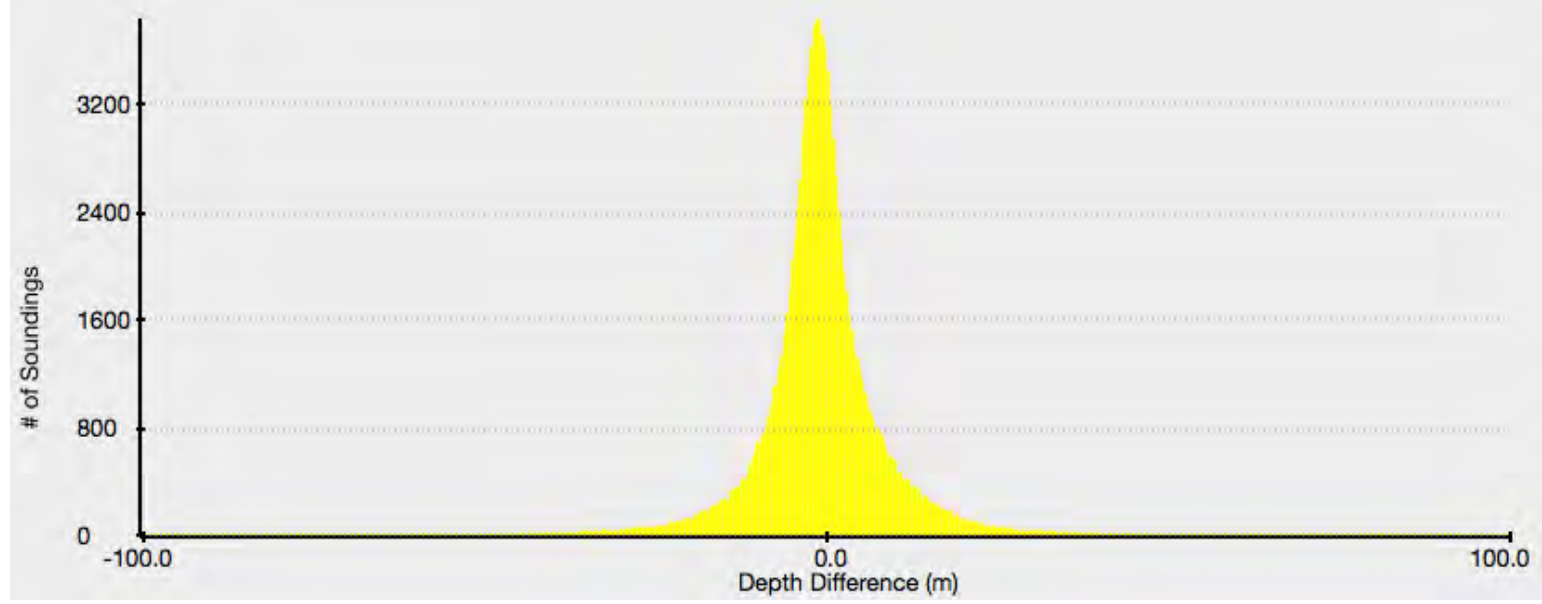

Histogram of sounding-depth differences from cross-line check of Line 305 and dipline 231 (smooth bathymetry). Kongsberg Maritime EM122.

Cross check statistics for the above lines.

\begin{tabular}{|c|c|c|}
\hline Line 305 vs dipline 231 & Mean water depth & $3504 \mathrm{~m}$ \\
\hline & Mean Z difference & $-0.64 \mathrm{~m}$ \\
\hline & Standard deviation & $9.90 \mathrm{~m}$ \\
\hline & Number of samples & 115,000 \\
\hline & Percent of water depth & $0.55 \%$ at $2 \sigma$ \\
\hline
\end{tabular}




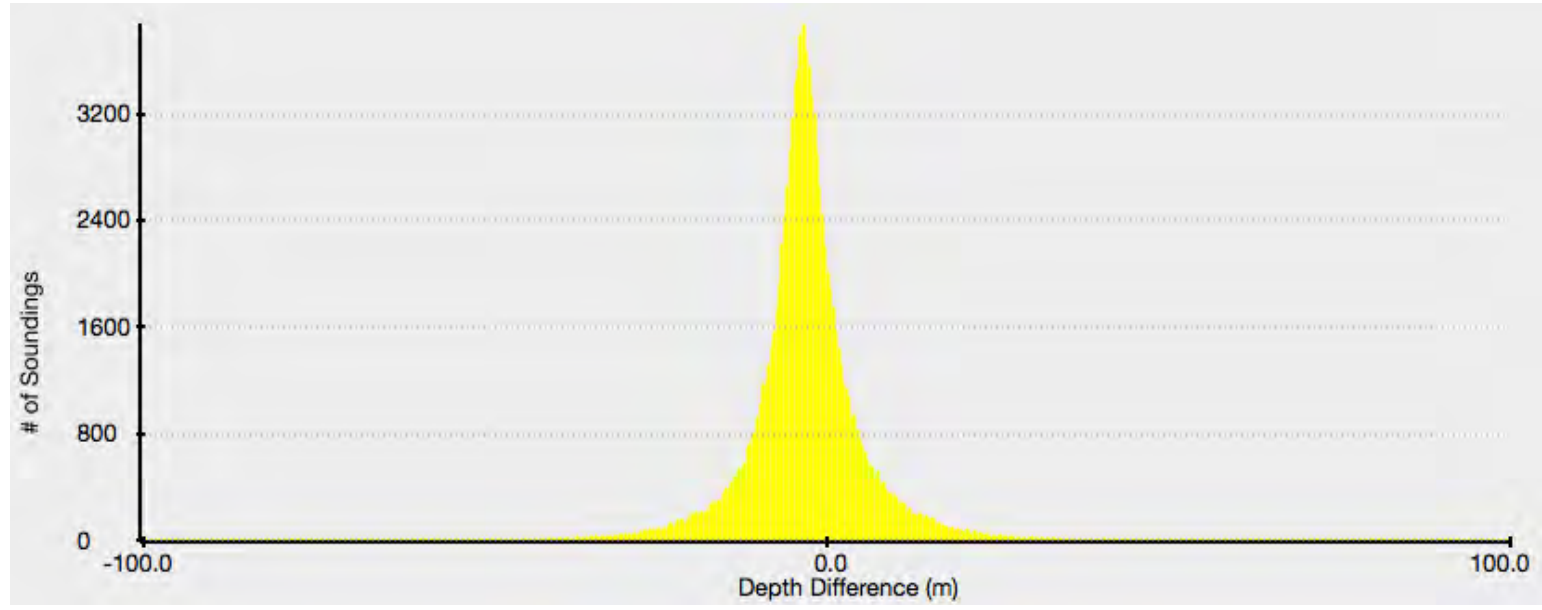

Histogram of sounding-depth differences from cross-line check of Line 293 and dipline 231 (smooth bathymetry). Kongsberg Maritime EM122.

Cross check statistics for the above lines.

\begin{tabular}{|c|c|c|}
\hline Line 293 vs dipline 231 & Mean water depth & $3406 \mathrm{~m}$ \\
\hline & Mean Z difference & $-2.86 \mathrm{~m}$ \\
\hline & Standard deviation & $9.11 \mathrm{~m}$ \\
\hline & Number of samples & 107,347 \\
\hline & Percent of water depth & $0.45 \%$ at $2 \sigma$ \\
\hline
\end{tabular}

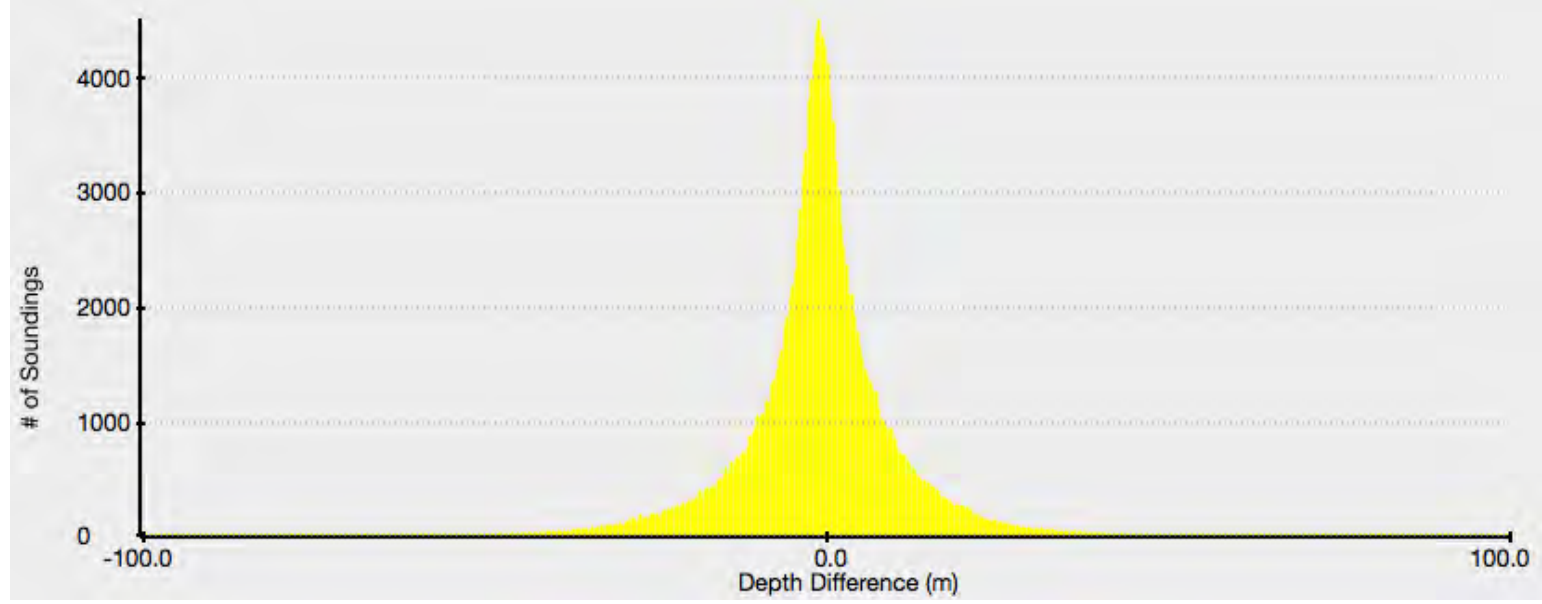

Histogram of sounding-depth differences from cross-line check of Line 297 and dipline 231 (smooth bathymetry). Kongsberg Maritime EM122.

Cross check statistics for the above lines.

\begin{tabular}{|c|c|c|}
\hline Line 297 vs dipline 231 & Mean water depth & $3466 \mathrm{~m}$ \\
\hline & Mean Z difference & $-0.91 \mathrm{~m}$ \\
\hline & Standard deviation & $11.22 \mathrm{~m}$ \\
\hline & Number of samples & 153,647 \\
\hline & Percent of water depth & $0.62 \%$ at $2 \sigma$ \\
\hline
\end{tabular}




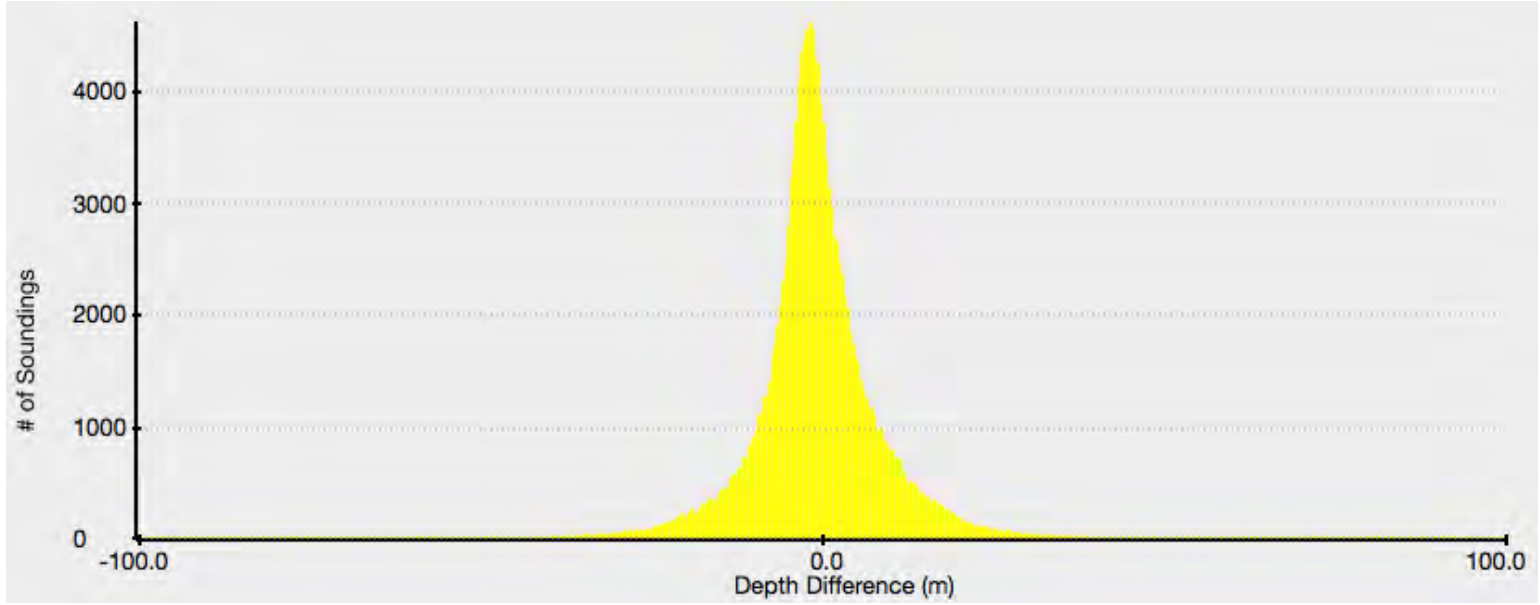

Histogram of sounding-depth differences from cross-line check of Line 289 and dipline 231 (smooth bathymetry). Kongsberg Maritime EM122.

Cross check statistics for the above lines.

\begin{tabular}{|c|c|c|}
\hline Line 289 vs dipline 231 & Mean water depth & $3317 \mathrm{~m}$ \\
\hline & Mean Z difference & $-0.57 \mathrm{~m}$ \\
\hline & Standard deviation & $9.54 \mathrm{~m}$ \\
\hline & Number of samples & 149,782 \\
\hline & Percent of water depth & $0.56 \%$ at $2 \sigma$ \\
\hline
\end{tabular}

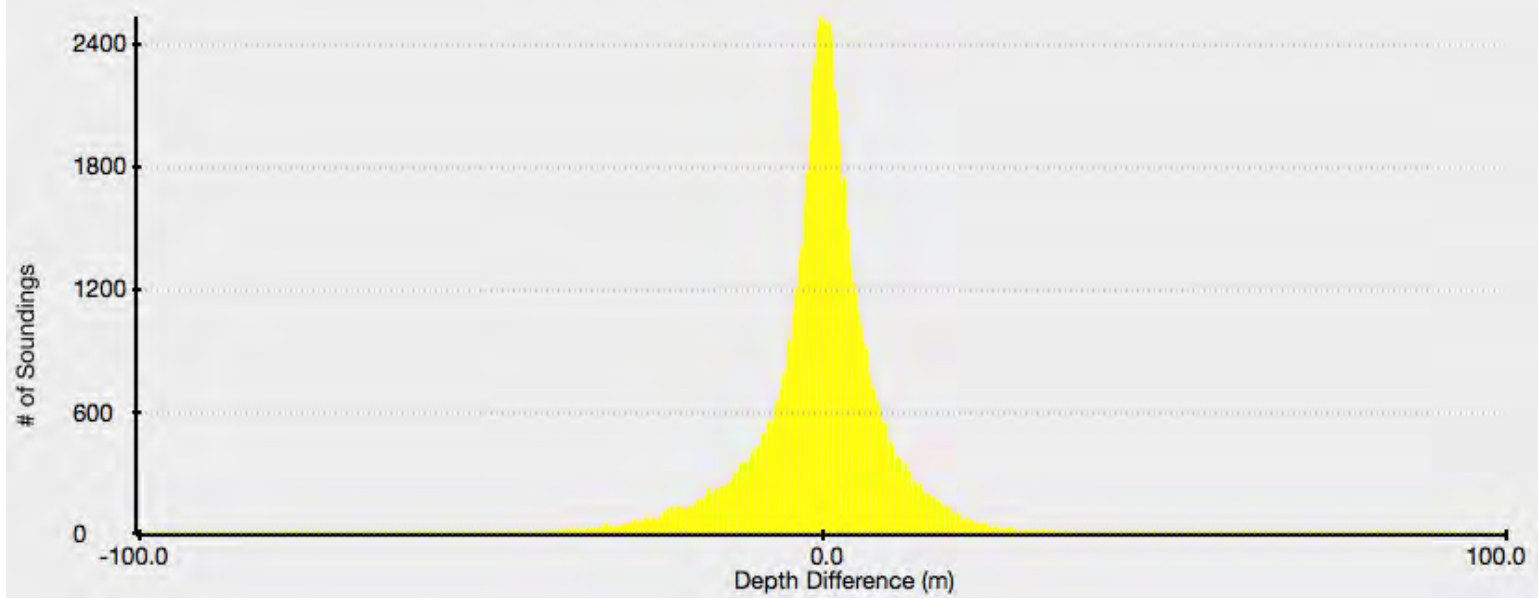

Histogram of sounding-depth differences from cross-line check of Line 285 and dipline 232 (smooth bathymetry). Kongsberg Maritime EM122.

Cross check statistics for the above lines.

\begin{tabular}{|c|c|c|}
\hline Line 285 vs dipline 232 & Mean water depth & $3250 \mathrm{~m}$ \\
\hline & Mean Z difference & $-0.24 \mathrm{~m}$ \\
\hline & Standard deviation & $9.55 \mathrm{~m}$ \\
\hline & Number of samples & 79,461 \\
\hline & Percent of water depth & $0.58 \%$ at $2 \sigma$ \\
\hline
\end{tabular}




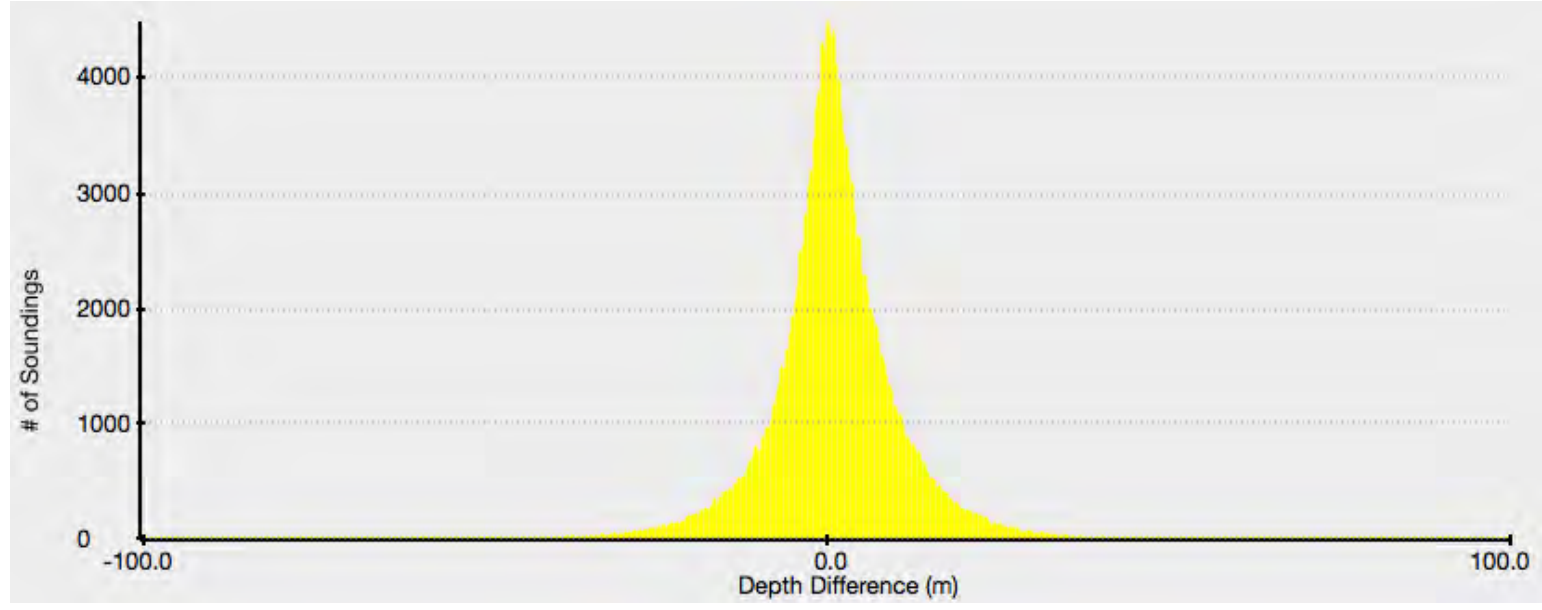

Histogram of sounding-depth differences from cross-line check of Line 276 and dipline 232 (smooth bathymetry). Kongsberg Maritime EM122.

Cross check statistics for the above lines.

\begin{tabular}{|c|c|c|}
\hline Line 276 vs dipline 232 & Mean water depth & $3164 \mathrm{~m}$ \\
\hline & Mean Z difference & $1.28 \mathrm{~m}$ \\
\hline & Standard deviation & $9.54 \mathrm{~m}$ \\
\hline & Number of samples & 158,489 \\
\hline & Percent of water depth & $0.64 \%$ at $2 \sigma$ \\
\hline
\end{tabular}

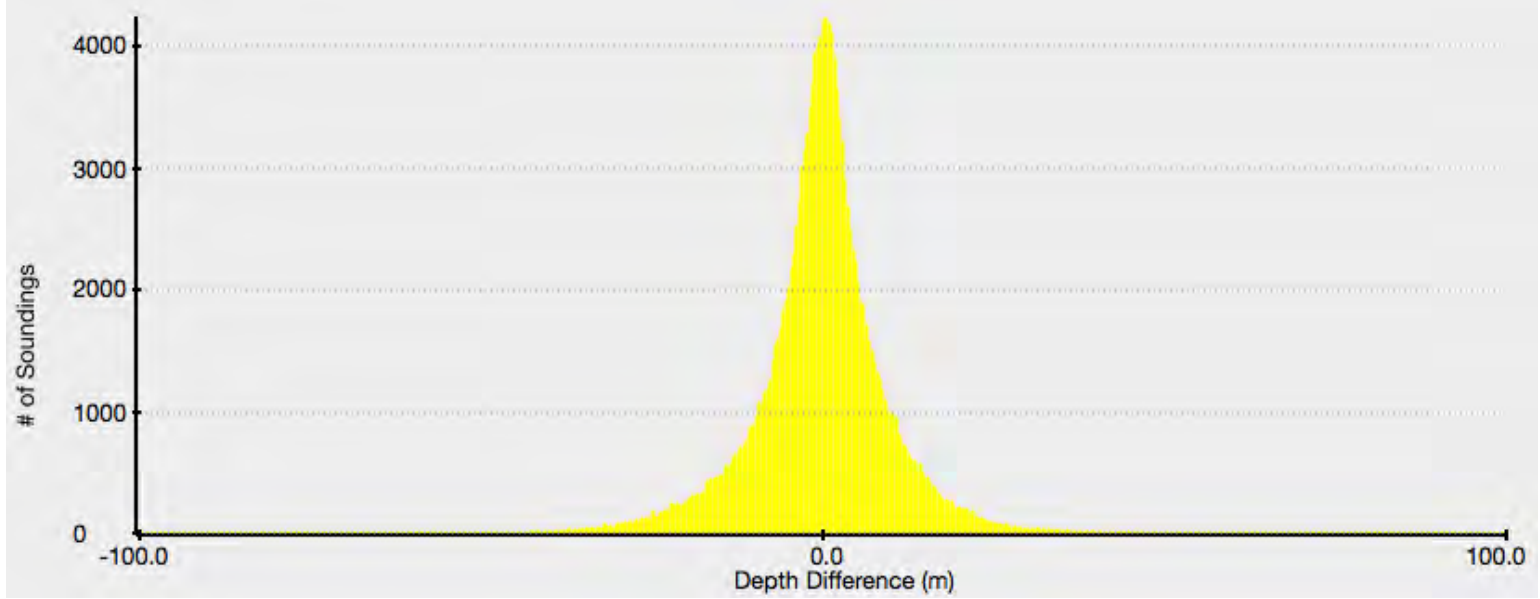

Histogram of sounding-depth differences from cross-line check of Line 281 and dipline 232 (smooth bathymetry). Kongsberg Maritime EM122.

Cross check statistics for the above lines.

\begin{tabular}{|c|c|c|}
\hline Line 281 vs dipline 232 & Mean water depth & $3183 \mathrm{~m}$ \\
\hline & Mean Z difference & $-0.05 \mathrm{~m}$ \\
\hline & Standard deviation & $10.20 \mathrm{~m}$ \\
\hline & Number of samples & 156,530 \\
\hline & Percent of water depth & $0.64 \%$ at $2 \sigma$ \\
\hline
\end{tabular}




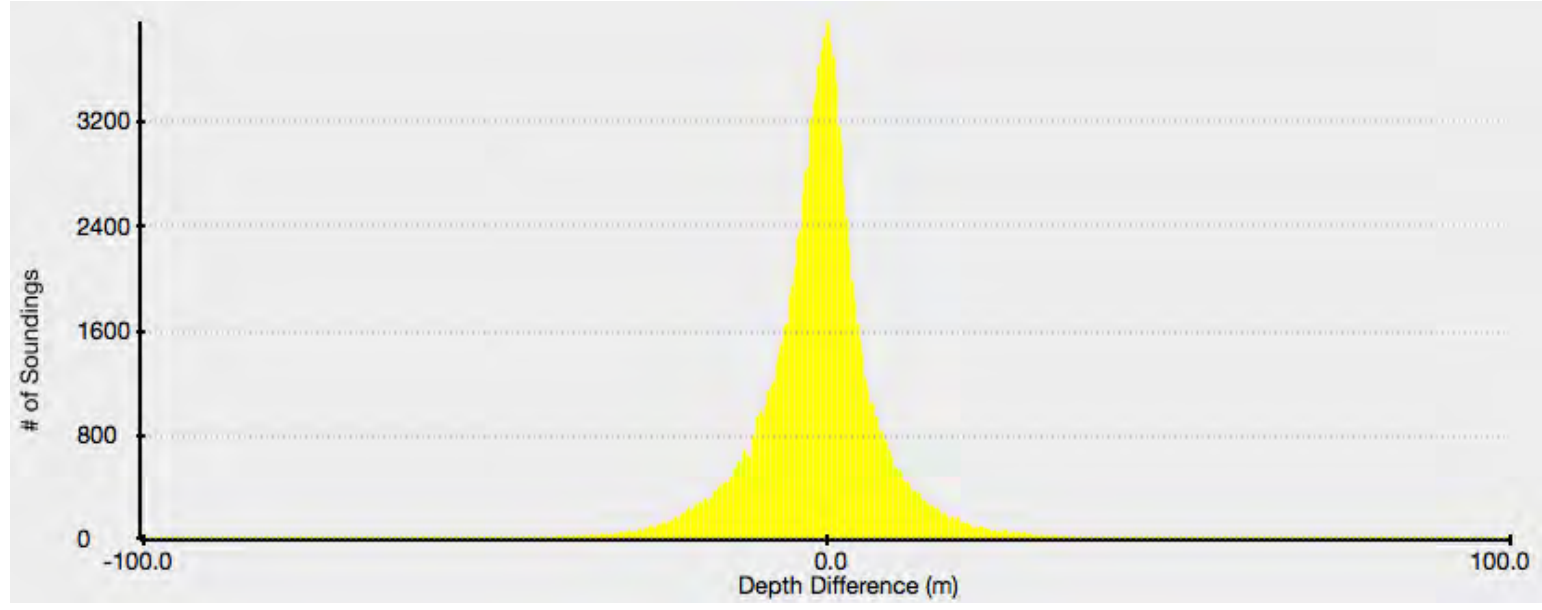

Histogram of sounding-depth differences from cross-line check of Line 271 and dipline 232 (smooth bathymetry). Kongsberg Maritime EM122.

Cross check statistics for the above lines.

\begin{tabular}{|c|c|c|}
\hline Line 271 vs dipline 232 & Mean water depth & $3152 \mathrm{~m}$ \\
\hline & Mean Z difference & $-0.96 \mathrm{~m}$ \\
\hline & Standard deviation & $9.15 \mathrm{~m}$ \\
\hline & Number of samples & 127,056 \\
\hline & Percent of water depth & $0.55 \%$ at $2 \sigma$ \\
\hline
\end{tabular}

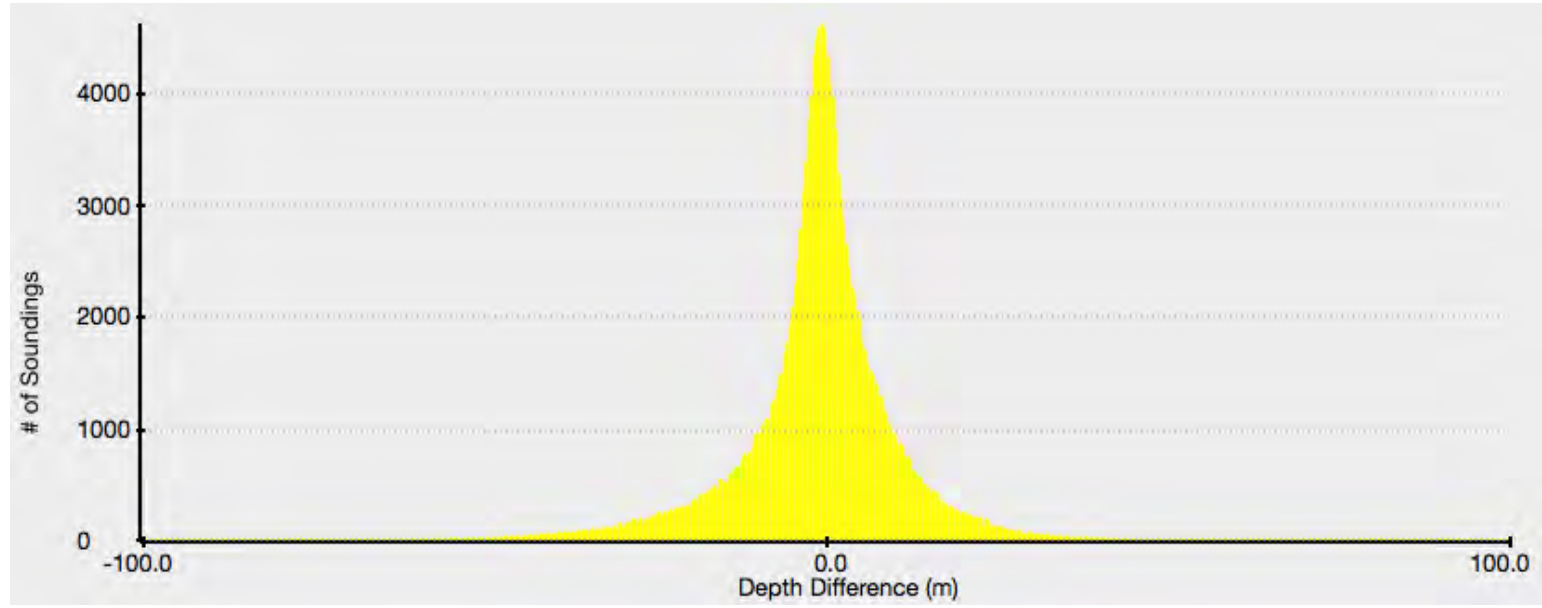

Histogram of sounding-depth differences from cross-line check of Line 266 and dipline 232 (smooth bathymetry). Kongsberg Maritime EM122.

Cross check statistics for the above lines.

\begin{tabular}{|c|c|c|}
\hline Line 266 vs dipline 232 & Mean water depth & $3136 \mathrm{~m}$ \\
\hline & Mean Z difference & $-1.10 \mathrm{~m}$ \\
\hline & Standard deviation & $11.89 \mathrm{~m}$ \\
\hline & Number of samples & 162,634 \\
\hline & Percent of water depth & $0.72 \%$ at $2 \sigma$ \\
\hline
\end{tabular}




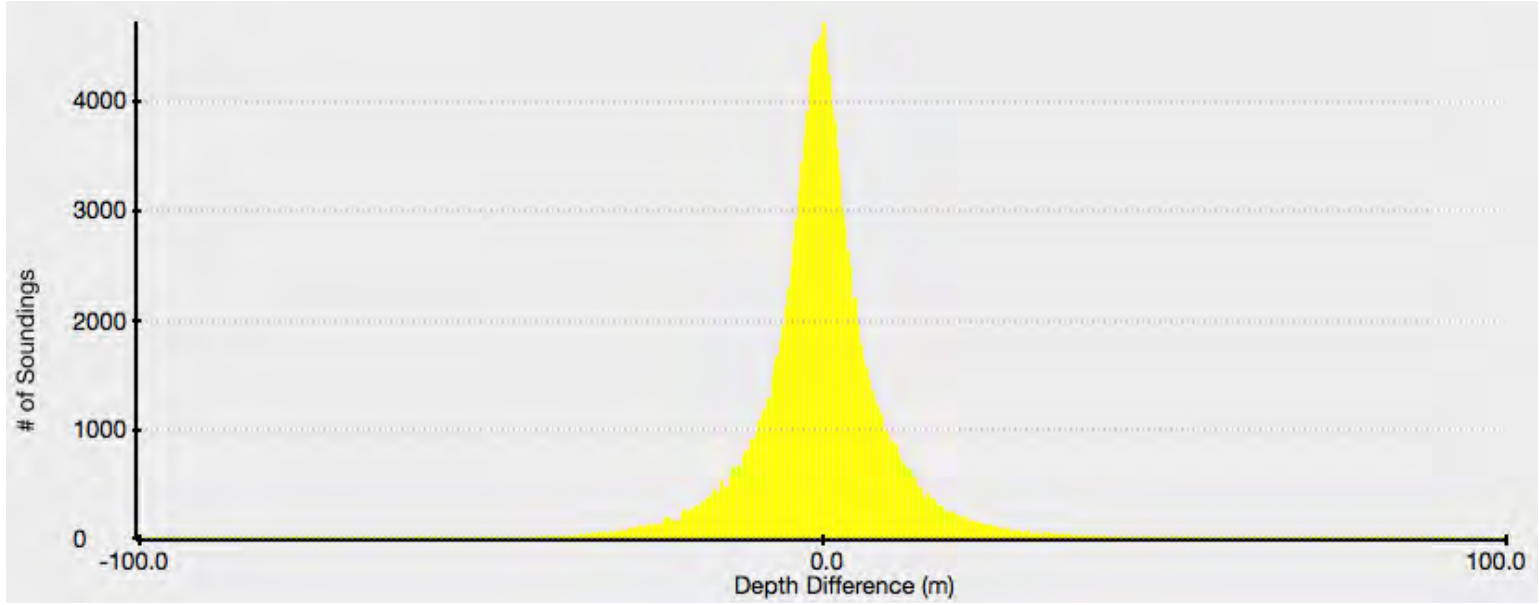

Histogram of sounding-depth differences from cross-line check of Line 262 and dipline 232 (smooth bathymetry). Kongsberg Maritime EM122.

Cross check statistics for the above lines.

\begin{tabular}{|c|c|c|}
\hline Line 262 vs dipline 232 & Mean water depth & $3116 \mathrm{~m}$ \\
\hline & Mean Z difference & $0.08 \mathrm{~m}$ \\
\hline & Standard deviation & $10.40 \mathrm{~m}$ \\
\hline & Number of samples & 160,411 \\
\hline & Percent of water depth & $0.67 \%$ at $2 \sigma$ \\
\hline
\end{tabular}

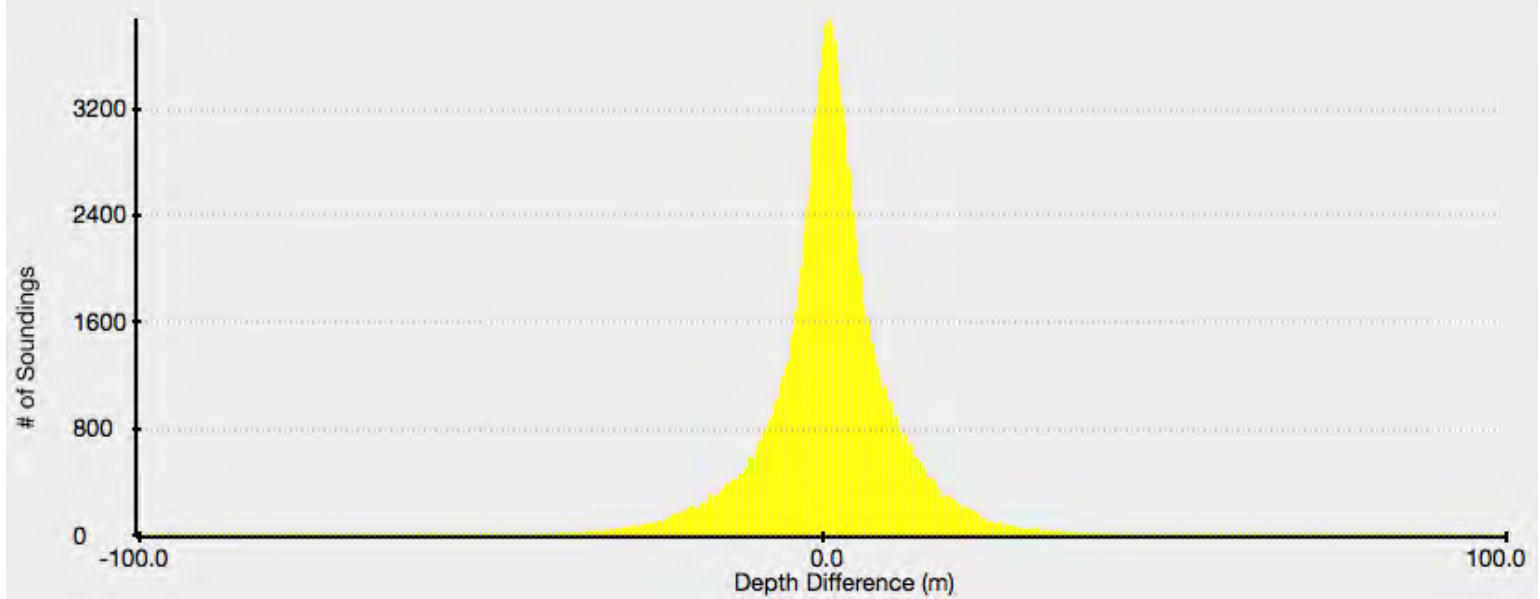

Histogram of sounding-depth differences from cross-line check of Line 253 and dipline 232 (smooth bathymetry). Kongsberg Maritime EM122.

Cross check statistics for the above lines.

\begin{tabular}{|c|c|c|}
\hline Line 253 vs dipline 232 & Mean water depth & $3048 \mathrm{~m}$ \\
\hline & Mean Z difference & $1.39 \mathrm{~m}$ \\
\hline & Standard deviation & $10.02 \mathrm{~m}$ \\
\hline & Number of samples & 132,377 \\
\hline & Percent of water depth & $0.70 \%$ at $2 \sigma$ \\
\hline
\end{tabular}




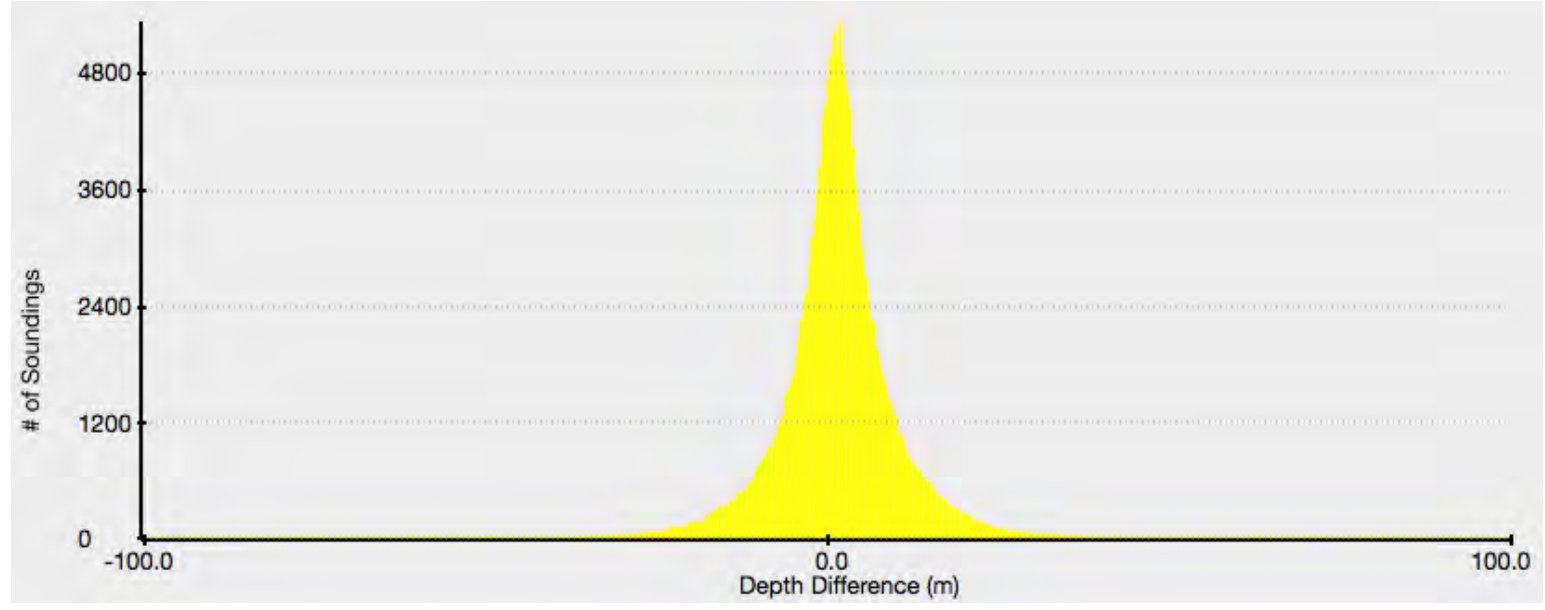

Histogram of sounding-depth differences from cross-line check of Line 256 and dipline 232 (smooth bathymetry). Kongsberg Maritime EM122.

Cross check statistics for the above lines.

\begin{tabular}{|c|c|c|}
\hline Line 256 vs dipline 232 & Mean water depth & $3082 \mathrm{~m}$ \\
\hline & Mean Z difference & $1.73 \mathrm{~m}$ \\
\hline & Standard deviation & $8.96 \mathrm{~m}$ \\
\hline & Number of samples & 167,754 \\
\hline & Percent of water depth & $0.63 \%$ at $2 \sigma$ \\
\hline
\end{tabular}

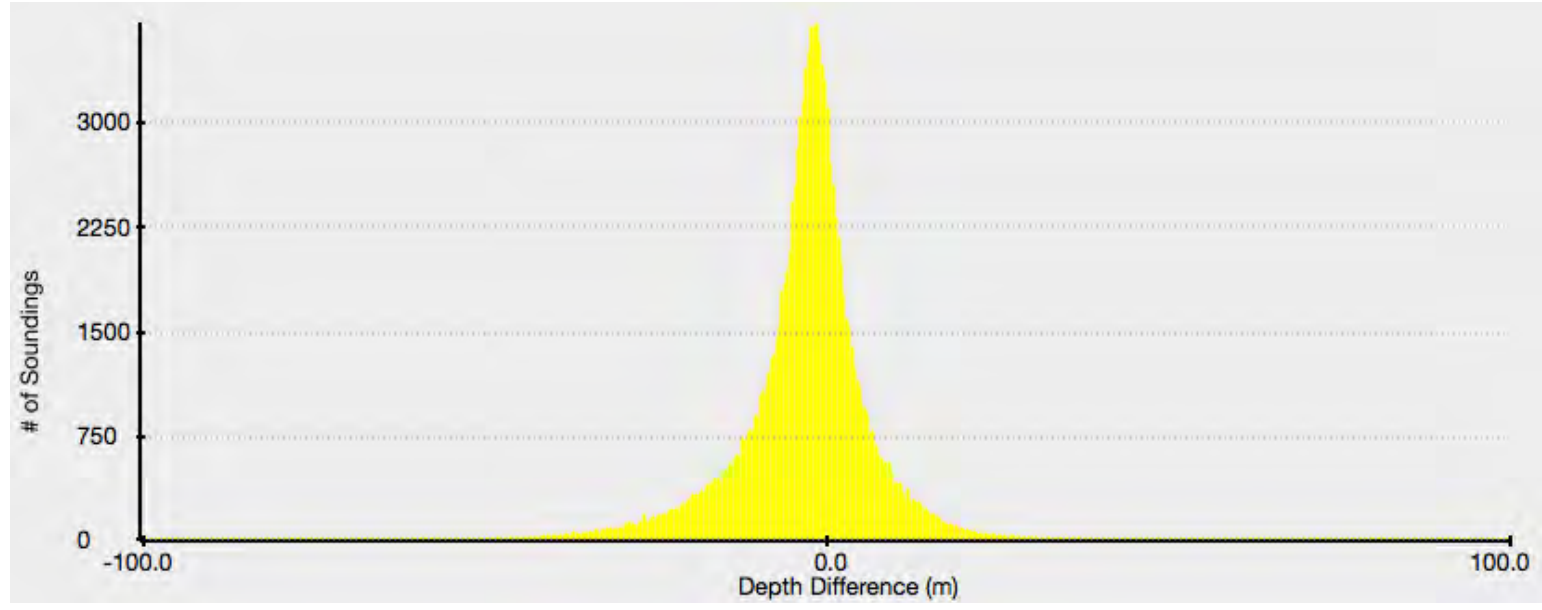

Histogram of sounding-depth differences from cross-line check of Line 247 and dipline 232 (smooth bathymetry). Kongsberg Maritime EM122.

Cross check statistics for the above lines.

\begin{tabular}{|l|c|c|}
\hline Line 247 vs dipline 232 & Mean water depth & $3026 \mathrm{~m}$ \\
\hline & Mean Z difference & $-2.95 \mathrm{~m}$ \\
\hline & Standard deviation & $10.07 \mathrm{~m}$ \\
\hline & Number of samples & 121,005 \\
\hline & Percent of water depth & $0.57 \%$ at $2 \sigma$ \\
\hline
\end{tabular}




\title{
Appendix G: Built-In Self Tests (BIST) of EM122
}

\author{
G-1. Built-in Self Test (BIST) of KM1811 EM122 conducted at the pier in Honolulu prior \\ to departure.
}

Saved: 2018.07.02 01:06:54

Sounder Type: 122, Serial no.: 109

$\begin{array}{llcc}\text { Date Time } & \text { Ser. No. } & \text { BIST } & \text { Result } \\ \text { 2018.07.02 01:00:13.777 } & 109 & 0 & \text { OK }\end{array}$

Number of BSP67B boards: 2

BSP 1 Master 2.2.3 090702 4.30709134.3070913

BSP 1 Slave 2.2.3 0907026.0080902

BSP 1 RXI FPGA 3.6080821

BSP 1 DSP FPGA A 4.0 070531

BSP 1 DSP FPGA B 4.0 070531

BSP 1 DSP FPGA C 4.0 070531

BSP 1 DSP FPGA D 4.0070531

BSP 1 PCI TO SLAVE A1 FIFO: ok BSP 1 PCI TO SLAVE A2 FIFO: ok BSP 1 PCI TO SLAVE A3 FIFO: ok BSP 1 PCI TO SLAVE B1 FIFO: ok BSP 1 PCI TO SLAVE B2 FIFO: ok BSP 1 PCI TO SLAVE B3 FIFO: ok BSP 1 PCI TO SLAVE C1 FIFO: ok BSP 1 PCI TO SLAVE C2 FIFO: ok BSP 1 PCI TO SLAVE C3 FIFO: ok BSP 1 PCI TO SLAVE D1 FIFO: ok BSP 1 PCI TO SLAVE D2 FIFO: ok BSP 1 PCI TO SLAVE D3 FIFO: ok BSP 1 PCI TO MASTER A HPI: ok BSP 1 PCI TO MASTER B HPI: ok BSP 1 PCI TO MASTER C HPI: ok BSP 1 PCI TO MASTER D HPI: ok BSP 1 PCI TO SLAVE A1 HPI: ok BSP 1 PCI TO SLAVE A2 HPI: ok BSP 1 PCI TO SLAVE A3 HPI: ok BSP 1 PCI TO SLAVE B1 HPI: ok BSP 1 PCI TO SLAVE B2 HPI: ok BSP 1 PCI TO SLAVE B3 HPI: ok BSP 1 PCI TO SLAVE C1 HPI: ok BSP 1 PCI TO SLAVE C2 HPI: ok BSP 1 PCI TO SLAVE C3 HPI: ok BSP 1 PCI TO SLAVE D1 HPI: ok BSP 1 PCI TO SLAVE D2 HPI: ok BSP 1 PCI TO SLAVE D3 HPI: ok 
BSP 2 Master 2.2.3 090702 4.30709134.3070913

BSP 2 Slave 2.2.3 0907026.0080902

BSP 2 RXI FPGA 3.6080821

BSP 2 DSP FPGA A 4.0070531

BSP 2 DSP FPGA B 4.0070531

BSP 2 DSP FPGA C 4.0070531

BSP 2 DSP FPGA D 4.0070531

BSP 2 PCI TO SLAVE A1 FIFO: ok BSP 2 PCI TO SLAVE A2 FIFO: ok BSP 2 PCI TO SLAVE A3 FIFO: ok BSP 2 PCI TO SLAVE B1 FIFO: ok BSP 2 PCI TO SLAVE B2 FIFO: ok BSP 2 PCI TO SLAVE B3 FIFO: ok BSP 2 PCI TO SLAVE C1 FIFO: ok BSP 2 PCI TO SLAVE C2 FIFO: ok BSP 2 PCI TO SLAVE C3 FIFO: ok BSP 2 PCI TO SLAVE D1 FIFO: ok BSP 2 PCI TO SLAVE D2 FIFO: ok BSP 2 PCI TO SLAVE D3 FIFO: ok BSP 2 PCI TO MASTER A HPI: ok BSP 2 PCI TO MASTER B HPI: ok BSP 2 PCI TO MASTER C HPI: ok BSP 2 PCI TO MASTER D HPI: ok BSP 2 PCI TO SLAVE A1 HPI: ok BSP 2 PCI TO SLAVE A2 HPI: ok BSP 2 PCI TO SLAVE A3 HPI: ok BSP 2 PCI TO SLAVE B1 HPI: ok BSP 2 PCI TO SLAVE B2 HPI: ok BSP 2 PCI TO SLAVE B3 HPI: ok BSP 2 PCI TO SLAVE C1 HPI: ok BSP 2 PCI TO SLAVE C2 HPI: ok BSP 2 PCI TO SLAVE C3 HPI: ok BSP 2 PCI TO SLAVE D1 HPI: ok BSP 2 PCI TO SLAVE D2 HPI: ok BSP 2 PCI TO SLAVE D3 HPI: ok

Summary:

BSP 1: OK

BSP 2: OK

2018.07.02 01:00:15.260 109 1 OK

High Voltage Br. 1

TX36 Spec: 99.0 - 121.0

$0-1 \quad 111.4$

0-2 111.0 


$$
\begin{array}{ll}
0-3 & 111.8 \\
0-4 & 111.4 \\
0-5 & 111.8 \\
0-6 & 112.3 \\
0-7 & 112.3 \\
0-8 & 112.3 \\
0-9 & 111.8 \\
0-10 & 111.8 \\
0-11 & 112.3 \\
0-12 & 111.8 \\
0-13 & 111.8 \\
0-14 & 112.3 \\
0-15 & 111.8 \\
0-16 & 111.8 \\
0-17 & 111.8 \\
0-18 & 111.4 \\
0-19 & 111.4 \\
0-20 & 112.3 \\
0-21 & 111.8 \\
0-22 & 111.8 \\
0-23 & 111.4 \\
0-24 & 111.8
\end{array}
$$

High Voltage Br. 2

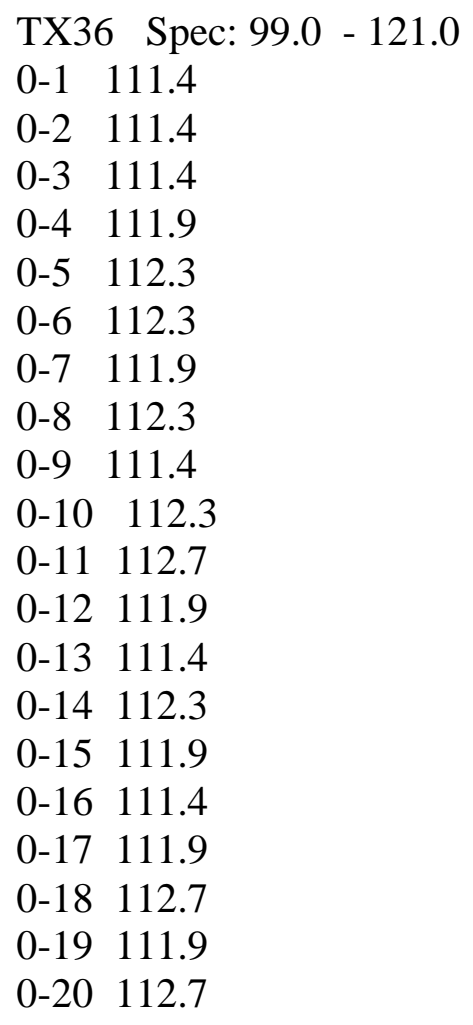




$$
\begin{array}{ll}
0-21 & 111.9 \\
0-22 & 111.9 \\
0-23 & 111.9 \\
0-24 & 111.4
\end{array}
$$

Input voltage $12 \mathrm{~V}$

TX36 Spec: 11.0 - 13.0

$0-1 \quad 11.9$

$0-2 \quad 11.9$

$0-3 \quad 12.0$

$0-4 \quad 11.9$

$0-5 \quad 11.9$

$0-6 \quad 12.0$

$0-7 \quad 12.0$

$0-8 \quad 12.0$

$0-9 \quad 11.9$

0-10 11.9

0-11 11.9

0-12 11.9

0-13 11.9

0-14 11.9

0-15 11.9

$0-16 \quad 11.8$

0-17 11.9

$0-18 \quad 12.0$

0-19 11.9

0-20 12.0

0-21 11.9

0-22 11.9

0-23 11.9

0-24 11.9

Digital 3.3V

TX36 Spec: $2.8-3.5$

$0-1 \quad 3.3$

$0-2 \quad 3.3$

$0-3 \quad 3.3$

$0-4 \quad 3.3$

$0-5 \quad 3.3$

$0-6 \quad 3.3$

$0-7 \quad 3.3$

$0-8 \quad 3.3$

$0-9 \quad 3.3$

$0-10 \quad 3.3$ 


$\begin{array}{ll}0-11 & 3.3 \\ 0-12 & 3.3 \\ 0-13 & 3.3 \\ 0-14 & 3.3 \\ 0-15 & 3.3 \\ 0-16 & 3.3 \\ 0-17 & 3.3 \\ 0-18 & 3.3 \\ 0-19 & 3.3 \\ 0-20 & 3.3 \\ 0-21 & 3.3 \\ 0-22 & 3.3 \\ 0-23 & 3.3 \\ 0-24 & 3.3\end{array}$

Digital 2.5V

TX36 Spec: $2.4-2.6$

$0-1 \quad 2.5$

$0-2 \quad 2.5$

$0-3 \quad 2.5$

$0-4 \quad 2.5$

$0-5 \quad 2.5$

$0-6 \quad 2.5$

$0-7 \quad 2.5$

$0-8 \quad 2.5$

$0-9 \quad 2.5$

$0-10 \quad 2.5$

$0-11 \quad 2.5$

$0-12 \quad 2.5$

$0-13 \quad 2.5$

$0-14 \quad 2.5$

$0-15 \quad 2.5$

$0-16 \quad 2.5$

$0-17 \quad 2.5$

$0-18 \quad 2.5$

$0-19 \quad 2.5$

$0-20 \quad 2.5$

$0-21 \quad 2.5$

$0-22 \quad 2.5$

$0-23 \quad 2.5$

$0-24 \quad 2.5$

Digital 1.5V

TX36 Spec: $1.4-1.6$ 


$\begin{array}{lc}0-1 & 1.5 \\ 0-2 & 1.5 \\ 0-3 & 1.5 \\ 0-4 & 1.5 \\ 0-5 & 1.5 \\ 0-6 & 1.5 \\ 0-7 & 1.5 \\ 0-8 & 1.5 \\ 0-9 & 1.5 \\ 0-10 & 1.5 \\ 0-11 & 1.5 \\ 0-12 & 1.5 \\ 0-13 & 1.5 \\ 0-14 & 1.5 \\ 0-15 & 1.5 \\ 0-16 & 1.5 \\ 0-17 & 1.5 \\ 0-18 & 1.5 \\ 0-19 & 1.5 \\ 0-20 & 1.5 \\ 0-21 & 1.5 \\ 0-22 & 1.5 \\ 0-23 & 1.5 \\ 0-24 & 1.5\end{array}$

Temperature

TX36 Spec: 15.0 - 75.0

0-1 37.2

$0-2 \quad 37.6$

$0-3 \quad 36.4$

$0-4 \quad 35.2$

$\begin{array}{ll}0-5 & 36.0\end{array}$

$0-6 \quad 36.4$

$\begin{array}{ll}0-7 & 36.4\end{array}$

$0-8 \quad 34.4$

$0-9 \quad 36.4$

$0-10 \quad 35.6$

$0-11 \quad 34.8$

$0-12 \quad 34.4$

$0-13 \quad 35.2$

$0-14 \quad 35.6$

$0-15 \quad 36.0$

$0-16 \quad 35.6$

$0-17 \quad 38.4$

$0-18 \quad 38.0$ 

0-19 37.6
$0-20 \quad 38.0$
$0-21 \quad 38.0$
$0-22 \quad 36.4$
$0-23 \quad 37.2$
0-24 36.4

Input Current 12V

TX36 Spec: $0.3-1.5$

$0-1 \quad 0.6$

$0-2 \quad 0.6$

$0-3 \quad 0.6$

$0-4 \quad 0.5$

$0-5 \quad 0.5$

$0-6 \quad 0.5$

$0-7 \quad 0.6$

$0-8 \quad 0.5$

$0-9 \quad 0.5$

$0-10 \quad 0.5$

$0-11 \quad 0.5$

$0-12 \quad 0.5$

$0-13 \quad 0.5$

$0-14 \quad 0.5$

$0-15 \quad 0.6$

$0-16 \quad 0.5$

$0-17 \quad 0.5$

$0-18 \quad 0.5$

$0-19 \quad 0.5$

$0-20 \quad 0.5$

$0-21 \quad 0.5$

$0-22 \quad 0.5$

$0-23 \quad 0.6$

$0-24 \quad 0.6$

TX36 power test passed

IO TX PPC Embedded PPC Download

2.11 1.14 Mar 5 2007/1.07 May 7 2013/1.11

TX36 unique firmware test $\mathrm{OK}$

2018.07.02 01:00:25.761 $109 \quad 2 \quad$ OK

Input voltage $12 \mathrm{~V}$ 
RX32 Spec: 11.0 - 13.0

7-1 11.7

$7-2 \quad 11.8$

Input voltage $6 \mathrm{~V}$

RX32 Spec: $5.0-7.0$

$\begin{array}{ll}7-1 & 5.7\end{array}$

$7-2 \quad 5.7$

Digital 3.3V

RX32 Spec: $2.8-3.5$

$7-1 \quad 3.3$

$7-2 \quad 3.3$

Digital 2.5V

RX32 Spec: $2.4-2.6$

$7-1 \quad 2.5$

$7-2 \quad 2.5$

Digital 1.5V

RX32 Spec: 1.4 - 1.6

$7-1 \quad 1.5$

$7-2 \quad 1.5$

Temperature

RX32 Spec: 15.0 - 75.0

$7-1 \quad 37.0$

$7-2 \quad 38.0$

Input Current 12V

RX32 Spec: 0.4 - 1.5

$7-1 \quad 0.6$

$7-2 \quad 0.6$

Input Current 6V

RX32 Spec: 2.4 - 3.3

$7-1 \quad 2.7$

$7-2 \quad 2.9$ 
RX32 power test passed

IO RX MB Embedded PPC Embedded PPC Download

1.12 1.14 May 5 2006/1.06 May 5 2006/1.07 Feb 18 2010/1.11

RX32 unique firmware test OK

2018.07.02 01:00:25.827 109 3 OK

High Voltage Br. 1

TX36 Spec: $99.0-121.0$

$0-1 \quad 111.4$

$0-2 \quad 111.0$

$0-3 \quad 111.8$

$0-4 \quad 111.4$

$0-5 \quad 112.3$

$0-6 \quad 112.3$

$0-7 \quad 112.3$

$0-8 \quad 111.8$

$0-9 \quad 111.8$

$0-10 \quad 111.8$

$0-11 \quad 112.3$

$0-12 \quad 112.3$

$0-13 \quad 111.8$

$0-14 \quad 112.3$

$0-15 \quad 111.8$

$0-16 \quad 111.8$

$0-17 \quad 111.8$

$0-18 \quad 111.4$

0-19 111.4

$0-20112.3$

$0-21 \quad 111.8$

$0-22 \quad 111.8$

$0-23 \quad 111.4$

$0-24 \quad 111.8$

High Voltage Br. 2

TX36 Spec: 99.0 - 121.0

0-1 111.4

$0-2 \quad 111.0$

$0-3 \quad 111.4$

$0-4 \quad 111.9$

$0-5 \quad 112.3$

0-6 112.3 


$$
\begin{array}{lc}
0-7 & 111.9 \\
0-8 & 111.9 \\
0-9 & 111.4 \\
0-10 & 112.3 \\
0-11 & 112.7 \\
0-12 & 111.9 \\
0-13 & 111.4 \\
0-14 & 112.3 \\
0-15 & 111.9 \\
0-16 & 111.4 \\
0-17 & 111.9 \\
0-18 & 112.3 \\
0-19 & 111.9 \\
0-20 & 112.7 \\
0-21 & 111.9 \\
0-22 & 111.9 \\
0-23 & 111.4 \\
0-24 & 111.0
\end{array}
$$

Input voltage $12 \mathrm{~V}$

TX36 Spec: 11.0 - 13.0

0-1 11.9

$0-2 \quad 11.9$

0-3 12.0

$0-4 \quad 11.9$

0-5 11.9

$0-6 \quad 12.0$

$0-7 \quad 12.0$

$0-8 \quad 12.0$

0-9 11.9

$0-10 \quad 11.9$

$0-11 \quad 11.9$

$0-12 \quad 11.9$

$0-13 \quad 11.9$

$0-14 \quad 11.9$

$0-15 \quad 11.9$

$0-16 \quad 11.8$

$0-17 \quad 11.9$

$0-18 \quad 11.9$

$0-19 \quad 11.9$

$0-20 \quad 12.0$

$0-21 \quad 11.9$

$0-22 \quad 11.9$

$0-23 \quad 11.9$

0-24 11.9 
RX32 Spec: $11.0-13.0$

$7-1 \quad 11.7$

$7-2 \quad 11.8$

Input voltage $6 \mathrm{~V}$

RX32 Spec: $5.0-7.0$

$7-1 \quad 5.7$

$7-2 \quad 5.7$

TRU power test passed

2018.07.02 01:00:25.944 109 4 OK

EM 122 High Voltage Ramp Test

Test Voltage:20.00 Measured Voltage: 18.00 PASSED

Test Voltage:60.00 Measured Voltage: 59.00 PASSED

Test Voltage: 100.00 Measured Voltage: 100.00 PASSED

Test Voltage: 110.00 Measured Voltage: 110.00 PASSED

Test Voltage:70.00 Measured Voltage: 75.00 PASSED

Test Voltage:30.00 Measured Voltage: 35.00 PASSED

6 of 6 tests OK

2018.07.02 01:02:43.100 109 $5 \quad$ OK

BSP 1 RXI TO RAW FIFO: ok

BSP 2 RXI TO RAW FIFO: ok

2018.07.02 01:02:47.567 $109 \quad 6 \quad$ OK

Receiver impedance limits [350.0 700.0] ohm

$\begin{array}{llll}\text { Board } 1 & 2 & 3 & 4\end{array}$

1: 497.9553 .1

2: 536.5554 .6

3: 545.2551 .9

4: 552.9555 .8

5: 556.6559 .6

6: 564.3538 .5

7: 571.2547 .8

8: 562.4560 .2

9: 488.1521 .3

10: 543.6531 .4 
11: 529.1558 .3

12: 542.8546 .8

13: 574.0526 .0

14: 527.6572 .7

15: 562.2519 .0

16: 563.5548 .5

17: 551.5508 .3

18: 557.0511 .1

19: $562.3 \quad 563.5$

20: 570.8565 .8

21: 517.6562 .4

22: 573.6526 .1

23: 572.9559 .6

24: 544.1561 .4

25: 560.7537 .3

26: 577.9572 .2

27: 495.1565 .5

28: 544.3545 .0

29: 507.4553 .3

30: 556.3509 .9

31: 592.7546 .9

32: 539.0553 .1

Receiver Phase limits [-20.0 20.0] deg

$\begin{array}{llll}\text { Board } 1 & 2 & 3 & 4\end{array}$

1: $4.0-0.5$

2: $\quad 0.4 \quad-1.0$

3: $0.0 \quad-0.9$

4: $-0.4 \quad-1.0$

5: $-1.2-0.5$

6: $-0.9 \quad 0.1$

7: $-1.4-0.3$

8: $-1.7-1.1$

9: $4.3 \quad 2.0$

10: $0.0 \quad 0.7$

11: $1.2-0.7$

12: $-0.4 \quad 0.3$

13: $-1.6 \quad 2.0$

14: $1.7-1.8$

15: -0.92 .7$

16: $-1.2-0.5$

17: $0.0 \quad 3.9$

18: -1.13 .2$

19: $-1.1-1.4$

20: $-2.4 \quad-1.8$

21: $2.8-1.5$ 
22: $-2.2 \quad 1.8$

23: $-1.8-1.0$

24: $0.8 \quad-1.6$

25: $-1.4 \quad 1.0$

26: $-2.0-2.0$

27: $4.1 \quad-0.9$

28: $0.1-0.1$

29: $4.1 \quad-0.7$

30: $0.0 \quad 2.6$

31: $-3.0 \quad 0.2$

32: $1.5 \quad-1.2$

Rx Channels test passed

2018.07.02 01:03:19.069 $109 \quad 7 \quad$ OK

Tx Channels test passed

2018.07.02 01:05:59.026 109 8 OK

RX NOISE LEVEL

Board No: 12

$\begin{array}{cccc}0: & 60.3 & 47.6 & \mathrm{~dB} \\ 1: & 55.7 & 47.4 & \mathrm{~dB} \\ 2: & 54.1 & 46.6 & \mathrm{~dB} \\ \text { 3: } & 51.7 & 45.6 & \mathrm{~dB} \\ \text { 4: } & 51.2 & 46.8 & \mathrm{~dB} \\ \text { 5: } & 50.4 & 47.0 & \mathrm{~dB} \\ \text { 6: } & 51.0 & 48.5 & \mathrm{~dB} \\ 7: & 49.7 & 48.2 & \mathrm{~dB} \\ \text { 8: } & 49.0 & 48.7 & \mathrm{~dB} \\ \text { 9: } & 48.4 & 47.9 & \mathrm{~dB} \\ 10: & 49.7 & 48.3 & \mathrm{~dB} \\ 11: & 48.7 & 48.1 & \mathrm{~dB} \\ 12: & 48.8 & 47.8 & \mathrm{~dB} \\ 13: & 48.1 & 47.5 & \mathrm{~dB} \\ 14: & 49.3 & 48.6 & \mathrm{~dB} \\ 15: & 48.7 & 48.7 & \mathrm{~dB} \\ 16: & 48.3 & 48.7 & \mathrm{~dB} \\ 17: & 47.5 & 48.7 & \mathrm{~dB} \\ 18: & 48.0 & 48.6 & \mathrm{~dB} \\ 19: & 47.6 & 49.5 & \mathrm{~dB} \\ 20: & 47.3 & 48.9 & \mathrm{~dB} \\ 21: & 47.0 & 50.9 & \mathrm{~dB} \\ 22: & 47.4 & 51.0 & \mathrm{~dB}\end{array}$


23: $48.1 \quad 49.3 \mathrm{~dB}$

24: $\quad 49.8 \quad 51.1 \mathrm{~dB}$

25: $\quad 49.0 \quad 51.0 \mathrm{~dB}$

26: $\quad 49.6 \quad 51.7 \mathrm{~dB}$

27: $\quad 49.1 \quad 51.1 \mathrm{~dB}$

28: $\quad 48.9 \quad 53.8 \mathrm{~dB}$

29: $\quad 48.4 \quad 55.2 \mathrm{~dB}$

30: $\quad 48.2 \quad 57.3 \mathrm{~dB}$

31: $47.9 \quad 62.4 \mathrm{~dB}$

Maximum noise at Board 2 Channel 31 Level: $62.4 \mathrm{~dB}$

Broadband noise test

Average noise at Board $151.0 \mathrm{~dB} \quad$ OK

Average noise at Board $2 \quad 52.0 \mathrm{~dB} \quad$ OK

2018.07.02 01:06:04.976 $109 \quad 9 \quad$ OK
RX NOISE SPECTRUM

Board No: 12

10.0 kHz: $\quad 45.9 \quad 47.1 \mathrm{~dB}$

$10.2 \mathrm{kHz}: \quad 47.0 \quad 48.1 \mathrm{~dB}$

$10.3 \mathrm{kHz}: \quad 48.5 \quad 49.0 \quad \mathrm{~dB}$

$10.4 \mathrm{kHz}: \quad 48.5 \quad 49.3 \mathrm{~dB}$

$10.6 \mathrm{kHz}: \quad 49.1 \quad 52.0 \mathrm{~dB}$

$10.7 \mathrm{kHz}: \quad 50.6 \quad 50.0 \mathrm{~dB}$

$10.9 \mathrm{kHz}: \quad 49.4 \quad 51.2 \mathrm{~dB}$

$11.0 \mathrm{kHz}: \quad 49.7 \quad 50.8 \mathrm{~dB}$

$11.2 \mathrm{kHz}: \quad 50.0 \quad 51.5 \mathrm{~dB}$

$11.3 \mathrm{kHz}: \quad 49.1 \quad 50.2 \mathrm{~dB}$

$11.4 \mathrm{kHz}: \quad 49.2 \quad 50.5 \mathrm{~dB}$

$11.6 \mathrm{kHz}: \quad 49.2 \quad 48.6 \mathrm{~dB}$

$11.7 \mathrm{kHz}: \quad 48.4 \quad 49.1 \mathrm{~dB}$

$11.9 \mathrm{kHz}: \quad 48.2 \quad 48.0 \mathrm{~dB}$

$12.0 \mathrm{kHz}: \quad 48.1 \quad 49.6 \mathrm{~dB}$

$12.1 \mathrm{kHz}: \quad 48.3 \quad 49.1 \mathrm{~dB}$

$12.3 \mathrm{kHz}: \quad 47.5 \quad 48.1 \mathrm{~dB}$

$12.4 \mathrm{kHz}: \quad 47.2 \quad 48.0 \mathrm{~dB}$

12.6 kHz: $\quad 46.8 \quad 47.3 \mathrm{~dB}$

$12.7 \mathrm{kHz}: \quad 45.9 \quad 48.4 \mathrm{~dB}$

$12.9 \mathrm{kHz}: \quad 46.3 \quad 50.4 \mathrm{~dB}$

$13.0 \mathrm{kHz}: \quad 45.3 \quad 48.4 \mathrm{~dB}$ 
Maximum noise at Board 2 Frequency $10.6 \mathrm{kHz}$ Level: $52.0 \mathrm{~dB}$

Spectral noise test

Average noise at Board $1 \quad 48.3 \mathrm{~dB} \quad$ OK

Average noise at Board $249.5 \mathrm{~dB} \quad$ OK

2018.07.02 01:06:10.927 $109 \quad 10 \quad$ OK

CPU: KOM CP6011

Clock $1795 \mathrm{MHz}$

Die 46 oC (peak: 62 oC @ 2018-07-02 - 00:58:41)

Board 49 oC (peak: 51 oC @ 2018-07-02 - 00:58:35)

Core $1.33 \mathrm{~V}$

$3 \mathrm{~V} 3 \quad 3.28 \mathrm{~V}$

$12 \mathrm{~V} \quad 11.91 \mathrm{~V}$

$-12 \mathrm{~V}-12.13 \mathrm{~V}$

BATT $3.14 \mathrm{~V}$

Primary network: 157.237.14.60:0xffff0000

Secondary network: 192.168.1.1:0xffffff00

2018.07.02 01:06:10.993 $109 \quad 15 \quad$ OK

EM 122

BSP67B Master: 2.2.3 090702

BSP67B Slave: 2.2.3 090702

CPU: 1.3 .8161001

DDS: 3.5 .10140106

DSV: 3.1 .8141125

RX32 version : Feb 182010 Rev 1.11

TX36 LC version : May 72013 Rev 1.11

VxWorks 5.5.1 Build 1.2/2-IX0100 May 16 2007, 11:31:17 
G-2. Built-in Self Test (BIST) of KM1811 EM122 conducted in deep water during transit from Honolulu to the Gulf of Alaska.

Saved: 2018.07.16 05:08:56

Sounder Type: 122, Serial no.: 109

Date Time Ser. No. BIST Result

2018.07.16 05:02:46.068 $109 \quad 0 \quad$ OK

Number of BSP67B boards: 2

BSP 1 Master 2.2.3 090702 4.30709134.3070913

BSP 1 Slave 2.2.3 0907026.0080902

BSP 1 RXI FPGA 3.6080821

BSP 1 DSP FPGA A 4.0070531

BSP 1 DSP FPGA B 4.0070531

BSP 1 DSP FPGA C 4.0070531

BSP 1 DSP FPGA D 4.0070531

BSP 1 PCI TO SLAVE A1 FIFO: ok BSP 1 PCI TO SLAVE A2 FIFO: ok BSP 1 PCI TO SLAVE A3 FIFO: ok BSP 1 PCI TO SLAVE B1 FIFO: ok BSP 1 PCI TO SLAVE B2 FIFO: ok BSP 1 PCI TO SLAVE B3 FIFO: ok BSP 1 PCI TO SLAVE C1 FIFO: ok BSP 1 PCI TO SLAVE C2 FIFO: ok BSP 1 PCI TO SLAVE C3 FIFO: ok BSP 1 PCI TO SLAVE D1 FIFO: ok BSP 1 PCI TO SLAVE D2 FIFO: ok BSP 1 PCI TO SLAVE D3 FIFO: ok BSP 1 PCI TO MASTER A HPI: ok BSP 1 PCI TO MASTER B HPI: ok BSP 1 PCI TO MASTER C HPI: ok BSP 1 PCI TO MASTER D HPI: ok BSP 1 PCI TO SLAVE A1 HPI: ok BSP 1 PCI TO SLAVE A2 HPI: ok BSP 1 PCI TO SLAVE A3 HPI: ok BSP 1 PCI TO SLAVE B1 HPI: ok BSP 1 PCI TO SLAVE B2 HPI: ok BSP 1 PCI TO SLAVE B3 HPI: ok BSP 1 PCI TO SLAVE C1 HPI: ok BSP 1 PCI TO SLAVE C2 HPI: ok BSP 1 PCI TO SLAVE C3 HPI: ok BSP 1 PCI TO SLAVE D1 HPI: ok BSP 1 PCI TO SLAVE D2 HPI: ok BSP 1 PCI TO SLAVE D3 HPI: ok BSP 2 Master 2.2.3 090702 4.3070913 4.3070913

BSP 2 Slave 2.2.3090702 6.0 080902

BSP 2 RXI FPGA 3.6080821 
BSP 2 DSP FPGA A 4.0070531

BSP 2 DSP FPGA B 4.0 070531

BSP 2 DSP FPGA C 4.0070531

BSP 2 DSP FPGA D 4.0070531

BSP 2 PCI TO SLAVE A1 FIFO: ok BSP 2 PCI TO SLAVE A2 FIFO: ok BSP 2 PCI TO SLAVE A3 FIFO: ok BSP 2 PCI TO SLAVE B1 FIFO: ok BSP 2 PCI TO SLAVE B2 FIFO: ok BSP 2 PCI TO SLAVE B3 FIFO: ok BSP 2 PCI TO SLAVE C1 FIFO: ok BSP 2 PCI TO SLAVE C2 FIFO: ok BSP 2 PCI TO SLAVE C3 FIFO: ok BSP 2 PCI TO SLAVE D1 FIFO: ok BSP 2 PCI TO SLAVE D2 FIFO: ok BSP 2 PCI TO SLAVE D3 FIFO: ok BSP 2 PCI TO MASTER A HPI: ok BSP 2 PCI TO MASTER B HPI: ok BSP 2 PCI TO MASTER C HPI: ok BSP 2 PCI TO MASTER D HPI: ok BSP 2 PCI TO SLAVE A1 HPI: ok BSP 2 PCI TO SLAVE A2 HPI: ok BSP 2 PCI TO SLAVE A3 HPI: ok BSP 2 PCI TO SLAVE B1 HPI: ok BSP 2 PCI TO SLAVE B2 HPI: ok BSP 2 PCI TO SLAVE B3 HPI: ok BSP 2 PCI TO SLAVE C1 HPI: ok BSP 2 PCI TO SLAVE C2 HPI: ok BSP 2 PCI TO SLAVE C3 HPI: ok BSP 2 PCI TO SLAVE D1 HPI: ok BSP 2 PCI TO SLAVE D2 HPI: ok BSP 2 PCI TO SLAVE D3 HPI: ok

Summary:

BSP 1: OK

BSP 2: OK

2018.07.16 05:02:47.551 $109 \quad 1 \quad$ OK

High Voltage Br. 1

TX36 Spec: $99.0-121.0$

$0-1 \quad 111.0$

$0-2 \quad 111.0$

$0-3 \quad 111.4$

$0-4 \quad 111.0$

$0-5 \quad 111.8$ 


$$
\begin{array}{lc}
0-6 & 111.8 \\
0-7 & 112.3 \\
0-8 & 111.8 \\
0-9 & 111.4 \\
0-10 & 111.8 \\
0-11 & 111.8 \\
0-12 & 111.8 \\
0-13 & 111.4 \\
0-14 & 111.8 \\
0-15 & 111.8 \\
0-16 & 111.8 \\
0-17 & 111.4 \\
0-18 & 111.4 \\
0-19 & 111.4 \\
0-20 & 111.8 \\
0-21 & 111.4 \\
0-22 & 111.4 \\
0-23 & 111.4 \\
0-24 & 111.8
\end{array}
$$

High Voltage Br. 2

TX36 Spec: 99.0 - 121.0

0-1 111.0

$0-2 \quad 111.0$

$0-3 \quad 111.0$

$0-4 \quad 111.4$

$0-5 \quad 111.9$

$0-6 \quad 112.3$

$0-7 \quad 111.9$

$0-8 \quad 111.9$

$0-9 \quad 111.0$

$0-10 \quad 111.9$

$0-11 \quad 112.3$

$0-12 \quad 111.9$

0-13 111.0

$0-14111.9$

$0-15 \quad 111.9$

$0-16 \quad 111.0$

0-17 111.9

$0-18 \quad 112.3$

0-19 111.9

$0-20112.7$

$0-21 \quad 111.4$

$0-22 \quad 111.4$

0-23 111.4 


\section{0-24 111.0}

Input voltage $12 \mathrm{~V}$

TX36 Spec: 11.0 - 13.0

0-1 11.9

$0-2 \quad 11.9$

0-3 12.0

$0-4 \quad 11.9$

$0-5 \quad 11.9$

0-6 11.9

$0-7 \quad 12.0$

$0-8 \quad 12.0$

$0-9 \quad 11.9$

$0-10 \quad 11.9$

$0-11 \quad 11.9$

$0-12 \quad 11.9$

$0-13 \quad 11.9$

$0-14 \quad 11.9$

$0-15 \quad 11.9$

$0-16 \quad 11.8$

$0-17 \quad 11.9$

$0-18 \quad 11.9$

$0-19 \quad 11.9$

$0-20 \quad 12.0$

$0-21 \quad 11.9$

$0-22 \quad 11.9$

$0-23 \quad 11.9$

0-24 11.9

Digital 3.3V

TX36 Spec: $2.8-3.5$

$0-1 \quad 3.3$

$0-2 \quad 3.3$

$0-3 \quad 3.3$

$0-4 \quad 3.3$

$\begin{array}{ll}0-5 & 3.3 \\ 0-6 & 3.3\end{array}$

0-6 3.3

0-7 3.3

0-8 3.3

$0-9 \quad 3.3$

$0-10 \quad 3.3$

0-11 3.3

0-12 3.3

0-13 3.3 

$0-14 \quad 3.3$
$0-15 \quad 3.3$
$0-16 \quad 3.3$
$0-17 \quad 3.3$
$0-18 \quad 3.3$
$0-19 \quad 3.3$
0-20 3.3
$0-21 \quad 3.3$
$0-22 \quad 3.3$
$0-23 \quad 3.3$
$0-24 \quad 3.3$

Digital 2.5V

\begin{tabular}{lll}
\hline TX36 & Spec: 2.4 - 2.6 \\
$0-1$ & 2.5 \\
$0-2$ & 2.5 \\
$0-3$ & 2.5 \\
$0-4$ & 2.5 \\
$0-5$ & 2.5 \\
$0-6$ & 2.5 \\
$0-7$ & 2.5 \\
$0-8$ & 2.5 \\
$0-9$ & 2.5 \\
$0-10$ & 2.5 \\
$0-11$ & 2.5 \\
$0-12$ & 2.5 \\
$0-13$ & 2.5 \\
$0-14$ & 2.5 \\
$0-15$ & 2.5 \\
$0-16$ & 2.5 \\
$0-17$ & 2.5 \\
$0-18$ & 2.5 \\
$0-19$ & 2.5 \\
$0-20$ & 2.5 \\
$0-21$ & 2.5 \\
$0-22$ & 2.5 \\
$0-23$ & 2.5 \\
$0-24$ & 2.5
\end{tabular}

Digital 1.5V

TX36 Spec: $1.4-1.6$

$\begin{array}{ll}0-1 & 1.5 \\ 0-2 & 1.5 \\ 0-3 & 1.5\end{array}$




$\begin{array}{lc}0-4 & 1.5 \\ 0-5 & 1.5 \\ 0-6 & 1.5 \\ 0-7 & 1.5 \\ 0-8 & 1.5 \\ 0-9 & 1.5 \\ 0-10 & 1.5 \\ 0-11 & 1.5 \\ 0-12 & 1.5 \\ 0-13 & 1.5 \\ 0-14 & 1.5 \\ 0-15 & 1.5 \\ 0-16 & 1.5 \\ 0-17 & 1.5 \\ 0-18 & 1.5 \\ 0-19 & 1.5 \\ 0-20 & 1.5 \\ 0-21 & 1.5 \\ 0-22 & 1.5 \\ 0-23 & 1.5 \\ 0-24 & 1.5\end{array}$

Temperature

TX36 Spec: 15.0 - 75.0
$0-1 \quad 38.8$
$0-2 \quad 39.2$
$0-3 \quad 38.0$
$0-4 \quad 36.4$
$0-5 \quad 38.0$
$0-6 \quad 38.0$
$0-7 \quad 38.0$
$0-8 \quad 35.6$
$0-9 \quad 37.6$
$0-10 \quad 36.8$
$0-11 \quad 36.0$
$0-12 \quad 35.6$
$0-13 \quad 36.4$
$0-14 \quad 36.8$
$0-15 \quad 37.6$
$0-16 \quad 37.2$
$0-17 \quad 39.6$
$0-18 \quad 39.6$
$0-19 \quad 39.2$
$0-20 \quad 39.2$
$0-21 \quad 39.2$ 
$\begin{array}{ll}0-22 & 38.0\end{array}$

0-23 38.8

0-24 38.4

Input Current 12V

TX36 Spec: $0.3-1.5$

$0-1 \quad 0.6$

$0-2 \quad 0.6$

$0-3 \quad 0.6$

$0-4 \quad 0.5$

$0-5 \quad 0.5$

$0-6 \quad 0.5$

$0-7 \quad 0.6$

$0-8 \quad 0.5$

$0-9 \quad 0.5$

$0-10 \quad 0.5$

$0-11 \quad 0.5$

$0-12 \quad 0.5$

$0-13 \quad 0.5$

$0-14 \quad 0.5$

$0-15 \quad 0.5$

$0-16 \quad 0.5$

$0-17 \quad 0.5$

$0-18 \quad 0.5$

$0-19 \quad 0.5$

$0-20 \quad 0.5$

$0-21 \quad 0.5$

$0-22 \quad 0.5$

$0-23 \quad 0.6$

$0-24 \quad 0.6$

TX36 power test passed

IO TX PPC Embedded PPC Download

2.11 1.14 Mar 5 2007/1.07 May 7 2013/1.11

TX36 unique firmware test OK

2018.07.16 05:02:47.668 $109 \quad 2 \quad$ OK

Input voltage $12 \mathrm{~V}$

RX32 Spec: 11.0 - 13.0

$7-1 \quad 11.7$

$7-2 \quad 11.8$ 
Input voltage $6 \mathrm{~V}$

RX32 Spec: $5.0-7.0$

$7-1 \quad 5.7$

$7-2 \quad 5.7$

Digital 3.3V

RX32 Spec: $2.8-3.5$

7-1 3.3

$7-2 \quad 3.3$

Digital 2.5V

RX32 Spec: $2.4-2.6$

$7-1 \quad 2.5$

$7-2 \quad 2.5$

Digital 1.5V

RX32 Spec: $1.4-1.6$

$7-1 \quad 1.5$

$7-2 \quad 1.5$

Temperature

RX32 Spec: 15.0 - 75.0

$7-1 \quad 39.0$

$7-2 \quad 39.0$

Input Current 12V

RX32 Spec: 0.4 - 1.5

$7-1 \quad 0.6$

$7-2 \quad 0.6$

Input Current 6V

RX32 Spec: 2.4 - 3.3

$7-1 \quad 2.7$

$7-2 \quad 2.9$

RX32 power test passed

IO RX MB Embedded PPC Embedded PPC Download 
1.12 1.14 May 5 2006/1.06 May 5 2006/1.07 Feb 18 2010/1.11

RX32 unique firmware test $\mathrm{OK}$

2018.07.16 05:02:47.735 $109 \quad 3 \quad$ OK

High Voltage Br. 1

TX36 Spec: $99.0-121.0$

$0-1 \quad 111.0$

$0-2 \quad 110.6$

$0-3 \quad 111.4$

$0-4 \quad 111.0$

$0-5 \quad 111.8$

$0-6 \quad 112.3$

$0-7 \quad 112.3$

$0-8 \quad 111.8$

$0-9 \quad 111.4$

$0-10 \quad 111.8$

$0-11 \quad 111.8$

$0-12 \quad 111.8$

0-13 111.4

$0-14111.8$

$0-15111.8$

$0-16111.8$

$0-17 \quad 111.4$

0-18 111.4

$0-19 \quad 111.4$

$0-20111.8$

$0-21 \quad 111.4$

$0-22 \quad 111.4$

0-23 111.4

$0-24 \quad 111.8$

High Voltage Br. 2

TX36 Spec: 99.0 - 121.0

$0-1 \quad 111.0$

$0-2 \quad 111.0$

$0-3 \quad 111.0$

$0-4 \quad 111.4$

$0-5 \quad 111.9$

$0-6 \quad 112.3$

$0-7 \quad 111.9$

$0-8 \quad 111.9$

$0-9 \quad 111.0$ 


$$
\begin{array}{ll}
0-10 & 111.9 \\
0-11 & 112.3 \\
0-12 & 111.9 \\
0-13 & 111.0 \\
0-14 & 112.3 \\
0-15 & 111.9 \\
0-16 & 111.0 \\
0-17 & 111.9 \\
0-18 & 111.9 \\
0-19 & 111.9 \\
0-20 & 112.7 \\
0-21 & 111.4 \\
0-22 & 111.4 \\
0-23 & 111.4 \\
0-24 & 111.0
\end{array}
$$

Input voltage $12 \mathrm{~V}$

TX36 Spec: 11.0 - 13.0

0-1 11.9

$0-2 \quad 11.9$

0-3 12.0

$0-4 \quad 11.9$

$0-5 \quad 11.9$

$0-6 \quad 12.0$

$\begin{array}{ll}0-7 & 12.0\end{array}$

$0-8 \quad 12.0$

$0-9 \quad 11.9$

$0-10 \quad 11.9$

$0-11 \quad 11.9$

$0-12 \quad 11.9$

$0-13 \quad 11.9$

$0-14 \quad 11.9$

$0-15 \quad 11.9$

$0-16 \quad 11.8$

$0-17 \quad 11.9$

$0-18 \quad 12.0$

$0-19 \quad 11.9$

$0-20 \quad 12.0$

$0-21 \quad 11.9$

$0-22 \quad 11.9$

$0-23 \quad 11.9$

$0-24 \quad 11.9$

RX32 Spec: 11.0 - 13.0

7-1 11.7 


\section{$7-2 \quad 11.8$}

Input voltage $6 \mathrm{~V}$

RX32 Spec: $5.0-7.0$

$7-1 \quad 5.7$

$7-2 \quad 5.7$

TRU power test passed

2018.07.16 05:02:47.851 $109 \quad 4 \quad$ OK

EM 122 High Voltage Ramp Test

Test Voltage:20.00 Measured Voltage: 17.00 PASSED

Test Voltage:60.00 Measured Voltage: 59.00 PASSED

Test Voltage: 100.00 Measured Voltage: 100.00 PASSED

Test Voltage: 110.00 Measured Voltage: 110.00 PASSED

Test Voltage:70.00 Measured Voltage: 75.00 PASSED

Test Voltage:30.00 Measured Voltage: 35.00 PASSED

6 of 6 tests $\mathrm{OK}$

2018.07.16 05:05:05.008 109 5 OK

BSP 1 RXI TO RAW FIFO: ok

BSP 2 RXI TO RAW FIFO: ok

2018.07.16 05:05:09.475 $109 \quad 6 \quad$ OK

Receiver impedance limits [350.0 700.0] ohm

$\begin{array}{llll}\text { Board } 1 & 2 & 3 & 4\end{array}$

1: 502.1552 .2

2: 536.8553 .8

3: 546.5549 .6

4: 550.7555 .2

5: 555.7558 .8

6: 561.3537 .9

7: 570.4546 .5

8: 561.0558 .7

9: 488.4522 .2

10: $542.5 \quad 532.7$

11: 527.2557 .4

12: 541.2548 .7

13: $570.5 \quad 527.8$

14: 525.8572 .8 
15: 558.6520 .6

16: 561.8549 .5

17: 547.9509 .1

18: $555.5 \quad 512.1$

19: 559.9562 .8

20: 566.8565 .8

21: $515.2 \quad 562.0$

22: 569.9527 .3

23: 569.3558 .6

24: 540.8560 .0

25: 558.4538 .6

26: $575.7 \quad 571.2$

27: 496.0565 .8

28: 545.2545 .6

29: 506.6553 .5

30: 554.9511 .5

31: $589.3 \quad 547.2$

32: 538.2551 .9

Receiver Phase limits [-20.0 20.0] deg

$\begin{array}{llll}\text { Board } 1 & 2 & 3 & 4\end{array}$

1: $3.5-0.4$

2: $\quad 0.2-0.9$

3: $-0.3-0.7$

4: $-0.4 \quad-0.9$

5: $-1.3 \quad-0.4$

6: $-0.8 \quad 0.1$

7: $-1.5-0.2$

8: $-1.8 \quad-1.0$

9: $4.1 \quad 1.9$

10: $-0.1 \quad 0.6$

11: $1.2-0.6$

12: $-0.4 \quad 0.2$

13: $-1.5 \quad 1.8$

14: $1.8-1.9$

15: $-0.7 \quad 2.6$

16: $-1.1 \quad-0.6$

17: $0.2 \quad 3.8$

18: $-1.1 \quad 3.1$

19: $-1.1-1.4$

20: $-2.2 \quad-1.8$

21: $2.9-1.5$

22: $-2.1 \quad 1.7$

23: $-1.6-0.9$

24: $0.9-1.5$

25: $-1.3 \quad 0.9$ 
26: $-2.0-1.9$

27: $3.9-1.0$

28: $-0.1-0.1$

29: $4.0-0.6$

30: $0.0 \quad 2.5$

31: $-2.8 \quad 0.2$

32: $1.5-1.1$

Rx Channels test passed

2018.07.16 05:05:41.026 $109 \quad 7 \quad$ OK

Tx Channels test passed

2018.07.16 05:08:21.000 $109 \quad 8 \quad$ OK
RX NOISE LEVEL

Board No: $1 \quad 2$

\begin{tabular}{|c|c|c|c|}
\hline : & 69.5 & 52.5 & \\
\hline & 65.2 & 51.7 & \\
\hline & 63.9 & 50.8 & \\
\hline 3: & 61.8 & 50.2 & $\mathrm{~dB}$ \\
\hline 4: & 61.1 & 51.3 & $\mathrm{~dB}$ \\
\hline & 60.0 & 51.2 & $\mathrm{~dB}$ \\
\hline $6:$ & 58.8 & 54.1 & $\mathrm{~dB}$ \\
\hline 7: & 57.4 & 53.3 & \\
\hline 8: & 55.8 & 53.5 & $\mathrm{~dB}$ \\
\hline 9: & 56.0 & 53.1 & $\mathrm{~dB}$ \\
\hline 0: & 55.9 & 52.6 & $\mathrm{dF}$ \\
\hline & 53.9 & 51.8 & $\mathrm{dE}$ \\
\hline 2 & 55.1 & 51.6 & $\mathrm{dE}$ \\
\hline 3 & 53.5 & 51.7 & $\mathrm{dF}$ \\
\hline 4 & 53.6 & 52.4 & ut \\
\hline . & 53.9 & 52.6 & \\
\hline 6 & 54.2 & 52.5 & \\
\hline 17: & 52.7 & 51.9 & $\mathrm{dF}$ \\
\hline 8 & 52.0 & 52.5 & $\mathrm{dt}$ \\
\hline 19: & 51.7 & 52.9 & $\mathrm{dH}$ \\
\hline 20: & 51.9 & 52.8 & $\mathrm{dF}$ \\
\hline & 51.6 & 53.9 & \\
\hline & 51.4 & 54.3 & $\mathrm{dF}$ \\
\hline & 51.9 & 54.1 & \\
\hline & 54.4 & 55.3 & \\
\hline & 52.4 & 55.0 & \\
\hline & 52.6 & 56. & \\
\hline
\end{tabular}


27: $\quad 52.1 \quad 55.6 \mathrm{~dB}$

28: $\quad 51.5 \quad 57.5 \mathrm{~dB}$

29: $\quad 51.4 \quad 58.9 \mathrm{~dB}$

30: $\quad 51.6 \quad 61.1 \mathrm{~dB}$

31: $\quad 52.9 \quad 67.6 \mathrm{~dB}$

Maximum noise at Board 1 Channel 0 Level: $69.5 \mathrm{~dB}$

Broadband noise test

Average noise at Board $1 \quad 58.9 \mathrm{~dB} \quad$ OK

Average noise at Board $2 \quad 56.5 \mathrm{~dB} \quad$ OK

2018.07.16 05:08:26.950 $109 \quad 9 \quad$ OK
RX NOISE SPECTRUM

Board No: 12

$10.0 \mathrm{kHz}: \quad 55.0 \quad 54.2 \mathrm{~dB}$

$10.2 \mathrm{kHz}: \quad 56.4 \quad 55.5 \mathrm{~dB}$

$10.3 \mathrm{kHz}: \quad 59.6 \quad 55.3 \mathrm{~dB}$

$10.4 \mathrm{kHz}: \quad 60.0 \quad 57.1 \mathrm{~dB}$

$10.6 \mathrm{kHz}: \quad 57.0 \quad 56.4 \mathrm{~dB}$

$10.7 \mathrm{kHz}: \quad 61.5 \quad 58.1 \mathrm{~dB}$

$10.9 \mathrm{kHz}: \quad 59.4 \quad 58.0 \mathrm{~dB}$

$11.0 \mathrm{kHz}: \quad 58.0 \quad 56.3 \mathrm{~dB}$

$11.2 \mathrm{kHz}: \quad 60.8 \quad 56.9 \mathrm{~dB}$

$11.3 \mathrm{kHz}: \quad 59.1 \quad 56.1 \mathrm{~dB}$

$11.4 \mathrm{kHz}: \quad 57.9 \quad 56.5 \mathrm{~dB}$

$11.6 \mathrm{kHz}: \quad 60.9 \quad 56.1 \mathrm{~dB}$

$11.7 \mathrm{kHz}: \quad 58.5 \quad 55.7 \mathrm{~dB}$

$11.9 \mathrm{kHz}: \quad 58.0 \quad 54.8 \mathrm{~dB}$

$12.0 \mathrm{kHz}: \quad 59.9 \quad 56.2 \mathrm{~dB}$

$12.1 \mathrm{kHz}: \quad 57.0 \quad 54.9 \mathrm{~dB}$

$12.3 \mathrm{kHz}: \quad 57.1 \quad 53.7 \mathrm{~dB}$

$12.4 \mathrm{kHz}: \quad 55.7 \quad 53.1 \mathrm{~dB}$

$12.6 \mathrm{kHz}: \quad 56.1 \quad 54.2 \mathrm{~dB}$

$12.7 \mathrm{kHz}: \quad 58.0 \quad 54.3 \mathrm{~dB}$

$12.9 \mathrm{kHz}: \quad 55.7 \quad 52.7 \mathrm{~dB}$

$13.0 \mathrm{kHz}: \quad 57.7 \quad 51.9 \mathrm{~dB}$

Maximum noise at Board 1 Frequency $10.7 \mathrm{kHz}$ Level: $61.5 \mathrm{~dB}$

Spectral noise test 
Average noise at Board $1 \quad 58.5 \mathrm{~dB} \quad$ OK

Average noise at Board $255.6 \mathrm{~dB}$ OK

2018.07.16 05:08:32.917 $109 \quad 10 \quad$ OK

CPU: KOM CP6011

Clock $1795 \mathrm{MHz}$

Die 49 oC (peak: 60 oC @ 2018-07-12 - 05:06:16)

Board 51 oC (peak: 55 oC @ 2018-07-12 - 05:31:52)

Core $1.33 \mathrm{~V}$

$3 \mathrm{~V} 3 \quad 3.28 \mathrm{~V}$

$12 \mathrm{~V} \quad 11.91 \mathrm{~V}$

$-12 \mathrm{~V}-12.13 \mathrm{~V}$

BATT $3.18 \mathrm{~V}$

Primary network: 157.237.14.60:0xffff0000

Secondary network: 192.168.1.1:0xfffff00

2018.07.16 05:08:32.984 $109 \quad 15 \quad$ OK

EM 122

BSP67B Master: 2.2.3 090702

BSP67B Slave: 2.2.3 090702

CPU: 1.3 .8161001

DDS: 3.5 .10140106

DSV: 3.1 .8141125

RX32 version : Feb 182010 Rev 1.11

TX36 LC version : May 72013 Rev 1.11

VxWorks 5.5.1 Build 1.2/2-IX0100 May 16 2007, 11:31:17 